\title{
Detailed Analysis of the Wake and Free-Flow Characteristics at the Goodnoe Hills MOD-2 Site
}

\author{
D. L. Elliott \\ J. C. Barnard
}

July 1989

Prepared for the U.S. Department of Energy under Contract DE-AC06-76RLO 1830

Pacific Northwest Laboratory Operated for the U.S. Department of Energy by Battelle Memorial Institute 


\title{
DISCLAIMER
}

This program was prepared as an account of work sponsored by an agency of the United States Government. Neither the United States Government nor any agency thereof, nor Battelle Memorial Institute, nor any or their employees, makes any warranty, expressed or implied, or assumes any legal liability or responsibility for the accuracy, completeness, or usefulness of any information, apparatus, product, or process disclosed, or represents that its use would not infringe privately owned rights. Reference herein to any specific commercial product, process, or service by trade name, trademark, manufacturer, or otherwise, does not necessarily constitute or imply its endorsement, recommendation, or favoring by the United States Government of any agency thereof, or Battelle Memorial institute. The views and opinions of authors expressed herein do not necessarily state or reflect those of the United States Government or any agency thereof.

\author{
PACIFIC NORTHWEST LABORATORY \\ operated by \\ BATTELLE MEMORIAL INSTITUTE \\ for the \\ UNITED STATES DEPARTMENT OF ENERGY \\ under Contract DE-AC06-76RLO 1830
}

Printed in the United States of America

Available to DOE and DOE contractors from the

Office of Scientific and Technical Information, P.O. Box 62, Oak Ridge, TN 37831; prices availabie from (615) 576-8401. FTS 626-8401.

Available to the public from the National Technical Information Service, U.S. Department of Commerce, 5285 Port Royal Rd., Springfieid, VA 22161.

NTIS Price Codes, Microfiche A01

\begin{tabular}{|c|c|}
\hline \multicolumn{2}{|c|}{ Printed Copy } \\
\hline Pages & $\begin{array}{l}\text { Price } \\
\text { Codes }\end{array}$ \\
\hline$\overline{001-025}$ & $\overline{\mathrm{A} 02}$ \\
\hline $026-050$ & $\mathrm{A03}$ \\
\hline $051-075$ & $\mathrm{~A} 04$ \\
\hline $076-100$ & A05 \\
\hline $101-125$ & A06 \\
\hline $126-150$ & $\mathrm{~A} 07$ \\
\hline $151-175$ & A08 \\
\hline $176-200$ & A09 \\
\hline $201-225$ & A10 \\
\hline $226-250$ & A11 \\
\hline $251-275$ & $\mathrm{~A} 12$ \\
\hline $276-300$ & A13 \\
\hline
\end{tabular}


PNL-6921

UC-261

DETAILED ANALYSIS OF THE WAKE AND FREE-FLOW CHARACTERISTICS AT THE GOODNOE HILLS MOD-2 SITE

D. L. Elljott

J. C. Barnard

July 1989

Prepared for

the U.S. Department of Energy

under Contract DE-ACO6-76RLO 1830

Pacific Northwest Laboratory

Richland, Washington 99352 


\section{ABSTRACT}

Wind data collected at nine meteorological towers at the Goodnoe Hills MOD-2 wind turbine site were analyzed to characterize the wind flow over the site both in the absence and presence of wind turbine wakes. Although previous studies have examined the wake and free-flow characteristics at the site, data collected in 1985 from nine towers permitted a much more detailed and accurate analysis than was previously possible.

Characteristics of the free flow examined were the variability of wind speed and turbulence intensity across the site as a function of wind direction and surface roughness. The nine towers' data revealed that scattered areas of trees upwind of the site caused pronounced variations in the wind flow over the site. At two towers that were frequently downwind of an extensive grove of trees, up to $30 \%$ reductions in wind speed and a factor of 2 to 3 increase in turbulence intensity were measured. A substantial increase in the magnitude of the wind gusts, as well as a considerable decrease in the mean wind speed, was observed when a tower was downwind of the trees.

Wake characteristics analyzed included the average velocity deficits, wake turbulence, wake width, wake trajectory, vertical profile of the wake, and the stratification of wake properties as a function of the ambient wind speed and turbulence intensity. The nine towers' data permitted a detailed analysis of the wake behavior downwind of the turbines at various distances from 2 to 10 rotor diameters (D). The relationship between velocity deficit and downwind distance was surprisingly linear, with average maximum deficits ranging from $34 \%$ at $2 \mathrm{D}$ down to $7 \%$ at $10 \mathrm{D}$. Largest deficits were at low wind speeds and low turbulence intensities. Average wake widths were $2.8 \mathrm{D}$ at a downwind distance of $10 \mathrm{D}$. Implications for turbine spacing are that, for a wind farm with a 10-D row separation, array losses would be significantily greater for a 2-D than a 3-D spacing because of incremental effects caused by overlapping wakes. Other interesting wake properties observed were the wake turbulence (which was greatest along the flanks of the wake), the vertical variation of deficits (which were greater below hub height than above), and the trajectory of the wake (which was essentially straight). 


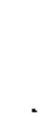




\section{SUMMARY}

Wind data collected at nine meteorological towers at the Goodnoe Hills MOD-2 wind turbine site were analyzed to characterize the wind flow over the site both in the absence and presence of wakes. The nine towers and the three wind turbines were located on a relatively flat and broad ridge, and the terrain relief across the site itself was mostly gently sloping. Vegetation across the site consisted primarily of grass and low sagebrush, although two areas of trees penetrated the site. These trees provided the opportunity to examine the effects of changes in surface roughness on the wind flow variability across the site.

The towers used in the experiment were seven 32-m portable towers and two permanent tall towers. All nine towers were instrumented with bivane anemometers at a height of $32 \mathrm{~m}(105 \mathrm{ft})$. Additional anemometers were located at various heights on the two tall towers. The nine towers were arranged in an approximate east-west grid pattern, in general alignment with prevailing westerly winds, consisting of three rows of three towers each--an upwind row for observing the ambient inflow conditions and two downwind rows for observing the near wakes and far wakes, respectively. This tower arrangement was also suitable for observing the free-flow variability across the site when the turbines were not operating.

The free-flow variability was examined by comparing the wind speeds and turbulence intensities at each tower to a common reference tower. The mean wind speeds at $32 \mathrm{~m}$, averaged over all wind directions, were uniform across the site; wind speeds among the nine towers differed by less than 5\%. Mean turbulence intensities were also uniform, except at one tower that was frequently downwind of an area of trees and had about a 20\% higher average turbulence intensity than a 71 the other towers. However, considerable variability was observed among the nine towers when the wind speed and turbulence intensity ratios were stratified by wind direction. Most of this variability was linked to changes in the surface roughness. At two towers, a $20 \%$ to $30 \%$ reduction in wind speed and a $100 \%$ to $150 \%$ increase in turbulence intensity were observed when these towers were downwind of an extensive grove of pine and juniper trees. At three other towers, up to $10 \%$ reduction in wind speed and $50 \%$ 
increase in turbulence intensity were observed when these towers were downwind of a grove of scrub oak trees. Terrain-induced effects on the free flow were evident at some of the towers, which caused variations of up to $10 \%$ in wind speed and $30 \%$ in turbulence intensity.

The 1-s time series of wind speeds at $32 \mathrm{~m}$ were examined to determine how changes in the surface roughness from grass to trees affected the wind characteristics over smali time scales. A substantial increase in the magnitude of the wind gusts, as well as a considerable decrease in the mean wind speed, was observed when a tower was downwind of the trees rather than grass and sagebrush. Implications for a wind turbine at a height of about $30 \mathrm{~m}$ and located downwind of the trees would be reduced power output, more variable power output, more start/stop cycles, and increased stress caused by the increased turbulence.

Wake characteristics of the flow examined when the wind turbines were operating included velocity deficit, wake turbulence, wake width, wake trajectory, vertical profile of the wake, and the classification of wake properties as a function of the ambient wind speed and turbulence intensity. The arrangement of the towers with respect to the turbines permitted observations of the wake characteristics at various downwind distances ranging from 2 to 10 rotor diameters (D). Most of the wake data were collected at a height of $32 \mathrm{~m}$; the MOD-2 hub height was $61 \mathrm{~m}$ and the bottom of the rotor disk was $15 \mathrm{~m}$ above ground.

Average maximum velocity deficits at $32 \mathrm{~m}$ ranged from $34 \%$ at $2 \mathrm{D}$ to $7 \%$ at $10 \mathrm{D}$. A regression line fit to velocity deficits indicated that the deficit would decrease to near $0 \%$ at $12 \mathrm{D}$. The relationship between velocity deficit and downwind distance was surprisingly linear. Maximum velocity deficits occurred at or near the center of the wake, in the near wake as well as the far wake.

Average maximum turbulence intensities at $32 \mathrm{~m}$ in the wake were 1.7 to 2.0 times greater than ambient values at distances of 2 to $4 \mathrm{D}$ and 1.2 to 1.5 times greater at distances of 5 to $10 \mathrm{D}$. However, maximum turbulence intensities occurred along the flanks of the wake, not in the center of the wake, for distances out to $6 \mathrm{D}$. 
Average widths of the turbine wake at $32 \mathrm{~m}$ were determined for the full wake and the wake core. The wake core was defined as that part of the wake in which the velocity deficit is at least $50 \%$ of the maximum velocity deficit. Average widths of the fut 1 wake ranged from $1.6 \mathrm{D}$ at a distance of $2 \mathrm{D}$ to $2.8 \mathrm{D}$ at a distance of $10 \mathrm{D}$. Widths of the wake core ranged from $0.8 \mathrm{D}$ at $2 \mathrm{D}$ to $1.7 \mathrm{D}$ at $10 \mathrm{D}$. Implications for turbine spacing are that, for a wind farm with a 10-D row separation, array losses would be significantly greater for a 2-D turbine spacing than a 3-D spacing because of incremental effects caused by overlapping wakes. Decreasing the lateral spacing to $1.5 \mathrm{D}$ would result in substantially greater wake losses than for $2 D$ because the wake cores would be overlapping.

Curvature of the wake trajectory was not evident. The absence of wake curvature implies that the wind direction variability across the site was, on the average, quite small and essentially negligible.

The vertical profile of the wake was examined at $5.9 \mathrm{D}$ and $8.4 \mathrm{D}$, based on an analysis of the velocity deficits at six levels on a tall tower encompassing the entire rotor height of the MOD-2 (15 $\mathrm{m}$ to $107 \mathrm{~m})$. The maximum velocity deficits were at the hub-height level $(61 \mathrm{~m})$, but the wake decayed much more rapidly above the hub height than below the hub height. At $8.4 \mathrm{D}$, the measured deficits at $15 \mathrm{~m}$ and $32 \mathrm{~m}$ were only slightly less than those at hub height, which indicates that in the far wake the ground effect diminishes wake decay.

velocity deficits in the turbine wake were also examined as a function of the ambient wind speed and turbulence intensity at several downwind distances ranging from $1.9 \mathrm{D}$ to $8.4 \mathrm{D}$. Velocity deficits were highest at low wind speeds (high thrust coefficients) and low turbulence intensities and lowest at high wind speeds (low thrust coefficients) and high turbulence intensities. Turbulence effects on the velocity deficits were substantially greater at low wind speeds than at high wind speeds. The effects of wind speed on the deficits were substantially greater at low turbulence intensities than at high turbulence intensities. 



\section{ACKNOWLEDGMENTS}

We would like to thank several individuals who contributed to the success of this study. John Buck, Bernie Holst, Owen Abbey, and Gary Dennis were invaluable in maintaining equipment onsite and keeping the nine-tower network operational. Larry Wendell was very helpful in interpreting the results from the data. Gene Gower assisted in producing the computer-generated plots, Rosemary Ellis assisted in the typing and preparation of the report, and Betsy Owczarski assisted in editing the report. 


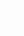




\section{CONTENTS}

SUMMARY

1.0 INTRODUCTION

\subsection{SITE AND DATA DESCRIPTION}

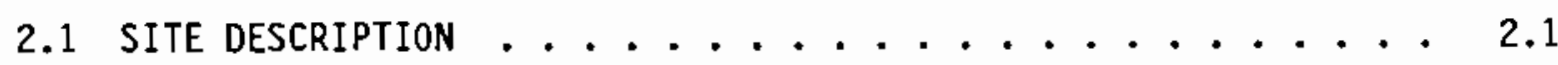

2.2 WIND INSTRUMENTATION AND DATA COLLECTION $\ldots \ldots . \ldots . \ldots$

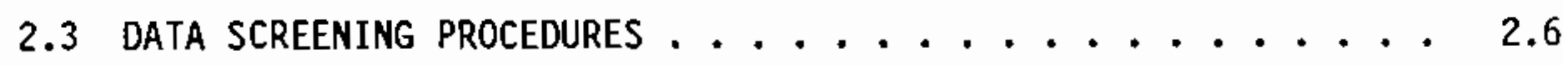

2.4 PREREQUISITES FOR DATA SELECTION $\ldots \ldots \ldots \ldots . \ldots . \ldots . \ldots$

2.5 SEgREgATION OF DATA INTO WAKE AND NON-WAKE SETS . . . . 2.8

2.6 FREQUENCY DISTRIBUTIONS OF WIND DIRECTION, WIND SPEED, AND TURBULENCE INTENSITY $\ldots \ldots . \ldots . \ldots . \ldots . \ldots$

2.7 ANALYSIS OF WIND DIRECTION DIFFERENCES . . . . . . . 2.10

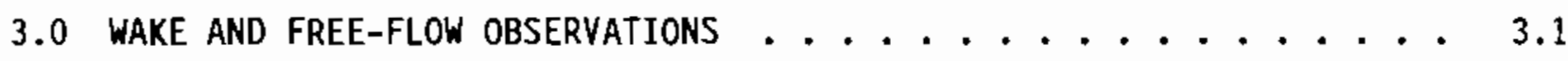

3.1 FREE-FLOW CHARACTERISTICS . . . . . . . . . 3.3

3.1.1 Towers 6 and 7 - Pronounced Tree-Induced Effects observed ................ 3.5

3.1.2 Towers 1, 2, and 9 - Variations in the Flow Linked to Changes in Surface Roughness .......... 3.7

3.1.3 Towers 3, 4, and 5 - Minor Flow Variability ..... 3.9

3.1.4 Tower 8 - Various Flow Influences Observed . . . . . 3.10

3.1.5 Effect of Trees on Depth of Turbulent Layer and Wind Shear ................... 3.11

3.1.6 Effects of Tree-Induced Turbulence on 1-s Time Series

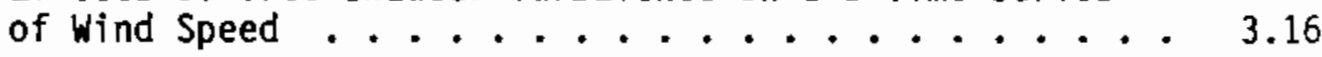

3.2 WAKE CHARACTERISTICS ........................... 3.17

3.2.1 Velocity Deficits .................... 3.20

3.2.2 Wake Turbulence Intensities . . . . . . . . 3.20

3.2 .3 Wake Widths ................ 3.22 
3.2 .4 Consequences for Turbine Spacing . . . . . . . 3.23

3.2 .5 Wake Trajectory ............... 3.24

3.2.6 Wind Direction Alignment Errors and Wake Curvature Implications ................... 3.27

3.2.7 Vertical Profile of the Wake .......... 3.27

3.2.8 Wind Direction Shear .............. 3.29

3.2.9 Velocity Deficits Stratified by Ambient wind Speed and Turbulence Intensity............. 3.29

4.0 CONCLUSIONS AND RECOMMENDATIONS . . . . . . . . . . . . 4.1

4.1 CONCLUSIONS FROM OBSERVATION AND ANALYSIS OF DATA . . . . 4.1

4.2 RECOMMENDATIONS FOR FUTURE WORK . . . . . . . . . . 4.3

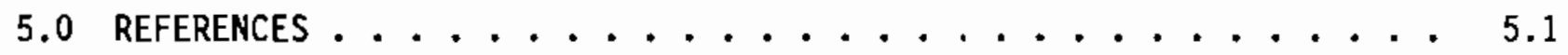

APPENDIX A - PERCENT FREQUENCY DISTRIBUTION OF WIND DIRECTION, WIND SPEED, AND TURBULENCE INTENSITY .......... A.1

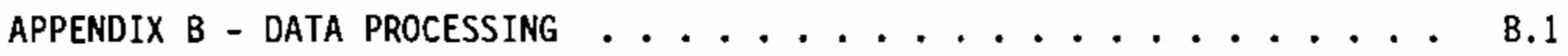

APPENDIX $c$ - COORDINATES AND ELEVATIONS OF TOWERS AND TURBINES . . . . c.1

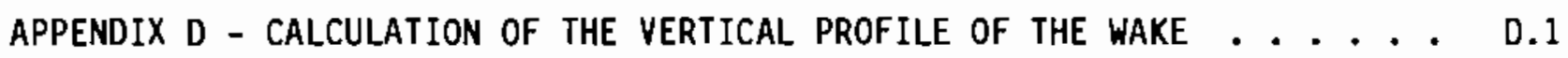

APPENDIX E - ESTIMATES OF MOD-2 ROTOR THRUST COEFFICIENTS . . . . . E. E.1 


\section{FIGURES}

2.1 Goodnoe Hills Test Site with the Three Turbines (T1, T2, and T3), the BPA and PNL Tall Towers, and the Seven Portable Towers . . . 2.2

2.2 Percent Frequency Distributions of Wind Direction, Wind Speed, and Turbulence Intensity for Tower 9, the BPA 32-m Anemometer . . . . 2.9

2.3a Percent Frequency Distributions of Wind Direction Differences Between Tower 9 (BPA 32-m) Anemometer and Each of the Other 32-m Anemometers ..........................

2.3b Percent Frequency Distributions of Wind Direction Differences Between Tower 9 (BPA 32-m) Anemometer and Anemometers on the PNL and BPA Towers .....................

3.1 Wind Speed Ratios (to Tower 9) for Each of the Nine Towers Plotted Versus Tower 9 Wind Direction, for the Wake and Non-Wake Data

3.2 Turbulence Intensity Ratios (to Tower 9) for Each of the Nine Towers Plotted Versus Tower 9 Wind Direction, for the Wake and Non-Wake Data Sets .....................

3.3 Goodnoe Hills Site Showing Areas of Trees that Influence the

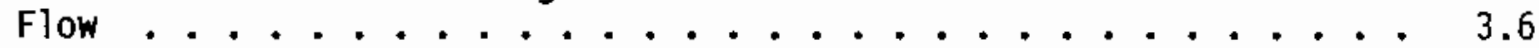

3.4 Average Turbulence Intensity Plotted Versus Wind Direction for Three Height Levels at the BPA and PNL Towers . . . . . . . . 3.12

3.5 Average Values of the Wind Shear Exponent, a, Plotted Versus Wind Direction for the BPA and PNL Towers .............

3.6 Comparison of the 1-5 Time Series of Wind Speeds at Towers 7 and 8

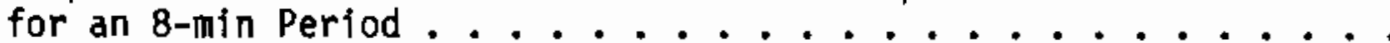

3.7 Average Maximum Velocity Deficits in the Turbine Wakes Plotted Versus Downwind Distance ..................

3.8 Average Wake widths of the Full Wake (Solid Line) and Wake Core Dashed Line) Plotted Versus Downwind Distance . . . . . . . . 3.24

3.9 Difference 8etween the Actual Direction From the Tower to the Turbine and the Wind Direction of the Maximum Velocity Deficit, Plotted Versus Downwind Distance ..............

3.10 Wind Speed Ratios for Each of the Six Height Levels of the PNL Tower Plotted Versus Wind Direction .............. 
3.11 Average Maximum Velocity Deficits (a) and Wind Direction of the Maximum Velocity Deficits (b) at the PNL Tower Plotted Versus Height Above Ground ................. 3.30

A.1 Frequency Distributions of Wind Direction for the Nine 32-m

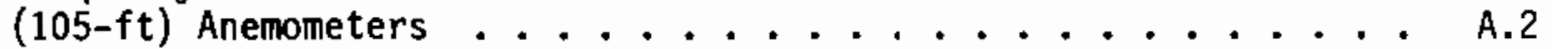

A.2 Frequency Distributions of Wind Direction for Anemometers on the PNL Tower and the BPA Tower (Excluding the 32-m (105-ft) Anemometers that are shown in Figure A.1 as Towers 8 and 9,

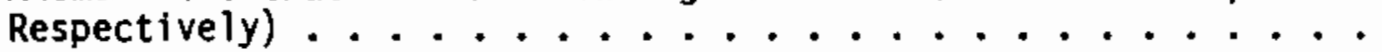

A.3 Frequency Distributions of Wind Speed for the Nine 32-m (105-ft)

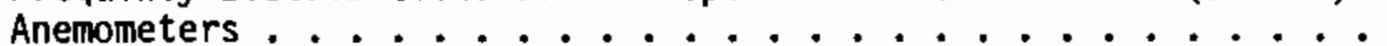

A.4 Frequency Distributions of Wind Speed for Anemometers on the PNL Tower and the BPA Tower (Excluding the 32-m (105-ft) Anemometers that are shown in Figure A.3 as Towers 8 and 9, Respectively...

A.5 Frequency Distributions of Turbulence Intensity for the Nine 32-m $(105-\mathrm{ft})$ Anemometers .................. A.6

A.6 Frequency Distributions of Turbulence Intensity for Anemometers on the PNL Tower and the 8PA (Excluding the 32-m (105-ft) Anemometers that are Shown in Figure A.5 as Towers 8 and 9, Respectively)...

B.1 Tower 5 Wind Direction Plotted Versus Tower $9(32 \mathrm{~m})$ Wind Direction for Both the Non-Wake and Wake Data Sets .......... B.2

B.2 Circle Over which Data are Averaged ........... B.5

E.1 MOD-2 Rotor Thrust Coefficient versus Wind Speed ........ E.1

E.2 Comparison of Rotor and System $C_{T}$ Curves for the MOD-2 .... E.3 


\section{TABLES}

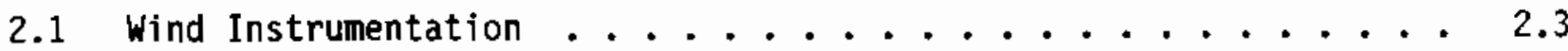

2.2 Type of Data Collected From the Nine Anemometer Bivanes . . . . . 2.4

2.3 Data Collected on the Distributed Data System From the PNL and BPA Towers and the Three Turbines . . . . . . . . . . 2.5

2.4 Average Wind Direction Difference Between Tower 9 (BPA 32-m) Anemometer and Each of the Other Anemometers . . . . . . . . 2.14

3.1 Directions and Distances Between the Towers and Turbines . . . . 3.20

3.2 Wake Statistics for the Ten Turbine/Tower Wake Scenarios . . . . 3.21

3.3 Average Maximum Velocity Deficits (\%) at 32 m Stratified by Ambient Wind Speed and Turbulence Intensity at $59 \mathrm{~m} . . . . . .32$ 


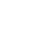




\subsection{INTRODUCTION}

A flow experiment was conducted at the Goodnoe Hills MOD-2 wind turbine site in 1985 by the Pacific Northwest Laboratory (PNL). The objective of the experiment was to collect data that would characterize wake behavior and variability of wind flow over the Goodnoe Hills MOD-2 wind turbine site.

From April to September 1985, nine bivane anemometers were located in a grid pattern across the Goodnoe Hills MOD-2 site. Each bivane sensor was installed on a tower at a height of $32 \mathrm{~m}(105 \mathrm{ft})$. The towers used in the experiment were the two permanent meteorological towers maintained by PNL and the Bonneville Power Administration (BPA) and seven $32-\mathrm{m}(105-\mathrm{ft})$ portable towers. Additional sensors were located at various heights on the PNL tower up to $107 \mathrm{~m}(350 \mathrm{ft})$ and on the 8PA tower up to $59 \mathrm{~m}(195 \mathrm{ft})$.

The Goodnoe Hills site, which is located in Washington State near $45^{\circ} 47.1^{\prime} \mathrm{N}$ and $120^{\circ} 33.4^{\prime} \mathrm{W}$, is approximately $32 \mathrm{~km}(20 \mathrm{mi})$ east of the town of Goldendale, Washington, and approximately $200 \mathrm{~km}$ (120 mi) east of Portland, Oregon. The site is on top of a ridge, oriented approximately east-west, at an elevation of about $800 \mathrm{~m}(2600 \mathrm{ft})$. The terrain is relatively $\mathrm{flat}$ at the top of the ridge, although several gullies penetrate the site on both the north and south sides of the ridge. The ridge drops quite steeply to the Columbia River on the south side and more gradually to the Goldendale Valley on the north side. Vegetation at the site consists primarily of low sagebrush and grass, and scrub oak and conifer trees occur in scattered areas along the northern and western parts of the site.

The M0D-2 wind turbine is a two-blade, teetering-hub, upwind machine. The rotor, which is $91 \mathrm{~m}(300 \mathrm{ft})$ in diameter, is attached to a nacelle housing the gearbox and a 2500-kW generator, and sits atop a cylindrical 61-m (200-ft) high tower. Rotor speed control is accomplished by pitch control of the outer $14 \mathrm{~m}(45 \mathrm{ft})$ of each blade. The machine cuts in at a hub-height wind speed of $6.2 \mathrm{~m} / \mathrm{s}(14 \mathrm{mph})$ and cuts out at $21 \mathrm{~m} / \mathrm{s}(47 \mathrm{mph})$.

The main goals of this report are to analyze the wind data collected at the nine towers and to characterize the wake and free-flow wind conditions at the site. Although several previous studies have examined the wake and 
free-flow characteristics at the Goodnoe Hills site, this report utilizes considerable additional data collected in 1985 to provide a more detailed and accurate analysis of the wake and free-flow characteristics at the site. For example, the nine towers' data permitted a more detailed analysis of the freeflow variability at the site, including the effects of terrain and vegetation on the wind characteristics measured at each tower. The nine towers' data also permitted a detailed analysis of the average wake velocity deficit, wake turbulence, wake width, and wake trajectory at various distances from 2 to 10 rotor diameters, and the variability of the wake deficits as a function of the ambient wind speed, wind direction, and turbulence intensity. In addition to the analysis of the nine towers' data, the vertical profile of the wake was also examined in greater detail than in previous studies. Data collected at six levels on the PNL tower, ranging from $15 \mathrm{~m}(50 \mathrm{ft})$ to $106 \mathrm{~m}(350 \mathrm{ft})$, were analyzed to determine the variation of the wake velocity deficit and wake trajectory with height above ground.

Previous studies for the Goodnoe Hills site include PNL studies reported by Elliott, Buck, and Barnard (1988); Buck and Renne (1985); Miller, Wegley, and Buck (1984); Liu et al. (1983); Lissaman, Zambrano, and Gyatt (1983); and Hadley and Renne (1983); and other studies such as those of Baker and Walker (1985, 1982); Miller (1985); Germain (1984); and Sullivan (1984). Most of the studies focused primarily on wake characteristics and velocity and power deficits induced by upwind turbine wakes. A variety of techniques and measurements were used in previous studies to estimate wake characteristics. These included turbine as well as tower parameters, measurements using kites and tethered balloons, and flow visualization. Phenomena that can affect the results of wake measurements, such as flow variability across the site and differences in machine operating conditions, were discussed and quantitatively treated in some of the previous studies. 


\subsection{SITE AND DATA DESCRIPTION}

\subsection{SITE DESCRIPTION}

Figure 2.1 is a map of the Goodnoe Hills site showing the topography and the locations of the nine meteorological towers and the three MOD-2 wind turbines. The towers and turbines were located along the northern and western part of a relatively flat and broad ridge that is oriented approximately in an east-west direction. The top of the ridge is at an elevation of approximately $800 \mathrm{~m}$ MSL $(2600 \mathrm{ft})$. To the south, the ridge drops quite steeply in about $5 \mathrm{~km}$ to the Columbia River at an elevation of $80 \mathrm{~m}$. The terrain is more gently sloping to the west and north into the Goldendale Valley, dropping to $600 \mathrm{~m}$ in approximately $8 \mathrm{~km}$. The slopes of the ridge are cut in several places by gullies or ravines, and one such gully penetrates the northern part of the site and extends nearly to the ridge crest.

The three MOD-2 wind turbines were installed in a triangular pattern with spacings of approximately 5, 7, and $10 \mathrm{D}$ between machines. This triangular pattern was chosen as part of the initial test plans for the site for the purpose of assessing the effects of the wake of an upwind machine on the power output of a downwind machine (Hadley and Renne 1983). In 1985 the operating characteristics were not the same for all three wind turbines. Turbine 3 had vortex generators on its blades, whereas turbines 1 and 2 were without vortex generators. The vortex generators on turbine 3 resulted in increased power production and a lower wind speed at which the turbine reached rated power output (Sullivan 1984; Elliott et al. 1988).

The meteorological towers installed at the site were seven 32-m (105-ft) portable towers, depicted in Figure 2.1 by the numbers 1 through 7 , and the two permanent tall towers maintained by PNL and 8PA. For convenience, the PNL and BPA towers are also referred to as towers 8 and 9, respectively. The nine towers were arranged in a pattern consisting of three rows that are roughly perpendicular to the prevailing westerly winds. Towers 1,9 , and 2 represent the upwind row, towers 3, 4, and 5 the first downwind row for observing the near wake at distances of 2 to $4 \mathrm{D}$, and towers 8,6 , and 7 the second downwind row for observing the wake at intermediate distances ranging from 5 to $10 \mathrm{D}$. This tower arrangement was also useful for observing the 
free-flow variability across the site that could be caused by terrain and/or surface roughness effects.

Vegetation at the site consists primarily of low sagebrush and grass, al though there are also several areas of scattered trees as shown in Figure 2.1. The trees are primarily scrub oak, western juniper, and ponderosa pine.

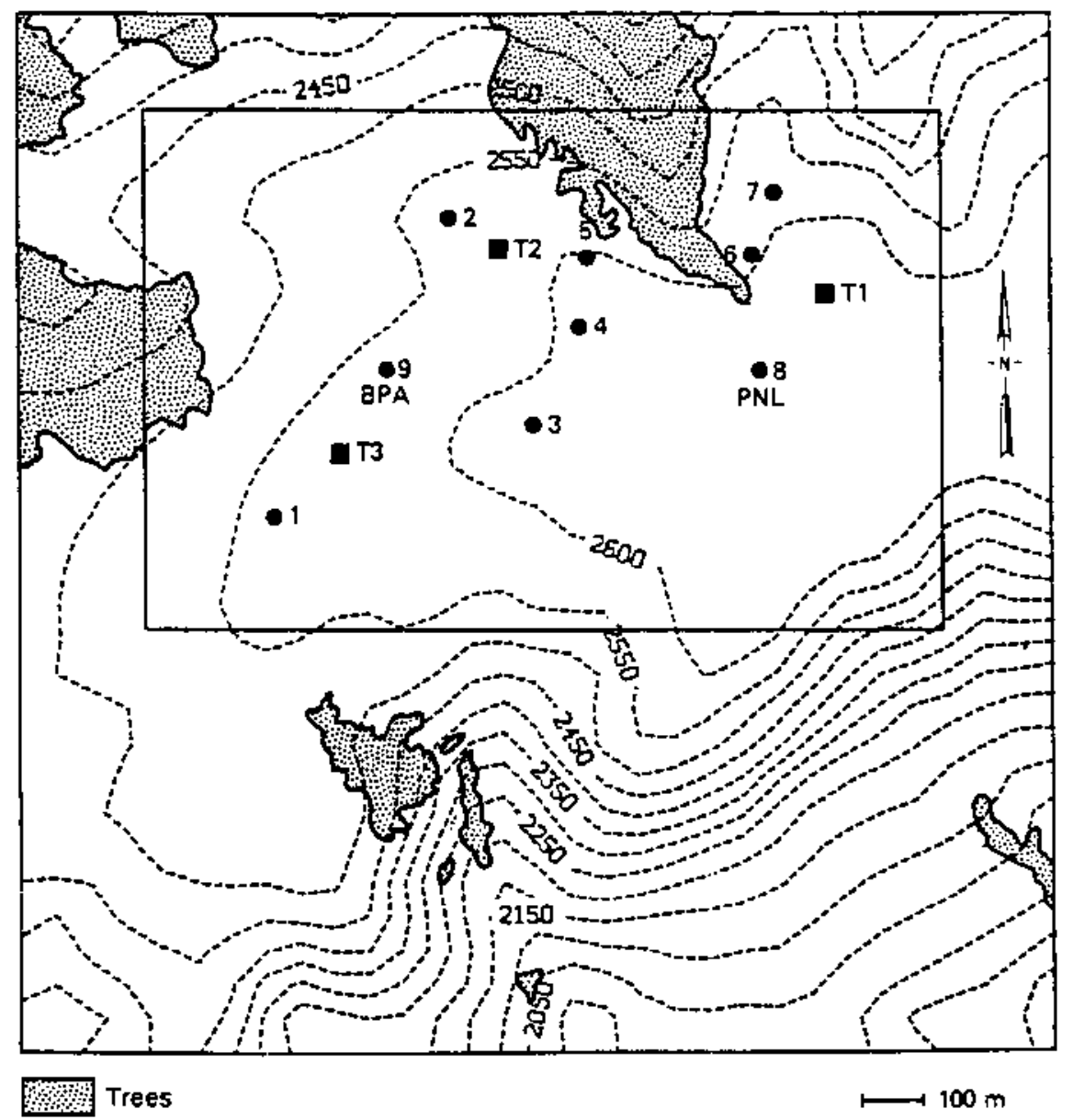

FIGURE 2.1. Goodnoe Hills Site with the Three Turbines (T1, T2, and T3), the BPA and PNL Tall Towers, and the Seven Portable Towers. Elevations above mean sea level are shown in feet; the contour interval is $50 \mathrm{ft}$. Areas of trees are indicated by shading. 


\subsection{WIND INSTRUMENTATION AND DATA COLLECTION}

Table 2.1 is a summary of the wind instrumentation installed at the BPA and PNL towers and the seven portable towers. The BPA and PNL towers were installed in the beginning of the MOD-2 test program in 1982. In 1985, both of these towers had wind sensors at several levels. The seven portable towers were installed in April 1985, and the wind sensors were placed at a height of $32 \mathrm{~m}(105 \mathrm{ft})$ above ground. At that time, wind sensors were also installed at the 32-m (105-ft) level of the BPA and PNL towers. These sensors were the same type as those installed on the seven portable towers, which were R. M. Young ${ }^{(a)}$ bivane anemometers.

TABLE 2.1. Wind Instrumentation

\begin{tabular}{|c|c|c|c|}
\hline Tower & Level (m) & $\begin{array}{l}\text { Wind } \\
\text { Instrumentation (a) } \\
\text { and Manufacturer }\end{array}$ & $\begin{array}{l}\text { Distance (m) } \\
\text { Constant for } \\
\text { Wind Speed } \\
\end{array}$ \\
\hline \multirow[t]{2}{*}{ BPA Tower } & 15,59 & $\begin{array}{l}\text { Belfort, } \\
\text { Aerovane, } \\
120 \text { HD Type L }\end{array}$ & 4.6 \\
\hline & 32 & $\begin{array}{l}\text { R. M. Young, } \\
\text { Anemometer Bivane } \\
\text { Model } 21003\end{array}$ & 0.8 \\
\hline \multirow[t]{2}{*}{ PNL Tower } & $\begin{array}{l}15,38 \\
61,84 \\
107\end{array}$ & $\begin{array}{l}\text { Climatronics, } \\
\text { Cup and Vane system } \\
\text { Model F460 }\end{array}$ & 2.4 \\
\hline & 32 & $\begin{array}{l}\text { R. M. Young, } \\
\text { Anemometer Bivane } \\
\text { Model } 21003\end{array}$ & 0.8 \\
\hline $\begin{array}{l}\text { Portable } \\
\text { Towers }\end{array}$ & 32 & $\begin{array}{l}\text { R. M. Young, } \\
\text { Anemometer Bivane } \\
\text { Model } 21003\end{array}$ & 0.8 \\
\hline
\end{tabular}

(a) Sensors manufactured by Belfort Instrument Company, Alhambra, California; R. M. Young, Traverse City, Michígan; Climatronics, Glendale, California.

(a) R. M. Young, Traverse City, Michigan. 
The data loggers used to record the data from the nine bivane anemometers were the Campbell Scientific ${ }^{(a)} 21 x$ microloggers. The data from the $21 \times$ s were sampled every second and averaged and recorded every minute. The types of 1-min averaged data recorded from the bivanes are identifjed in Table 2.2.

TABLE 2.2. Types of Data Collected From the Nine Anemometer Bivanes

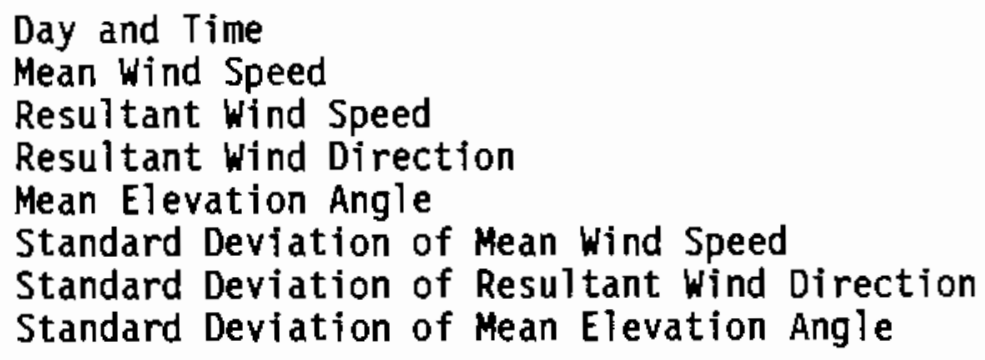

Wind data were collected at five other levels of the PNL tower and two other levels of the BPA tower, as shown in Table 2.1. Temperature and pressure data were also collected at specified levels of the PNL and BPA towers. These data from the BPA and PNL towers and the data from the three turbines were collected by PNL's Distributed Data System (DDS). The data recorded were 1-min averages and standard deviations based on 1-s samples. The data channels collected on the DDS during the 1985 experiment are listed in Table 2.3. The specifics of the DDS are included in a previous report (Elliott, Buck, and Barnard 1988).

(a) Campbell Scientific, Logan, Utah. 
TABLE 2.3. Data Collected on the Distributed Data System

From the PNL and BPA Towers and the Three Turbines

PNL TOWER:

1) Wind direction a $38 \mathrm{~m}(125 \mathrm{ft})$

2) Wind direction $015 \mathrm{~m}(50 \mathrm{ft})$

3) Wind direction $61 \mathrm{~m}(200 \mathrm{ft})$

4) Wind direction $107 \mathrm{~m}(350 \mathrm{ft})$

5) Wind speed o $38 \mathrm{~m}(125 \mathrm{ft})$

6) Wind speed $15 \mathrm{~m}(50 \mathrm{ft})$

7) Wind speed $061 \mathrm{~m}(200 \mathrm{ft})$

8) Wind speed $107 \mathrm{~m}(350 \mathrm{ft})$

9) Air temperature o $10 \mathrm{~m}(33 \mathrm{ft})$

10) Air temperature difference between $107 \mathrm{~m}$ and $10 \mathrm{~m}$

11) Air flow (temperature aspirator) $010 \mathrm{~m}(33 \mathrm{ft})$

12) Air flow (temperature aspirator) $107 \mathrm{~m}(350 \mathrm{ft})$

13) Atmospheric pressure $61 \mathrm{~m}(200 \mathrm{ft})$

14) Wind direction $84 \mathrm{~m}(275 \mathrm{ft})$

15) Wind speed $084 \mathrm{~m}(275 \mathrm{ft})$

BPA TOWER:

1) Wind speed $15 \mathrm{~m}(50 \mathrm{ft})$

2) Wind direction $015 \mathrm{~m}(50 \mathrm{ft})$

3) Wind speed o $59 \mathrm{~m}$ (195 ft)

4) Wind direction o $59 \mathrm{~m}(195 \mathrm{ft})$

5) Air temperature $015 \mathrm{~m}(50 \mathrm{ft})$

6) Atmospheric pressure gound level

TURB INES \#1,\#2,\#3:

1) Field current

2) Generator power

3) Utility power

4) Generator voltage

5) Rotor speed

6) Blade \#1 pitch angle

7) Yaw error

8) Nacelle position 


\subsection{DATA SCREENING PROCEDURES}

Data collection at the nine towers began in April and May 1985 and continued to October 1985. The total data set was initially screened to select the most suitable and complete data set for further analysis. Based on this initial screening, the period June 1, 1985, through August 31, 1985, was selected for this purpose.

Next, the wind data elements were examined for validity, which included performing "reasonableness" checks on the data to identify possible bad or questionable data values. The wind data elements examined were wind speed, wind direction, and standard deviation of wind speed at each of the seven towers and each level of the PNL and BPA towers. Turbine power output recorded by the DDS was also examined and verified against the time logs of the turbine operation recorded by the onsite observers.

A variety of methods was employed to screen the wind and turbine power data. Time series of the 1-min average values were plotted for each anemometer, and these time series data were compared against those of the other anemometers for the same time period. This comparison was facilitated by plotting, for a given data element, the time series of all nine 32-m bivane anemometers in such a manner that data from each anemometer could easily be compared to all the other anemometers. Similarly, the time series for the different levels of the PNL and BPA towers were plotted and visually examined. Using this procedure, we identified and eliminated some erroneous wind data, which otherwise could have been difficult to detect. A comparison of the DDS turbine power data against the turbine log data revealed some discrepancies; for example, several cases existed where the log data indicated a turbine was operating but the DDS indicated the turbine was off. Further investigation confirmed that the log data were correct in these cases, i.e., the turbine was operating and generating power but the turbine data were not being transmitted to the DDS. These turbine data composed less than $10 \%$ of the total turbine data. 


\subsection{PREREQUISITES FOR DATA SELECTION}

After they were screened, the data were segregated into subsets of wake and non-wake data for further evaluation. Several prerequisites needed to be established before the segregation of the data: for example, which anemometer to use as the reference upwind anemometer and what range of wind speeds and wind directions to use for the analysis.

The BPA 32-m anemometer was used as the reference anemometer, because it was the most centrally located upwind anemometer (being about midway between towers 1 and 2, the other upwind towers) and the upwind anemometer with the greatest amount of data. Although the BPA 59-m anemometer was nearest the MOD-2 hub height, it was not used as the reference anemometer for several reasons: 1) it was at a different level than the seven 32-m towers, which would have made comparison of the wind characteristics at these seven sites difficult; 2) it was a different type of wind sensor than those installed on the 32-m towers; and 3) it had about 4000 fewer 1 -min data records than the BPA 32-m level.

A prerequisite for wind speed is that it had to be at least $5.8 \mathrm{~m} / \mathrm{s}$ (13 $\mathrm{mph})$ at $61 \mathrm{~m}(200 \mathrm{ft})$, the turbine hub height, because the turbine cut-in speed was $6.2 \mathrm{~m} / \mathrm{s}(14 \mathrm{mph})$. However, because the $32-\mathrm{m}$ level was used as the reference anemometer, we extrapolated the $61-m$ speed to the $32-m$ level using the $1 / 7$ power law. This provided an equivalent minimum wind speed of $5.3 \mathrm{~m} / \mathrm{s}$ at the 32-m level of the BPA tower.

A preliminary analysis of the wind directions for wind speeds greater than $5.3 \mathrm{~m} / \mathrm{s}$ at $32 \mathrm{~m}$ revealed that more than $90 \%$ of the winds were from the southwest to northwest directions $\left(210^{\circ}\right.$ to $\left.340^{\circ}\right)$. Because the amount of data from other directions was insufficient for a detailed analysis of the wind flow characteristics, only directions from $210^{\circ}$ to $340^{\circ}$ were selected for further evaluation. Moreover, for certain easterly directions, the anemometers on the BPA and PNL towers would be in the wake of the towers, which would make the data from these directions of questionable quality. 


\subsection{SEGREGATION OF DATA INTO WAKE AND NON-WAKE SETS}

Next, criteria were established to segregate the data into subsets of wake and non-wake data. This segregation is necessary to properly evaluate wake effects. It is important to determine the difference in the ambient flow between an upwind tower and a tower downwind of a turbine so that flow differences caused by the wake can be distinguished from the ambient flow differences, which may be caused by terrain and/or surface roughness effects. Consequently, two different data sets--a non-wake and wake data set--were created to compare the non-wake and wake data from each anemometer with the reference anemometer, i.e., the BPA 32-m anemometer. Non-wake and wake data sets were created for each of the 16 anemometers at the Goodnoe Hills site, which included the anemometers for each of the seven 32-m towers, the three levels of anemometers at the BPA tower, and six levels of anemometers at the PNL tower.

The non-wake data sets were created by selecting wind data when turbines 2 and 3 (the two western turbines) were not operating. Because turbine 1 was located downwind of all the towers, its operation did not affect the wind characteristics at any of the towers. The turbine logs recorded by the onsite observers were used to determine if the turbines were operating or not. These logs were found to be more reliable than the turbine data recorded by the DDS, because sometimes the turbine data were not transmitted to the DDS even though the turbine was operating.

The wake data sets were created by selecting times when both turbines 2 and 3 were operating. If only turbine 2 was operating but turbine 3 was not operating, and vice versa, then the data were not included in either the wake or non-wake data sets.

\subsection{FREQUENCY DISTRIBUTIONS OF WIND DIRECTION, WIND SPEED, AND TURBULENCE INTENSITY}

To evaluate the non-wake and wake data sets from each anemometer, percent frequency distributions of the wind direction, wind speed, and turbulence intensity of the wind speed were plotted for each of the 16 anemometers. These frequency distributions, which are shown in Appendix $A$, were quite useful in performing "reasonableness" checks on the data from each anemometer. 
Figure 2.2 shows the frequency distributions of wind direction, wind speed, and turbulence intensity for tower 9, the BPA 32-m anemometer. The number of 1-min records and the mean values are also shown in Figure 2.2 for wake $(W)$ and non-wake $(N W)$ data sets. There were substantfally more data in the wake set than the non-wake set (559.1 hours versus 333.8 hours). Turbulence intensity is defined here as the standard deviation of the 1-s samples of the wind speed for a 1-min period divided by the mean speed for the same period. The peak occurrences of wind direction were centered near $270^{\circ}$ for the wake set and $275^{\circ}$ for the non-wake set, with a small secondary peak at $230^{\circ}$. Wind directions were between $250^{\circ}$ and $290^{\circ}$ more than $70 \%$ of the time. wind speeds were higher, on the average, in the wake set (with a mean of $9.5 \mathrm{~m} / \mathrm{s}$ ) than in the non-wake set (with a mean of $7.9 \mathrm{~m} / \mathrm{s}$ ). However, the turbulence intensity frequency distributions were very similar for the wake and non-wake sets, with mean values near 0.11 .
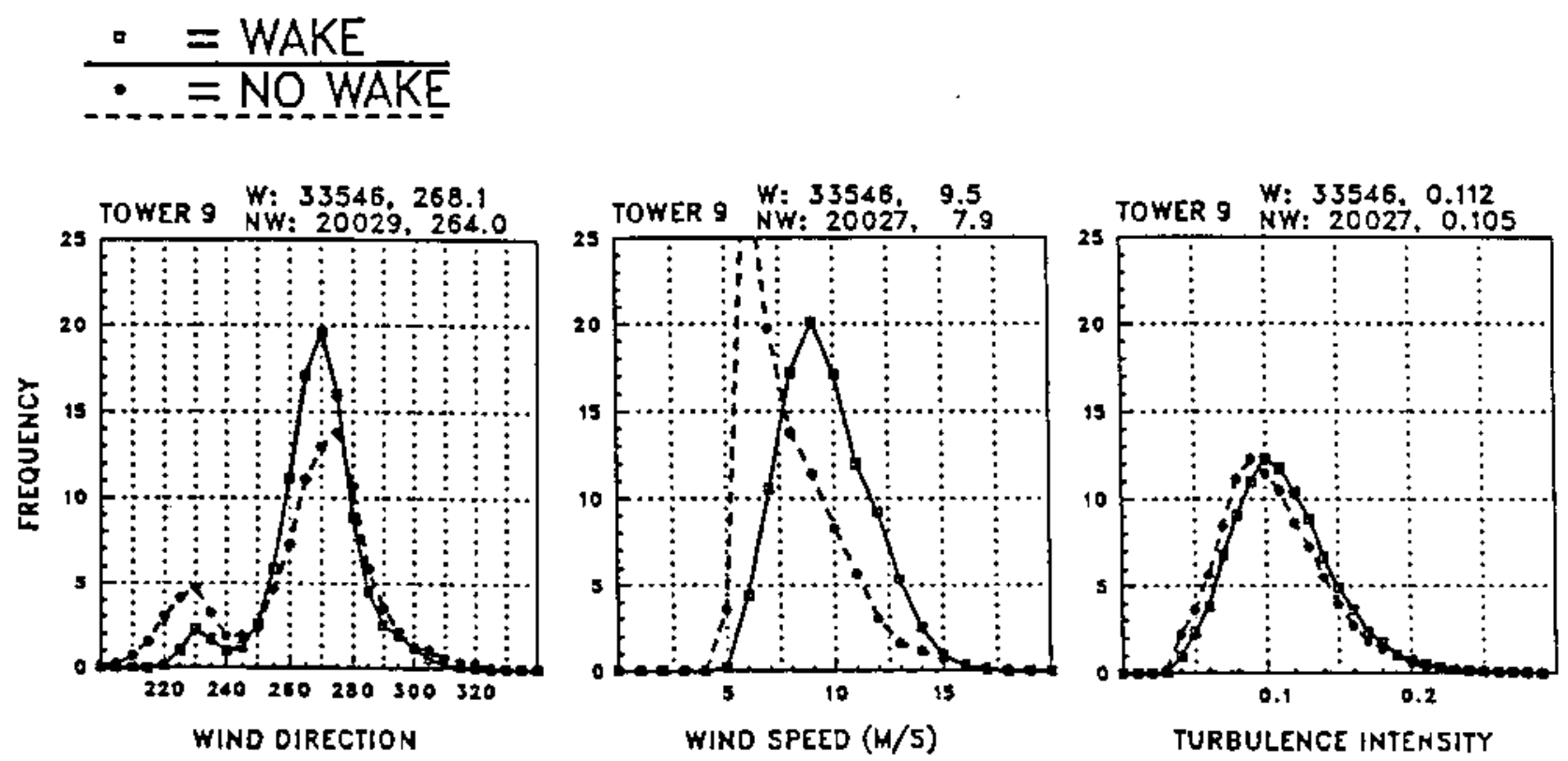

FIGURE 2.2. Percent Frequency Distributions of wind Direction, wind Speed, and Turbulence Intensity for Tower 9, the BPA 32-m Anemometer. The label above each figure indicates the number of 1 -min values and the means for the wake $(W)$ and non-wake (NW) cases. 


\subsection{ANALYSIS OF WIND DIRECTION DIFFERENCES}

An evaluation and comparison of the wind direction frequency distributions for the 16 anemometers across the site (see Appendix A) indicated that wind direction differences between some of the anemometers were much greater than expected. A more detailed analysis was performed to more accurately quantify and evaluate the wind direction differences among the 16 anemometers.

Frequency distributions of the wind direction differences between the tower 9 (BPA 32-m) anemometer and each of the 15 other anemometers were constructed. These frequency distributions are shown in Figures $2.3 \mathrm{a}$ and 2.3b, along with the number of $1-$ min records and mean wind direction difference for both the wake and non-wake data sets. Table 2.4 gives a summary of the mean wind direction differences between the tower 9 anemometer and each of the other anemometers.

Wind direction differences between some of the anemometers are much larger than would be expected, which implies that some of the wind direction sensors were not accurately aligned. For example, at the BPA tower the discrepencies in wind direction between the 32-m level and the $15-\mathrm{m}$ and $59-\mathrm{m}$ levels were $-9^{\circ}$ and $-13^{\circ}$, respectively, for the non-wake case. At the PNL tower, there was about a $19^{\circ}$ difference, on the average, between the directions at the 32- $\mathrm{m}$ and 38-m levels; note that these two anemometers were only $6 \mathrm{~m}$ apart. Differences of up to $10^{\circ}$ existed among the nine 32-m bivane anemometers. One of the anemometers (tower 2) initially showed a bimodal frequency distribution of wind direction differences, with the peak occurrences centered about $12^{\circ}$ apart. Through a comparison of the time series data for tower 2 to the time series of the other anemometers, we identified the time when the alignment of the sensor changed by about $12^{\circ}$. The wind directions after that time were adjusted by $12^{\circ}$ to restore the directions to the original alignment. The frequency distribution shown for tower 2 in Figure 2.3a is the corrected distribution.

At this stage of the analysis, we could not ascertain with any degree of confidence which of the 16 anemometers were most accurately aligned and which were significantly out of alignment. However, we were quite certain that the large wind direction differences observed between some of the anemometers were caused by errors in sensor alignment (with respect to true North) and 
not caused by flow variability. For this reason, we decided to use only one anemometer for the reference wind direction for the wake and free-flow analyses, rather than using the wind direction from each anemometer. The BPA 32-m anemometer was selected for this purpose, because it was already being used as the reference wind speed anemometer. 

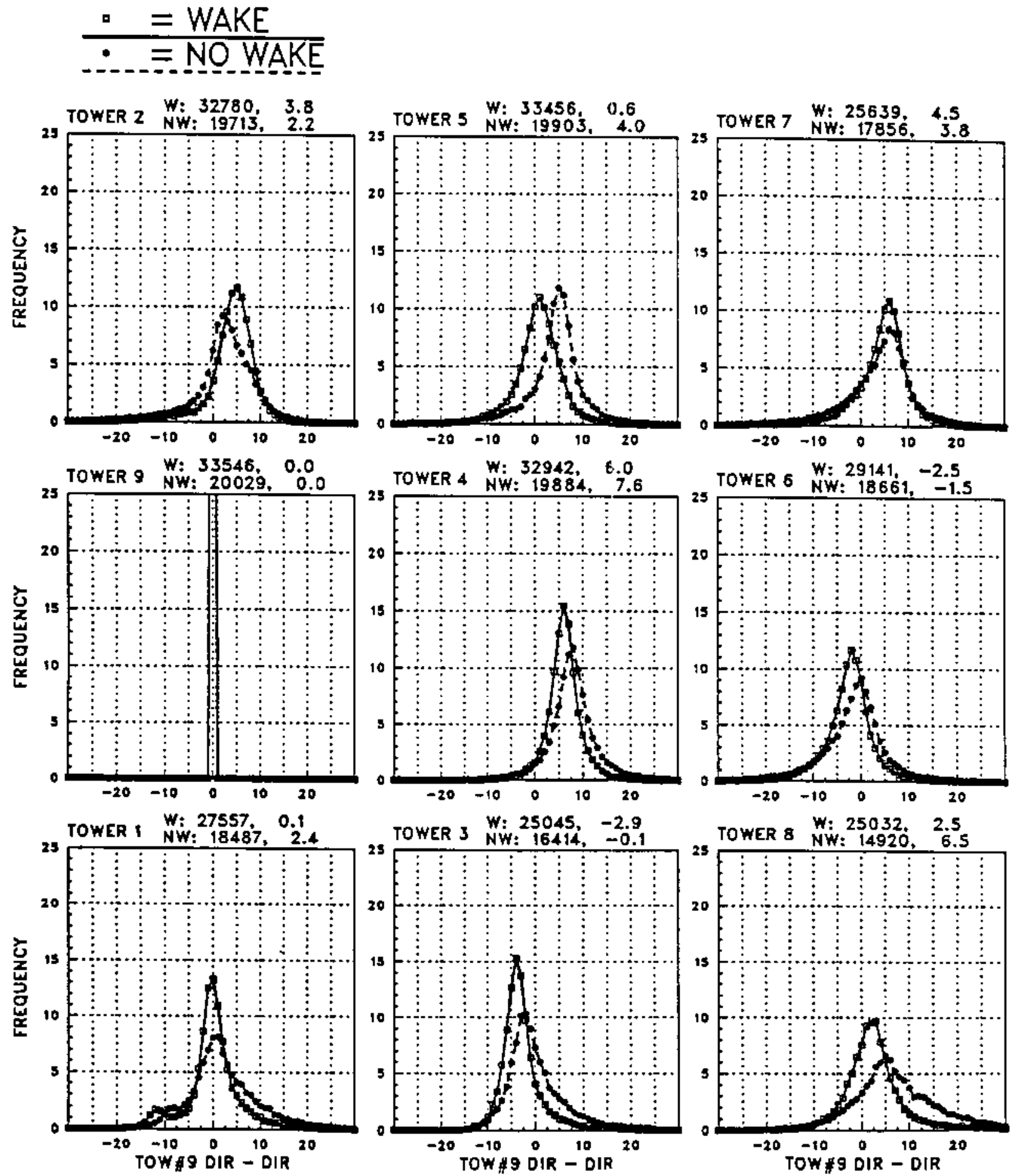

FIGURE 2.3a. Percent Frequency Distributions of Wind Direction Differences Between Tower 9 (BPA 32-m) Anemometer and Each of the Other 32-m Anemometers. The label above each figure indicates the number of 1-min values and the means for the wake $(W)$ and non-wake (NW) cases. 

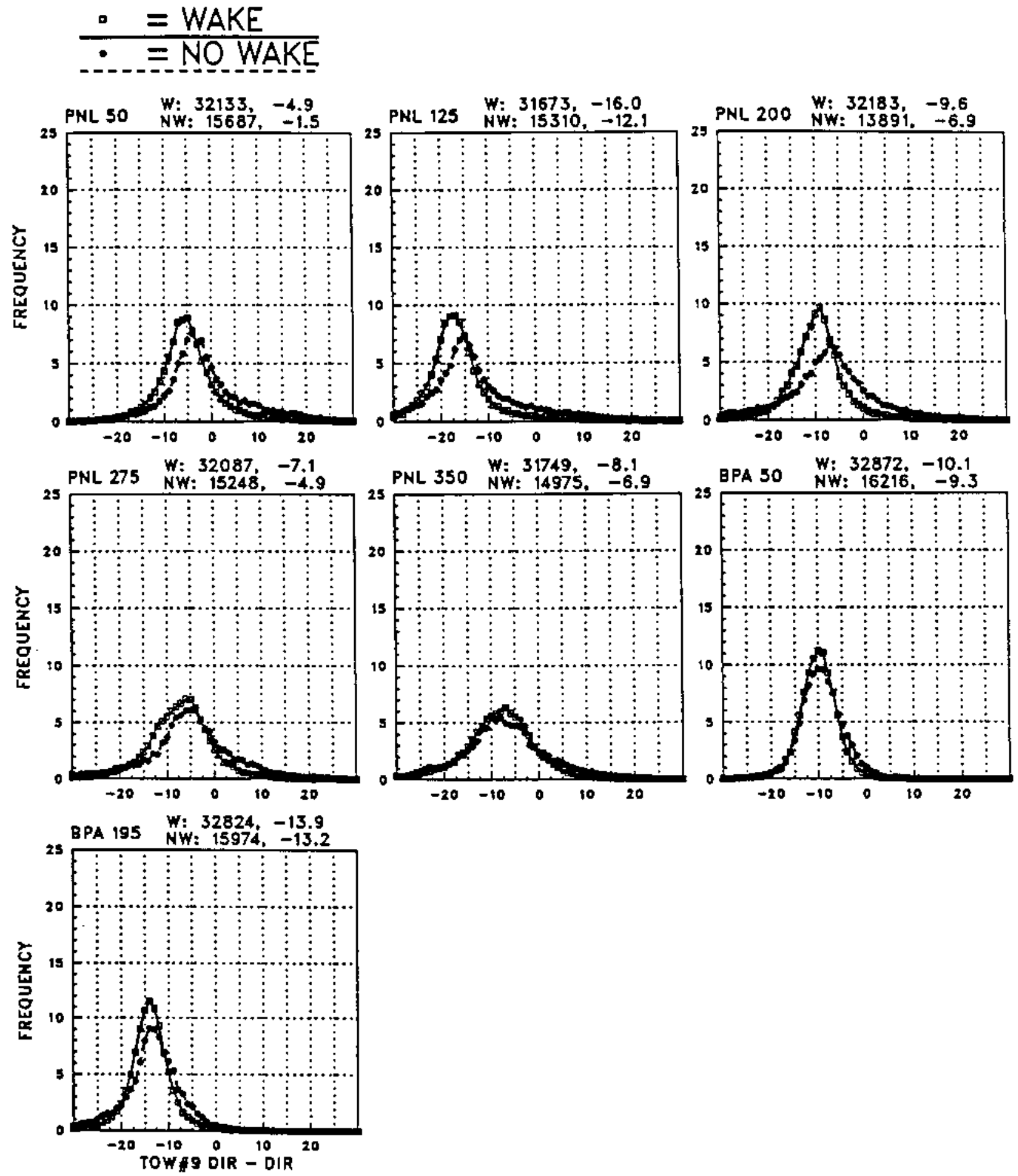

FIGURE 2.3b. Percent Frequency Distributions of Wind Direction Differences Between Tower 9 (BPA 32-m) Anemometer and Anemometers on the PNL and BPA Towers. The label above each figure indicates the number of 1-min values and the means for the wake (W) and nonwake (NW) cases. 
TABLE 2.4. Average Wind Direction Difference Between Tower 9 (BPA 32-m) Anemюmeter and Each of the Other Anemometers

\begin{tabular}{|c|c|c|}
\hline Anemometer & Non-Wake & Wake \\
\hline 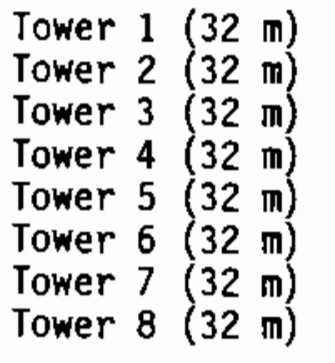 & $\begin{array}{r}2^{\circ} \\
2^{\circ} \\
0^{\circ} \\
8^{\circ} \\
4^{\circ} \\
-2^{\circ} \\
4^{\circ} \\
7^{\circ}\end{array}$ & $\begin{array}{r}0^{\circ} \\
4^{\circ} \\
-3^{\circ} \\
6^{\circ} \\
1^{\circ} \\
-3^{\circ} \\
5^{\circ} \\
3^{\circ}\end{array}$ \\
\hline 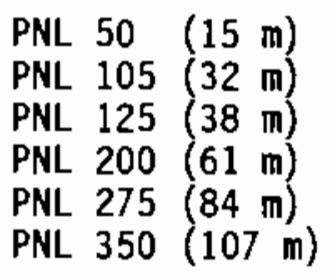 & $\begin{array}{r}-2^{\circ} \\
7^{\circ} \\
-12^{\circ} \\
-7^{\circ} \\
-5^{\circ} \\
-7^{\circ}\end{array}$ & $\begin{array}{r}-5^{\circ} \\
3^{\circ} \\
-16^{\circ} \\
-10^{\circ} \\
-7^{\circ} \\
-8^{\circ}\end{array}$ \\
\hline $\begin{array}{llll}\text { BPA } & 50 & (15 & \mathrm{m}) \\
\text { BPA } & 105 & (32 & \mathrm{m}) \\
\text { BPA } & 195 & (59 \mathrm{~m})\end{array}$ & $\begin{array}{r}-9^{\circ} \\
0^{\circ} \\
-13^{\circ}\end{array}$ & $\begin{array}{r}-10^{\circ} \\
0^{\circ} \\
-14^{\circ}\end{array}$ \\
\hline
\end{tabular}




\subsection{WAKE AND FREE-FLOW OBSERVATIONS}

In this section, wind data from the nine towers are analyzed to examine the free-flow variability over the site and the wake characteristics of the flow when the turbines are operating. In the previous section, we discussed the segregation of the data into wake and non-wake sets and the prerequisites established for selecting the wind data for the evaluation. Tower 9, the BPA 32-m anemometer, was selected as the reference upwind anemometer. Two characteristics of the free-flow variability are examined here: the variability of the wind speed and the turbulence intensity across the site as a function of wind direction. These are determined by comparing the wind speed and turbulence intensity at tower 9 to each of the other eight towers.

Various characteristics of the wake are examined: velocity deficit, wake width, wake turbulence, wake trajectory, wake vertical profile, and the classification of the wake properties as a function of the ambient wind speed and turbulence intensity. The arrangement of the meteorological towers with respect to the upwind turbines permitted observations of the wake characteristics at various distances ranging from 2 to $10 \mathrm{D}$. These are determined by comparing the wake and ambient flow at each of the towers.

Initially, the wake and non-wake data sets used for comparing the wake and ambient flow included wind directions from $210^{\circ}$ to $340^{\circ}$, as measured at tower 9 . Wind speeds had to be at least $5.3 \mathrm{~m} / \mathrm{s}$ at tower 9 . In the initial comparisons of the wind speed ratios for the wake and non-wake data sets, it was observed that tower 9 was in the wake of turbine 3 when wind directions were less than $230^{\circ}$. The actual centerline direction from tower 9 to turbine 3 is $207^{\circ}$. Because tower 9 was the reference upwind anemometer, we excluded wind directions less than $230^{\circ}$. For wind directions greater than $320^{\circ}$, the amount of data were determined to be insufficient to obtain any significant results. Therefore, the wind directions ultimately used for comparing the wake and ambient flow were $230^{\circ}$ to $320^{\circ}$.

Figure 3.1 shows the wind speed ratios for each of the nine towers, as a function of the tower 9 wind direction, for both the wake and non-wake data sets. Here the wind speed ratio is defined as the ratio of the wind speed at the given tower to the wind speed at tower 9. The plots in Figure 3.1 are 


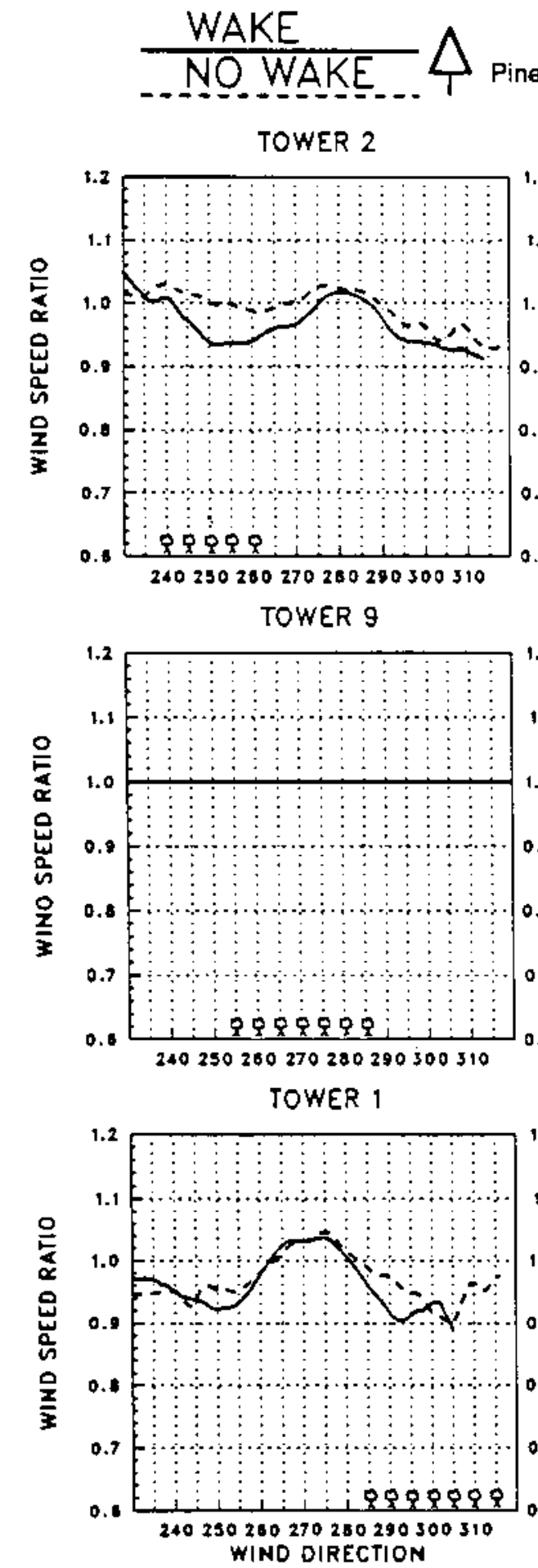

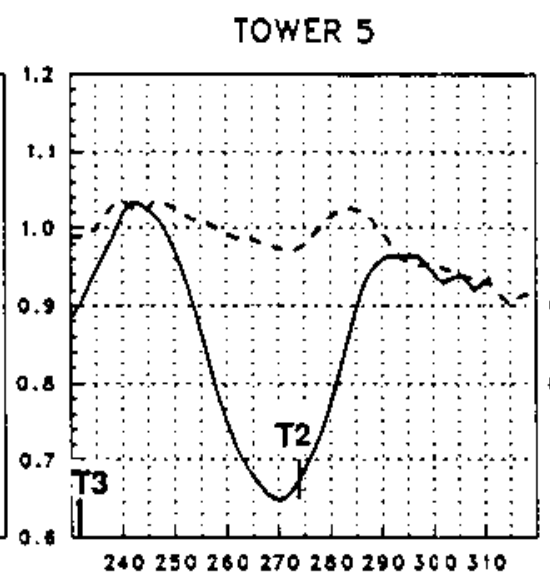

TOWER 5

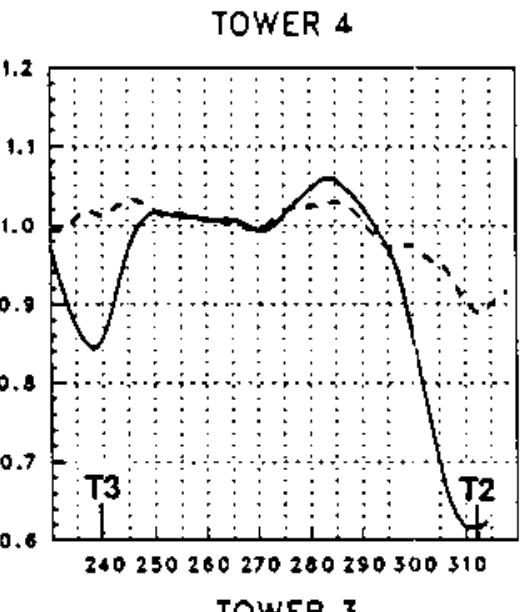

TOWER 3

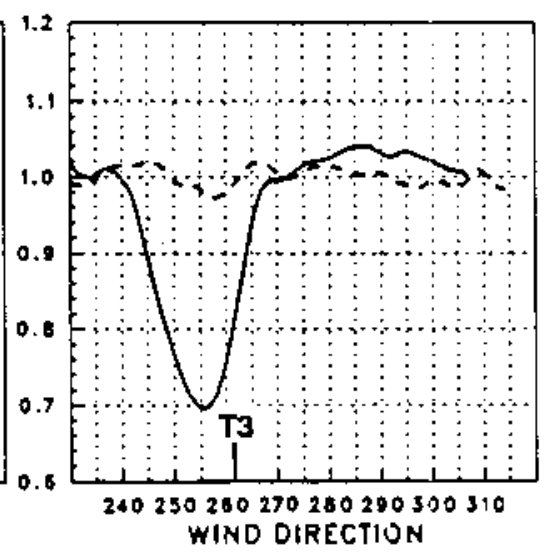

T2 or T3 Wind Turbines

\section{TOWER 7}

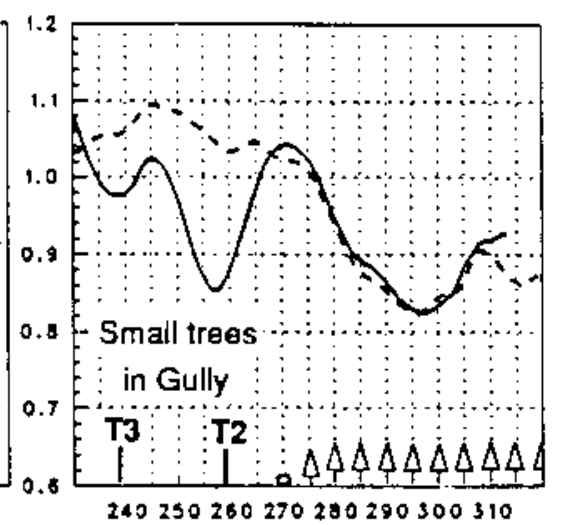

TOWER 6

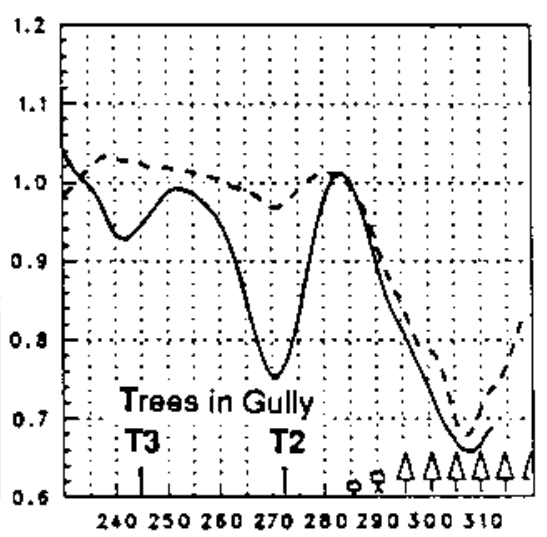

TOWER 8

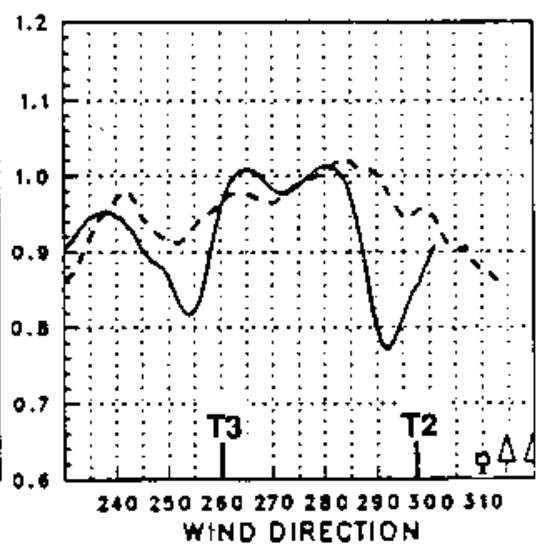

FIGURE 3.1. Wind Speed Ratios (to Tower 9) for Each of the Nine Towers Plotted Versus Tower 9 Wind Direction, for the Wake and NonWake Data Sets. Most of the curves stop short of $320^{\circ}$ because of a lack of data at the higher wind directions. For each tower, approximate directions of major groves of trees less than $500 \mathrm{~m}$ away and directions of wind turbines are indicated. 
arranged in the same general pattern as the physical layout of the towers, with towers 2, 9, and 1 being the upwind row, towers 5, 4, and 3 the first row downwind of turbines 2 and 3 , and towers 7,6 , and 8 the second row downwind of turbines 2 and 3 . In the same format, Figure 3.2 shows the turbulence intensity ratios for each of the nine towers. By definition, the ratios of wind speed and turbutence intensity for tower 9 are always unity because it is the reference tower.

The directions in which wind turbines and trees are located are also shown in Figures 3.1 and 3.2 to facilitate the interpretation of the wind speed and turbulence intensity ratios with respect to the upwind fetch. However, in viewing these plots, caution should be exercised in drawing any imnediate conclusions because of errors in the wind direction sensors as previously discussed in Section 2.7. For example, apparent discrepancies between the actual directions of the turbines and the wind directions of minimum wind speed ratios should not be construed as wake curvature. If the BPA 59-m anemometer were used for the wind direction, instead of the BPA 32-m anemometer, then the wind directions of minimum wind speed ratios in Figure 3.1 would shift to the right by about $15^{\circ}$. However, the directions of the wind turbines and trees would remain fixed, because they are based on actual compass directions and not wind directions. Wake trajectory and correction of wind direction errors are discussed in greater detail in Sections 3.2.5 and 3.2.6, respectively.

The data processing involved in making Figures 3.1 and $3.2--$ and also similar figures in this section--is explained in Appendix $B$.

\subsection{FREE-FLOW CHARACTERISTICS}

Using Figures 3.1 and 3.2, the free-flow variability of wind speed and turbulence intensity at each tower were examined with respect to that at the reference tower 9. The solid and dashed lines in these figures show the wind speed and turbulence intensity ratios when the turbines are operating and shut down, respectively. It is worthwhile to note that even when the turbines are operating, towers 1 and 2 are upwind of the turbines; thus, both the solid and dashed lines also represent wake-free conditions at these two towers. At towers 3 through 8 , those wind directions in which large discrepancies exist 
$\frac{\text { WAKE }}{\text { NOW. WAKE... }} \bigwedge_{\text {Pine and Juniper trees }} \mho_{\text {Scrub Oak Trees }}{ }_{1}^{\text {T2 or T3 }}$ Wind Turbines

TOWER 2

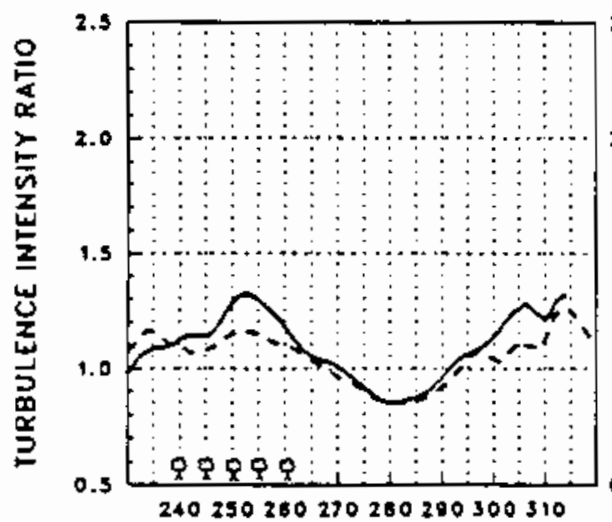

TOWER 9

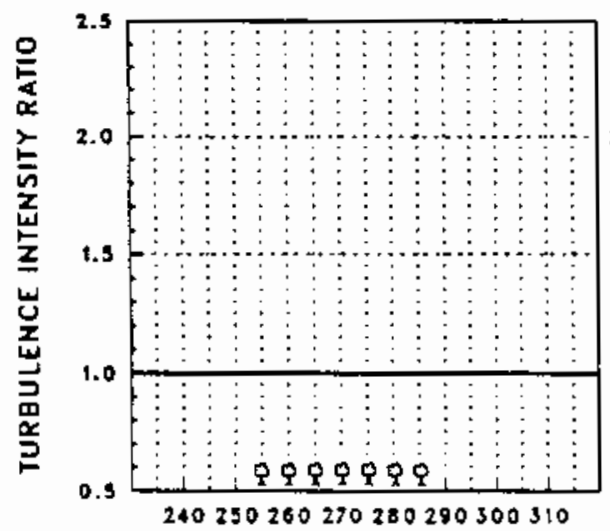

TOWER 1

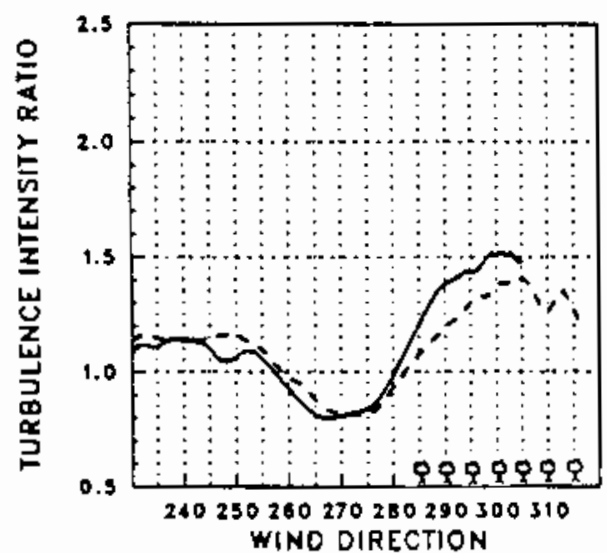

TOWER 5

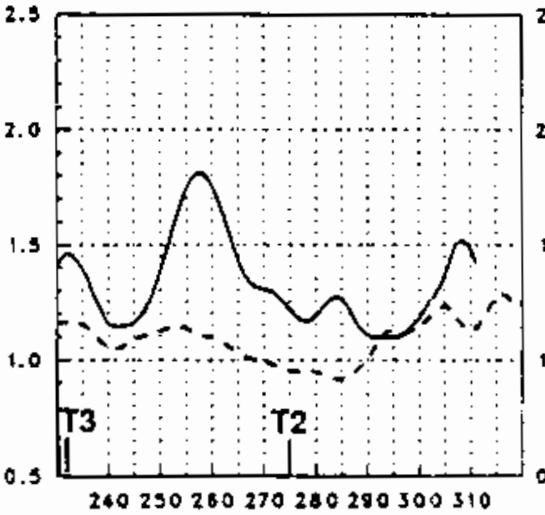

TOWER 4

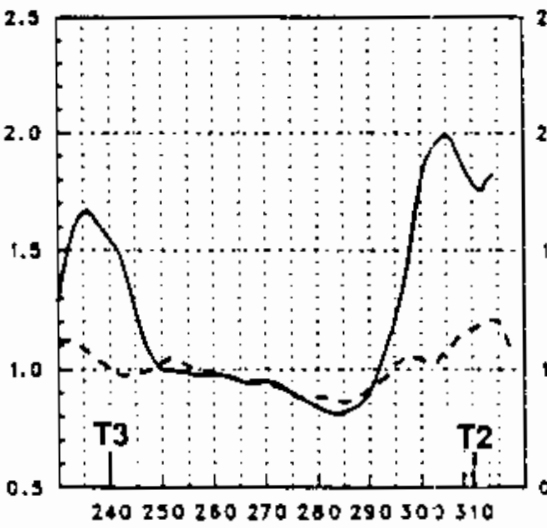

TOWER 3

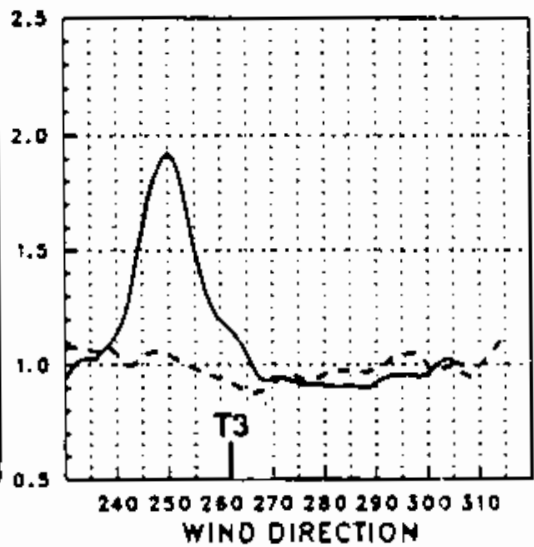

TOWER 7

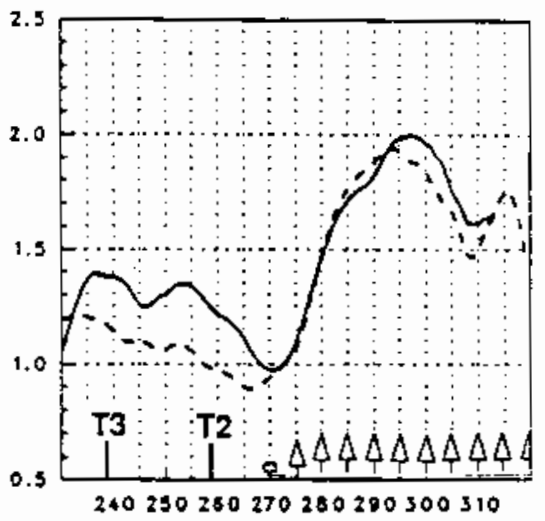

TOWER 6

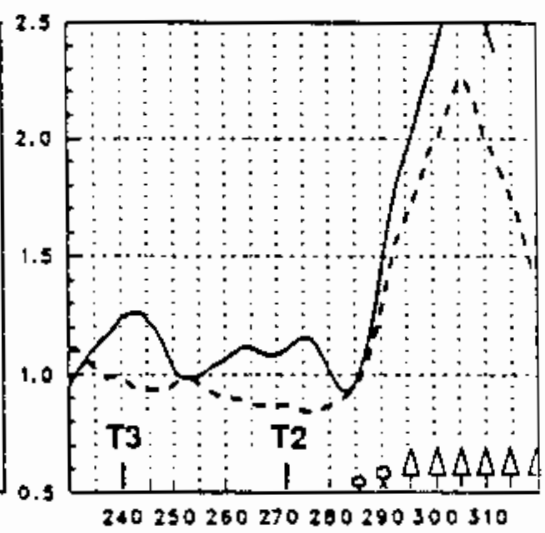

TOWER 8

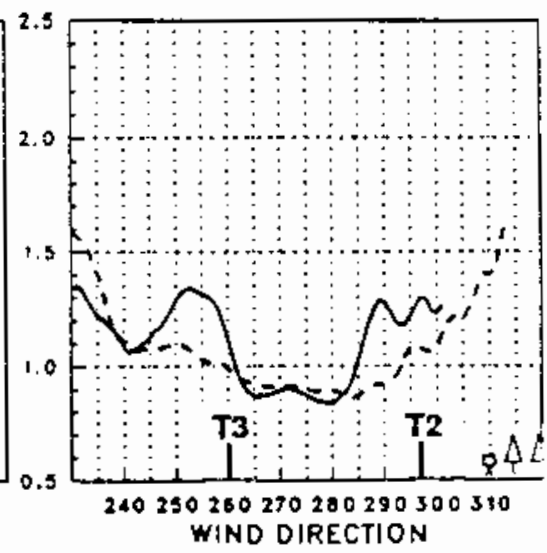

FIGURE 3.2. Turbulence Intensity Ratios (to Tower 9) for Each of the Nine Towers Plotted Versus Tower 9 Wind Direction, for the Wake and Non-Wake Data Sets. Most of the curves stop short of $320^{\circ}$ because of a lack of data at the higher wind directions. For each tower, approximate directions of major groves of trees less than $500 \mathrm{~m}$ away and directions of wind turbines are indicated. 
between the solid and dashed curves indicate where turbine wakes exist. Because the wake data set contains about $50 \%$ to $70 \%$ more data than the nonwake data set (depending on which tower is being considered), the ratios in the wake data set can usually be considered more significant than those in the non-wake data set. However, there is generally close agreement between both data sets in the free-flow ratios, especially at the most frequent wind directions of $260^{\circ}$ to $280^{\circ}$.

\subsubsection{Towers 6 and 7 - Pronounced Tree-Induced Effects Observed}

The free-flow wind speed ratios in Figure 3.1 show some interesting features. The greatest differences in the free-flow wind speeds from those at tower 9 were observed at towers 6 and 7. At tower 6 , the wind speed ratio is less than 0.7 when directions are about $305^{\circ}$ to $310^{\circ}$. For wind directions between about $285^{\circ}$ and $310^{\circ}$ at tower 6 , there is very good agreement in the wind speed ratios between the non-wake and wake data sets, which further confirms that this substantial reduction in the free-flow wind speeds at tower 6 is a real phenomenon. The speed ratios at tower 6 are less than 0.9 over a fairly broad wind direction sector from about $290^{\circ}$ to $320^{\circ}+$. In Figure 3.2, the turbulence intensity ratios for tower 6 are much higher for this wind direction sector than for other directions, with the ratio peaking between 2.0 and 3.0 at about $305^{\circ}$.

The terrain and surface roughness features upwind of tower 6 in this direction sector were examined, using aerial photographs of the site and detailed terrain maps, to investigate the possible cause of the substantial decrease in wind speeds and increase in turbulence intensities. A fairly extensive and dense grove of pine and juniper is found upwind of tower 6 in direction of about $300^{\circ}$ to $310^{\circ}$ as indicated in Figure 3.3. The trees grow along the upper slopes of the western side of the gully north of tower 5 and turbine 2. Based on aerial photographs of the site, the pines are estimated to be about 10 to $18 \mathrm{~m}$ in height and the junipers about 5 to $12 \mathrm{~m}$. Thus, the $30 \%$ reduction in wind speed and approximately $150 \%$ increase in turbulence intensity at about $305^{\circ}$ is primarily attributed to the wake effect of the trees, although it is possible that terrain effects could account for some of this variability. To further emphasize the effect of the trees on the flow at tower 6 , a radial has been drawn in Figure 3.3 that extends from tower 6 in a 


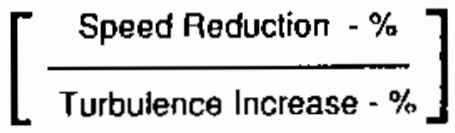

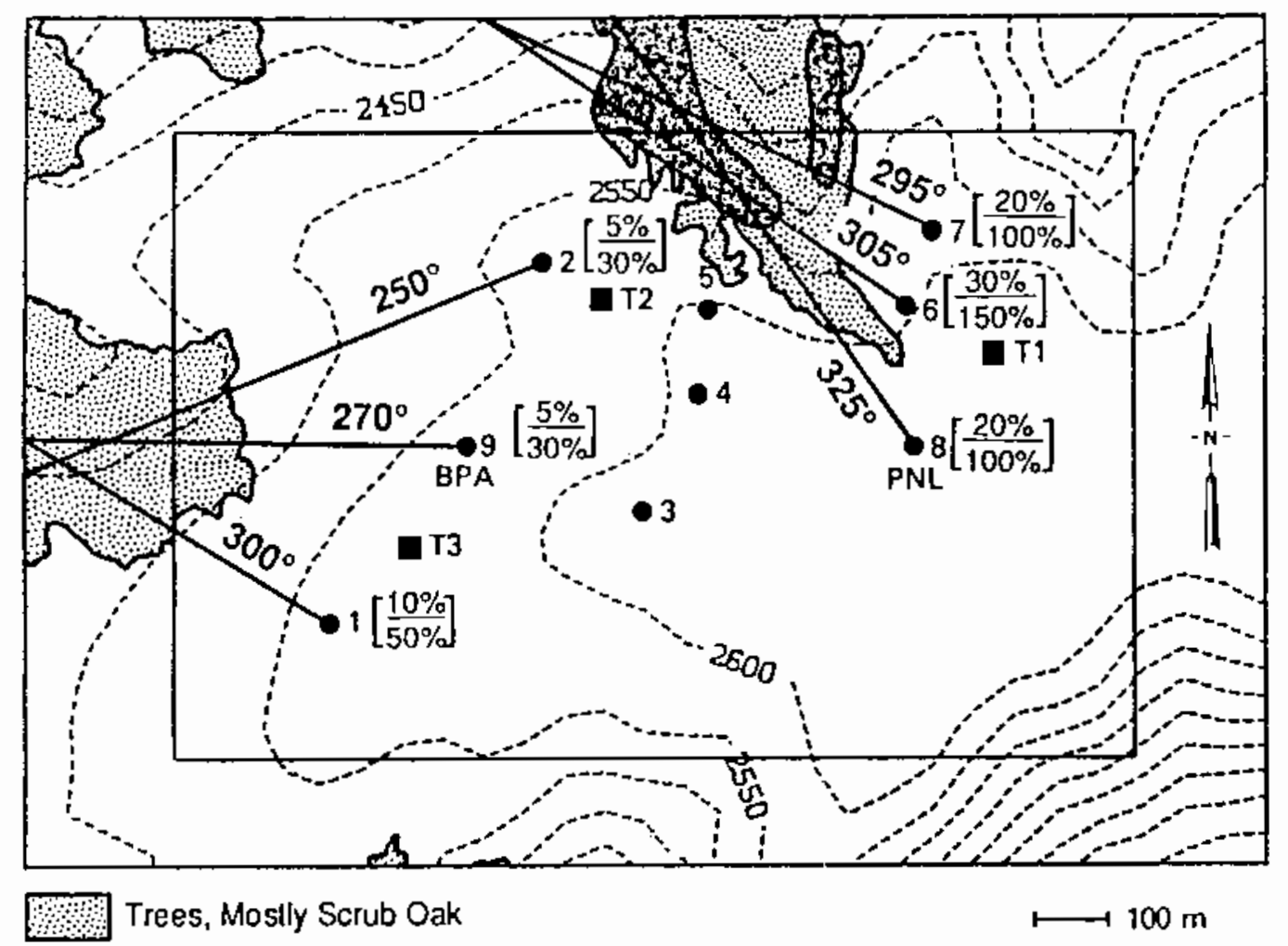

Fing Groves of Larger Pine and Juniper Trees

FIGURE 3.3. Goodnoe Hills Site Showing Areas of Trees that Influence the Flow. Radials indicating approximate directions from which the flow at towers are most influenced by the upwind fetch of trees are shown as solid black lines. Estimates of the percent reduction in wind speed and percent increase in turbulence due to the trees are shown for each of these radials.

direction of $305^{\circ}$. It is at about this direction that the maximum reduction in velocity and maximum increase in turbulence occur and, as shown by the radial, the wind first goes directly over the trees before reaching the tower.

As seen in Figure 3.3, smaller trees that are mostly scrub oak trees occur to the west and southwest of tower 6 . These trees are generally confined to the gully and apparently have little effect on the free-flow winds at tower 6 , as the speed ratios are near 1.0 and the turbulence intensity ratios are 0.8 to 1.0 from these directions. West of this gully, the terrain is 
generally flat to gently sloping and the vegetation cover is grass and low sagebrush, so the winds from these directions experience a relatively smooth fetch.

At tower 7 , the free-flow ratios in Figures 3.1 and 3.2 show that almost a $20 \%$ reduction in wind speed and $100 \%$ increase in turbulence intensity occur when the wind directions are from $290^{\circ}$ to $300^{\circ}$; see Figure 3.3 where a $295^{\circ}$ radial has been drawn. Upwind of tower 7 in this direction is the same grove of pine and juniper that was attributed to cause the substantial decrease in the wind speeds and increase in turbulence intensities at tower 6 . The fetch over this grove of pine and juniper upwind of tower 7 is about $150 \mathrm{~m}$ to $200 \mathrm{~m}$, compared to a fetch of about $300 \mathrm{~m}$ upwind of tower 6 . The maximum velocity reductions at towers 6 and 7 are $30 \%$ and 20\%, respectivety. Because the length of the upwind fetch over the larger trees is greater for tower 6 than tower 7 , the magnitude of the velocity reduction appears to be related to the length of the fetch over these trees.

As shown in Figure 3.3, a smaller grove of pine and juniper trees is found along the upper slopes of the eastern side of the gully in a direction about $290^{\circ}$ to $330^{\circ}$ from tower 7 , and this grove probably also contributes to the reduction in wind speeds and increase in turbulence intensities observed at these wind directions. As with tower 6 , the trees to the southwest of tower 7 are generally confined to the gully and appear to have little effect on the winds at tower 7 . Moreover, when the winds are from the southwest, the wind speeds at tower 7 are about 5 to $10 \%$ greater than those at tower 9 and all the other towers as well. Tower 7 sits on a rib that extends northward from the broad east-west ridge and divides two major gullies. Apparently, there is a local terrain-induced acceleration of the winds over this rib. Perhaps this terrain-induced acceleration offsets some of the reduction effects caused by the larger trees in the west to northwest directions.

\subsubsection{Towers 1,2 , and 9 -Variations in the Flow Linked to Changes in Surface Roughness}

Towers 1 and 2, the two upwind towers in addition to tower 9, also show some significant variations in the ratios of wind speed and turbutence intensity. In Figures 3.1 and 3.2, both the solid and dashed lines for towers 1 and 2 represent free-flow conditions because these towers are never in the 
wake of the wind turbines when wind directions are between $230^{\circ}$ and $320^{\circ}$. Variations in the wind speed ratios are observed to be about $10 \%$, and variatjons in turbulence intensity ratio almost $70 \%$ at tower 1 and $50 \%$ at tower 2 . Note that when the speed ratio increases, the turbutence intensity ratio usually decreases, and vice versa.

An examination and comparison of the terrain and vegetation upwind of towers 1,2 , and 9 provides clues to the causes of these variations. In Figure 3.3, note that an area of trees, which are mostly scrub oak, is found generally to the west of tower 9 , to the northwest of tower 1 , and to the southwest of tower 2 . When the wind directions are $265^{\circ}$ to $275^{\circ}$, the wind speeds at tower 1 are about $4 \%$ greater than at tower 9 and turbulence intensities about $20 \%$ lower. These differences can be attributed to differences in the surface roughness and its effects on the upwind fetch. The vegetation upwind of tower 1 is grass and low sagebrush, whereas an extensive area of scattered trees that are mostly scrub oak begins about 300 m west of tower 9 and extends generally westward for more than $500 \mathrm{~m}$.

When the wind directions are $290^{\circ}$ to $315^{\circ}$, tower 1 is downwind of the trees whereas the vegetation upwind of tower 9 becomes grass and low sagebrush. (Small groves of scrub oak are located more than $600 \mathrm{~m}$ northwest of tower 9 but appear to have little influence on the wind flow at tower 9.) Consequently, tower 1 experiences a reduction in the wind speeds and an increase in the turbulence intensities when the wind direction shifts from west to northwest, whereas the opposite situation occurs at tower 9. For wind directions of $230^{\circ}$ to $250^{\circ}$, the lower wind speeds and higher turbulence intensities at tower 1 are probably caused by the fact that terrain upwind of tower 1 is quite flat for about $400 \mathrm{~m}$ and then slopes downward rather steeply, whereas the terrain upwind of tower 9 is gently sloping.

Tower 2 experiences lower wind speeds and higher turbulence intensities than tower 9 when wind directions are around $250^{\circ}$ and greater than $290^{\circ}$. For wind directions around $250^{\circ}$, tower 2 is directly downwind of the trees whereas tower 9 has a relatively smooth fetch over grass and low sagebrush. The reasons for the differences between towers 2 and 9 when the wind directions are greater than $290^{\circ}$ are not clearly discernible but could be caused by 
terrain that slopes more steeply upwind of tower 2 than upwind of tower 9 and by tower 2 being nearer to the distant trees in those directions.

Radials, indicating approximate directions from which the flow at towers 1, 9, and 2 are most influenced by the upwind fetch of trees, are shown in Figure 3.3 . Note that these radials traverse almost directly over the grove of scrub oak.

\subsubsection{Towers 3,4, and 5 - Minor Flow Variability}

At tower 3, the free-flow ratios (which are represented in Figures 3.1 and 3.2 by the dashed line for all directions and the solid line for directions greater than about $270^{\circ}$ ) are near unity, which indicates that the free-flow conditions at tower 3 are not much different than those at tower 9 . For wind directions of about $265^{\circ}$ to $290^{\circ}$, turbulence intensities are almost $10 \%$ less at tower 3 than at tower 9, whereas wind speeds are a few percent greater. A probable explanation is that although both tower 9 and tower 3 are downind of the trees for these wind directions, tower 3 is about $250 \mathrm{~m}$ further from the trees than tower 9 . Thus, the wake effect of the trees is reduced at tower 3 .

At tower 4 , the free-flow conditions are represented by the dashed line for all directions and the solid line in Figures 3.1 and 3.2 from about $250^{\circ}$ to $290^{\circ}$. Free-flow ratios are fairly close to unity over most directions. From about $275^{\circ}$ to $290^{\circ}$, tower 4 has slightly higher wind speeds and $10 \%$ to $20 \%$ lower turbulence intensities than tower 9. Again, these differences are probably attributed to the differences in the upwind surface roughnesses, because tower 9 is downwind of the trees while the vegetation upwind of tower 4 is mostly grass and low sagebrush. The reduced speeds and increased turbulence intensities at around $310^{\circ}$ at tower 4 cannot be easily explained. However, a possible explanation is terrain-induced effects similar to those observed at towers 2 and 5 .

At tower 5, only a small amount of data from the wake data set, from about $295^{\circ}$ to $310^{\circ}$, represents free-flow conditions, so the non-wake data set must be relied upon almost exclusively to observe the free-flow conditions. Wind speed and turbulence intensity ratios are close to 1.0 except for directions greater than about $290^{\circ}$. The slightly higher turbulence intensity ratios 
around $250^{\circ}$ and lower ratios around $280^{\circ}$ are probably a result of the differences in the upwind surface roughnesses. The reduced speeds and increased turbulence intensities from $300^{\circ}$ to $320^{\circ}$ are similar to free-flow ratios observed at towers 2 and 4 for these directions and are possibly due to terrain-induced effects. However, the large grove of trees to the north and north-northwest of tower 5 could also influence the flow from $300^{\circ}$ to $320^{\circ}$ even though it passes adjacent to these trees and not directly over them. For directions greater than about $330^{\circ}$ at tower 5 , these trees should have a very strong influence on tower 5 's wind flow characteristics, resulting in a substantial reduction in wind speed and increase in turbulence of comparable or greater magnitude than was observed at tower $i$.

\subsubsection{Tower 8 - Various Flow Influences Observed}

At tower 8, the free-flow conditions are represented in Figures 3.1 and 3.2 by the dashed line for all directions and the solid line from $230^{\circ}$ to $240^{\circ}$ and $265^{\circ}$ to $280^{\circ}$. The largest differences in the free-flow conditions between towers 8 and 9 are observed around wind directions of $230^{\circ}$ and $310^{\circ}$. At $230^{\circ}$, upwind of tower 8 , the terrain rises to the top of a crest and then drops off quite steeply down the other side of the crest, whereas upwind of tower 9, the terrain slopes gently downward. (The small rise upwind of tower 8 is not resolved by the terrain contours in Figure 3.3.) Thus, the reduced wind speeds and increased turbulence intensities at tower 8 at $230^{\circ}$ can probably be attributed to the fact that tower 8 is slightly to the lee of the ridge crest and experiences terrain-induced turbulence as a result of the steep terrain upwind of this crest.

At directions greater than about $300^{\circ}$, tower 8 is apparently in the wake of the same grove of trees that caused the large reductions in wind speed and increases in turbulence intensity observed at towers 6 and 7 . The maximum wake effect at tower 8 from these trees should occur at about $320^{\circ}$ to $325^{\circ}$, if sufficient data were available from those wind directions to observe it; this effect is indicated by the $325^{\circ}$ radial in Figure 3.3 that goes directly over the grove of pine and juniper trees.

When wind directions are $265^{\circ}$ to $285^{\circ}$, turbulence intensities at tower 8 are $10 \%$ to $20 \%$ lower than those at tower 9 . For these directions, tower 9 is 
only about $300 \mathrm{~m}$ downind of an extensive area of scrub oak trees, whereas tower 8 is about $1000 \mathrm{~m}$ downwind of these trees. Comparing the turbulence intensity ratios for tower 9 versus 3 , and 9 versus 8 , when the towers are downwind of these trees, one observes that the turbulence intensities decrease with increasing distance downwind of the trees with the highest turbulence intensities at tower 9 and the lowest turbulence intensities at tower 8 .

\subsubsection{Effects of Trees on Depth of Turbulent Layer and Wind Shear}

To investigate the depth of the tree-induced turbulent layer at the BPA tower when it is downwind of the trees, we analyzed and compared the variation of the turbulence intensity as a function of height and wind direction at the PNL and BPA towers. As previously mentioned, the BPA tower is about $300 \mathrm{~m}$ downwind of a grove of trees that are mostly scrub oak when the wind directions are from about $260^{\circ}$ to $290^{\circ}$, whereas the PNL tower is about $1000 \mathrm{~m}$ downwind of these trees (see Figure 3.3). These trees are estimated to range in height from about 5 to $12 \mathrm{~m}$.

Figure 3.4 shows, for each of three height levels of the BPA and PNL towers, the turbulence intensities as a function of wind direction. The turbulence intensities for the BPA tower are based on about $800 \mathrm{hr}$ of data from June through August, including all available data from both the wake and nonwake sets. Only periods when all three levels had data were included. The turbulence data available for the PNL tower were more limited because only non-wake data (i.e., turbines off) were included and data at the 15-m and 38-m levels were only avatlable during the month of June. Turbulence data were collected from June through August at only the 61-m level of the PNL tower. Thus, the turbulence intensities for the PNL tower shown in Figure 3.4 were based on about $125 \mathrm{hr}$ of data in June, representing only periods when all three levels had data.

At the BPA tower, the 15-m level turbulence intensities are strongly affected by the upwind fetch of the trees, because maximum turbulence intensities occur at directions of $265^{\circ}$ to $275^{\circ}$ when the upwind fetch is most directly over the trees. However, the $59-m$ level turbulence intensities at the BPA tower show an opposite trend from those at $15 \mathrm{~m}$, with minimum turbulence intensities when directions are $260^{\circ}$ to $280^{\circ}$. The trend with respect 
BPA TOWER

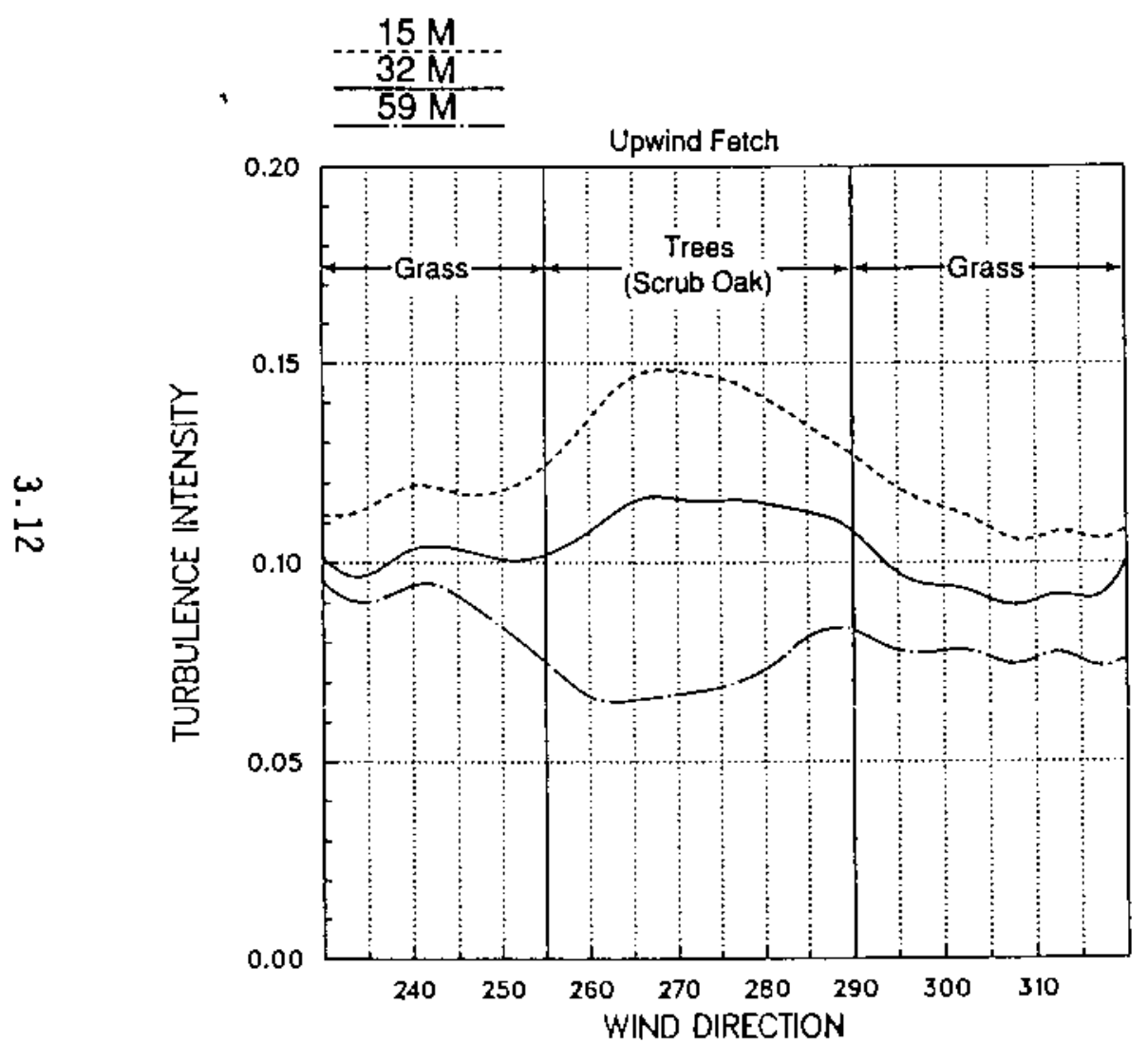

PNL. TOWER

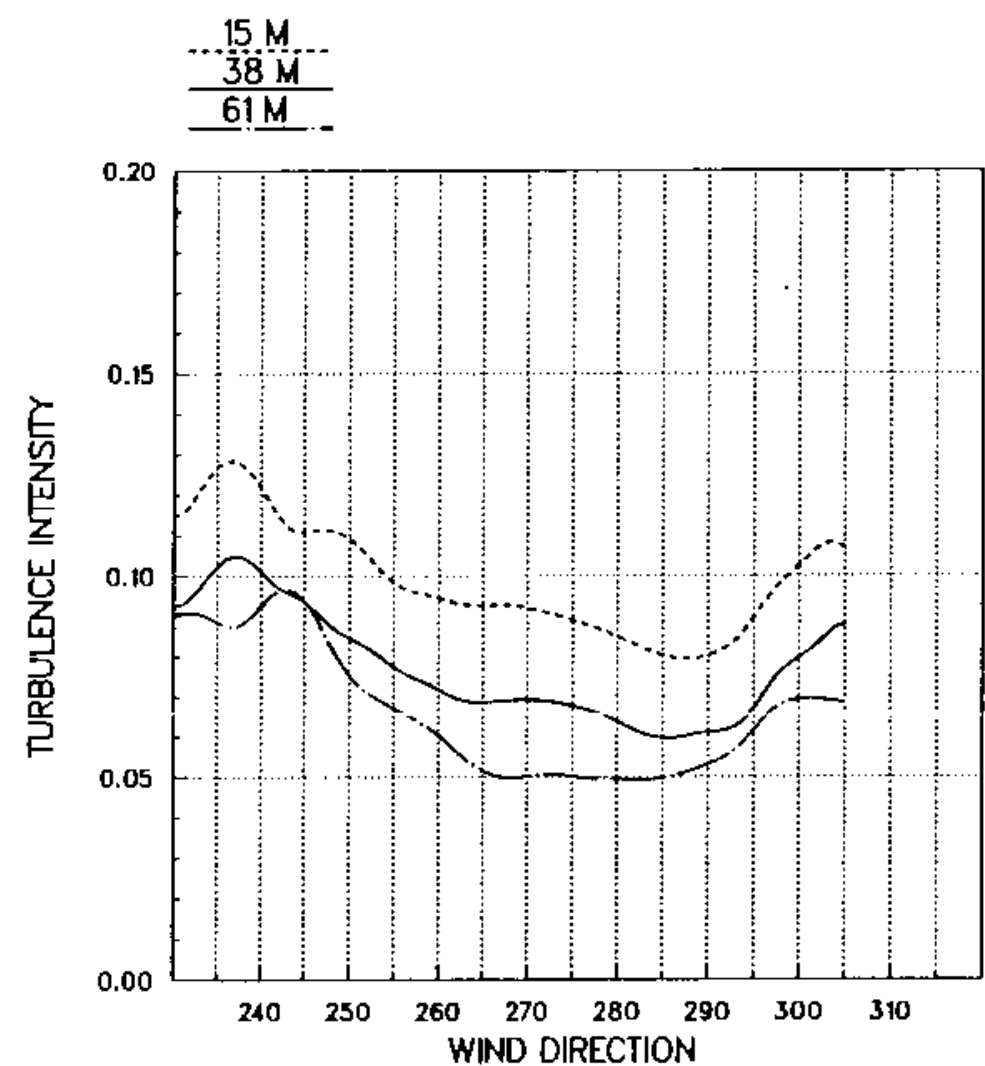

FIGURE 3.4. Average Yurbulence Intensity Plotted Versus Wind Direction for Three Height Levels at the BPA and PNL Towers. At the PNL tower the curves stop short of $320^{\circ}$ because of a lack of data at the higher wind directions. 
to wind direction observed at the 59-m level of the BPA tower is similar to that at the 61-m level of the PNL tower, with generally highest turbulence intensities for southwest directions and lowest turbulence intensities for west difections.

At the PNL tower, all three helght levels (see Figure 3.4) show similar trends in the turbulence variations with wind direction, with highest turbulence intensities for southwest directions and lowest turbulence intensities for west directions. There is no indication of any significant effect of the trees on the turbulence at the two lower height levels of the PNL tower. Apparently, the 1000-m separation distance between the trees and the PNL tower is sufficient to diminish the turbulence effects from the trees.

Comparing the turbulence intensities for the two lower height levels of the BPA and PNL towers in Figure 3.4, one can observe dramatic differences between the BPA and PNL towers in the turbulence intensity trends as a function of wind direction. These differences are most pronounced at $15 \mathrm{~m}$ and are greatest for the wind direction sector in which the BPA tower is downwind of the trees $\left(255^{\circ}\right.$ to $\left.290^{\circ}\right)$. Maximum differences between the BPA and PNL towers at $15 \mathrm{~m}$ occur when wind directions are about $265^{\circ}$ to $280^{\circ}$, which indicates that these are the directions in which the flow characteristics are most influenced by the upwind fetch of the trees.

While the effects of the trees on the turbulence at the BPA tower are quite evident at heights to at least $32 \mathrm{~m}$, they appear to be considerably reduced at $59 \mathrm{~m}$. However, the degree to which the 59-m level may be affected by the trees is difficult to estimate accurately with the existing data because different periods of data were used in the BPA and PNL tower analyses.

To obtain a more reliable estimate of the affect of the trees on the 59-m level of the BPA tower, a comparison of the wind speeds and turbulence intensities between the BPA tower 59-m level and the PNL tower 61-m level was carried out, using identical periods of non-wake data. Average ratios (PNL/BPA) of wind speed and turbulence intensity for directions between $260^{\circ}$ and $290^{\circ}$ were in the range of 1.05 to 1.10 for wind speed and 0.8 to 0.9 for turbulence intensity. Thus, the hub-height wind flow was slightly stronger and slightly less turbulent at the PNL tower than at the BPA tower. This 
indicates that the effects of trees could extend upwards to at least $59 \mathrm{~m}$ at the BPA tower (which is $300 \mathrm{~m}$ downwind of the trees), although these effects are substantially weaker at $59 \mathrm{~m}$ than at heights of 15 to $32 \mathrm{~m}$. However, other factors could also contribute to the PNL/BPA differences in the wind speeds and turbulence intensities at about the 60-m level, such as differences in sensor calibration and response characteristics, and terrain effects.

An analysis was also performed to estimate the effects of the trees on the wind shear profile with height. A power-law equation is commonly used to describe the wind shear or the variation of wind speed with height above ground:

$$
\frac{v_{2}}{v_{1}}=\left(\frac{z_{2}}{z_{1}}\right)^{a}
$$

where $v_{2}$ and $v_{1}$ are the mean wind speeds at heights $z_{2}$ and $z_{1}$, respectively, and $a$ is the power law exponent. The power law exponent is calculated by

$$
a=\frac{\ln \left(V_{2} / V_{1}\right)}{\ln \left(z_{2} / Z_{1}\right)} .
$$

Average long-term values of a for smooth (grassy), flat terrain are typically about 0.14. An increase in surface roughness and/or increase in atmospheric stability generally result in an increase in the wind shear and consequently an increase in $a$.

Figure 3.5 shows the values of $a$ as a function of wind direction for the BPA and PNL towers. Only non-wake data (i.e., turbines off) were used. The a values are shown for two intermediate layers and a composite layer spanning the lower half of the rotor disk. At both towers, shear exponents are largest in the lowest layer near the ground, as would be expected, because wind shear typically decreases with increasing height above ground. The remainder of this discussion will only address the shear exponent values for the composite layer, that is, the 15-m to 59-m layer at the BPA tower and the 15-m to $61-\mathrm{m}$ layer at the PNL tower. 
BPA TOWER

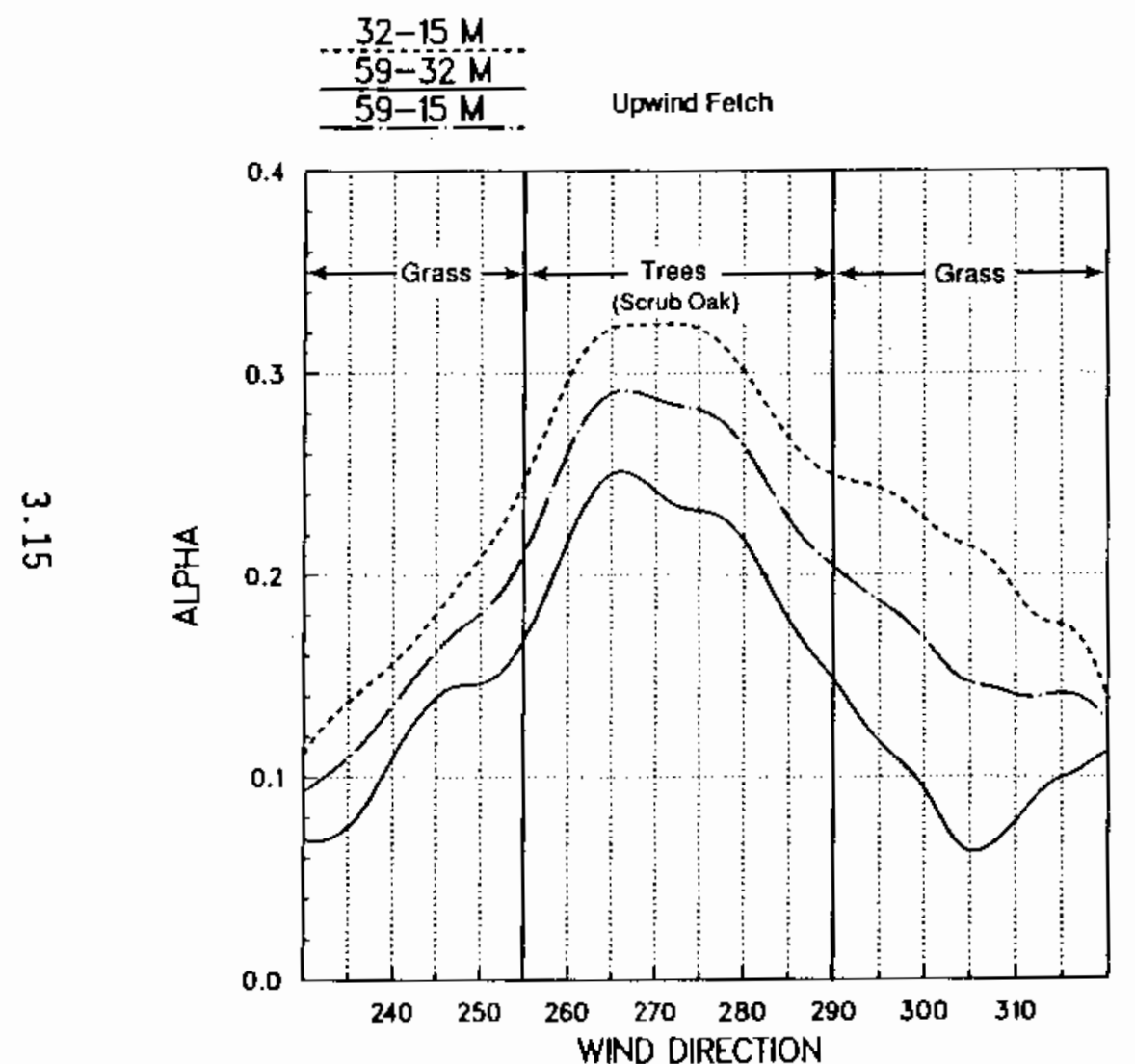

PNL TOWER

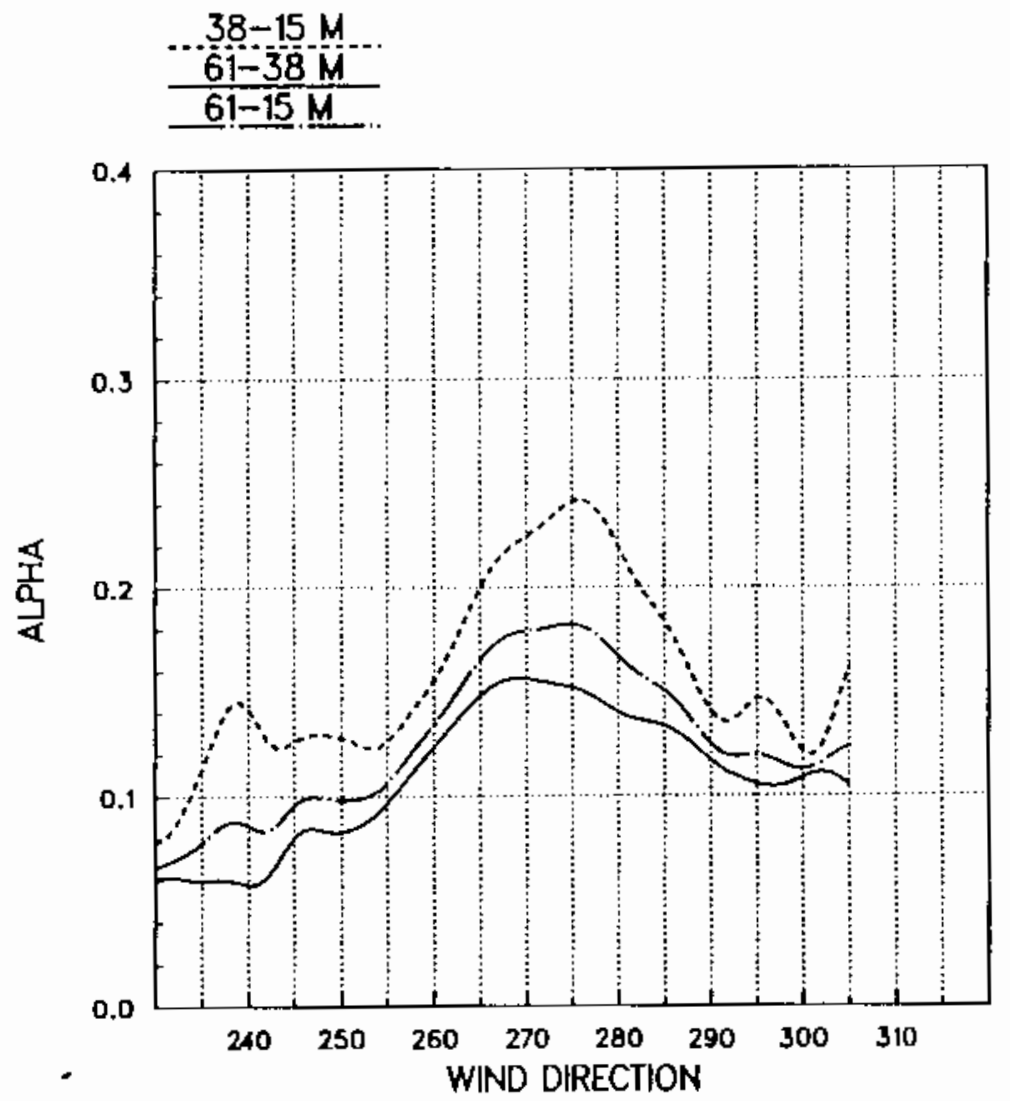

FIGURE 3.5. Average Values of the Wind Shear Exponent, a, Plotted Versus Wind Direction for the BPA and PNL Towers. At the PNL tower the curves stop short of $320^{\circ}$ because of a lack of data at the higher wind directions. 
At the BPA tower, average maximum $\alpha$ values were in the range of 0.28 to 0.29 and occurred for wind directions $265^{\circ}$ to $275^{\circ}$, which coincides with the directions of maximum turbulence intensities at $15 \mathrm{~m}$. This is the direction sector most influenced by the upwind fetch of the trees. Values of a exceeded 0.2 over the broad sector, $255^{\circ}$ to $290^{\circ}$, that experienced an increase in turbulence caused by the upwind fetch of the trees. For southwest and northwest directions, average values of a were considerably lower, ranging from 0.10 to 0.15 .

Values of $\alpha$ at the PNL tower were considerably lower than those at the $B P A$ tower when directions were $255^{\circ}$ to $280^{\circ}$. Average differences were in the range of 0.10 to 0.13 , with the maximum difference of 0.13 occurring at about $265^{\circ}$. For southwest and northwest directions, the PNL tower a values were only slightly lower than those at BPA, as differences were in the range of 0.02 to 0.06 .

At both the PNL and BPA towers, maximum $\alpha$ values occurred with west directions, but maximum $a$ values were 0.18 at the PNL tower compared to 0.29 at the BPA tower. At both towers, minimum $a$ values were associated with southwest directions, which are most frequent during the daytime hours when unstable atmospheric conditions and relatively high turbulence intensities often exist. During late evening and nighttime hours, when atmospheric conditions are typically quite stable and turbulence intensities quite low, westerly wind directions occur most frequently. Thus, the average maximum a values of about 0.18 at the PNL tower are probably due to the effects of nocturnal stability, whereas the much higher average maximum $a$ values of 0.29 at the BPA tower are probably due to a combination of the effects of nocturnal stability and the effects of the upwind fetch of the trees. As it turns out, the effects of nocturnal stability and the effects of the trees are each the greatest at the BPA tower when wind directions are in the range of $265^{\circ}$ to $275^{\circ}$. This combined effect of the stability and the trees results in the quite large wind shears observed at the BPA tower.

\subsubsection{Effects of Tree-Induced Turbulence on 1-s Time Series of Wind Speed}

One final investigation of the free-flow analysis was to examine how increased turbulence intensity caused by upwind trees affects the 1-s time series of the wind speeds. About $3 \mathrm{~h}$ of 1-s data had been collected from the 
nine towers on June 17, 1985; however, all but about $10 \mathrm{~min}$ of the data were influenced by turbine wakes, because the wind turbines were operating. The time series of the 1-s wind speeds at each of the nine towers were examined for an 8-min period (1632-1640 PST) when the wind turbines were shut down. The wind direction at tower 9 for this $8-m i n$ period averaged $284^{\circ}$, with a standard deviation of $8^{\circ}$. Average wind speeds at the nine towers for this 8 -min period ranged from $12.6 \mathrm{~m} / \mathrm{s}$ to $14.0 \mathrm{~m} / \mathrm{s}$, except for tower 7 , which had an average speed of only $9.2 \mathrm{~m} / \mathrm{s}$. Average turbulence intensities ranged from 9\% to $13 \%$, except for tower 7 which had an average turbulence intensity of $28 \%$.

This substantial reduction in the wind speeds and increase in the turbulence intensities observed at tower 7 when the wind direction is around $284^{\circ}$ is consistent with the findings previously discussed (see figures 3.1 and 3.2). At this wind direction, tower 7 is downwind of an extensive grove of pine and juniper trees, as seen in Figure 3.3.

Figure 3.6 shows a comparison of the 1-s time series data for towers 7 and 8 . The vegetation upwind of tower 8 in this wind direction is grass and low sagebrush; thus, the fetch upwind of tower 8 is quite smooth compared to that upwind of tower 7. Note in Figure 3.6 that the wind speed oscillations (i.e., the gustiness of the winds) at tower 7 are of much greater amplitude than those at tower 8. The implications for a wind turbine located at tower 7 (in contrast to one located at tower 8 ), with a hub height near $30 \mathrm{~m}$, would be reduced power output, more variable power output, more start/stop cycles, and probably increased stress caused by the increased turbulence. However, it is possible that turbine power output and performance could be improved significantly if the hub height were increased to $50 \mathrm{~m}$ or $60 \mathrm{~m}$.

\subsection{WAKE CHARACTERISTICS}

The wake effects downwind of the wind turbines when they were operating were examined by comparing the wake and ambient flow at each of the towers when a tower was determined to be downwind of a turbine. The arrangement of the towers with respect to the turbines permitted observations of the wake characteristics at various distances ranging from 2 to $10 \mathrm{D}$ (for the range of wind directions used in this report). It will be emphasized that the analysis 


\section{TOWER 7}

(Trees Upwind)

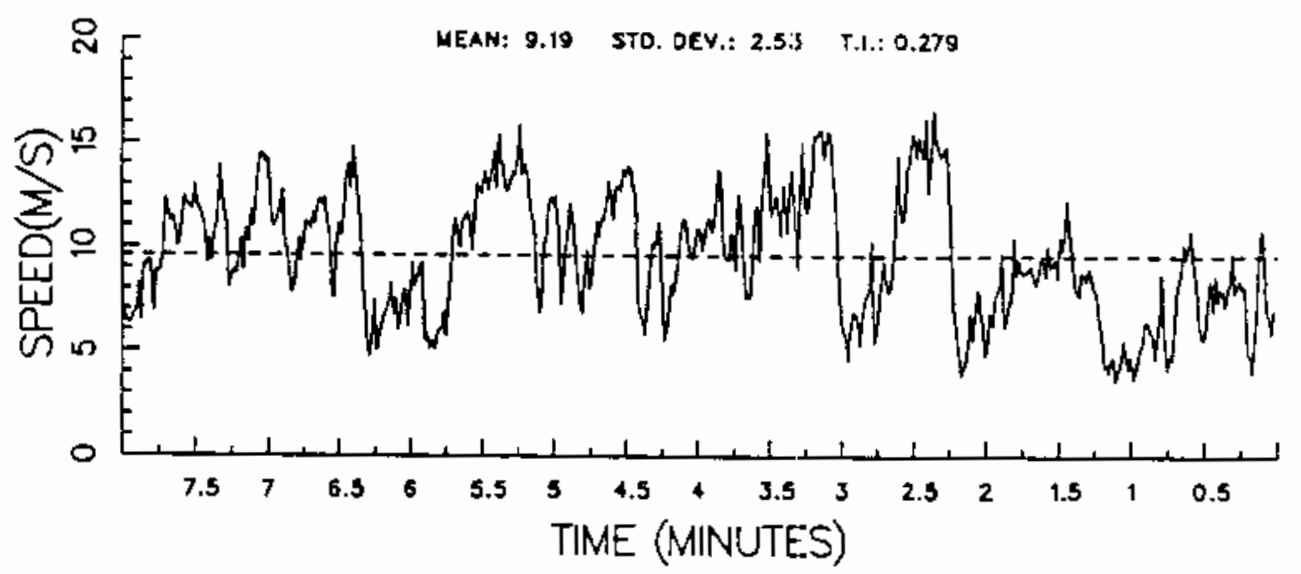

TOWER 8

(No Trees Upwind)

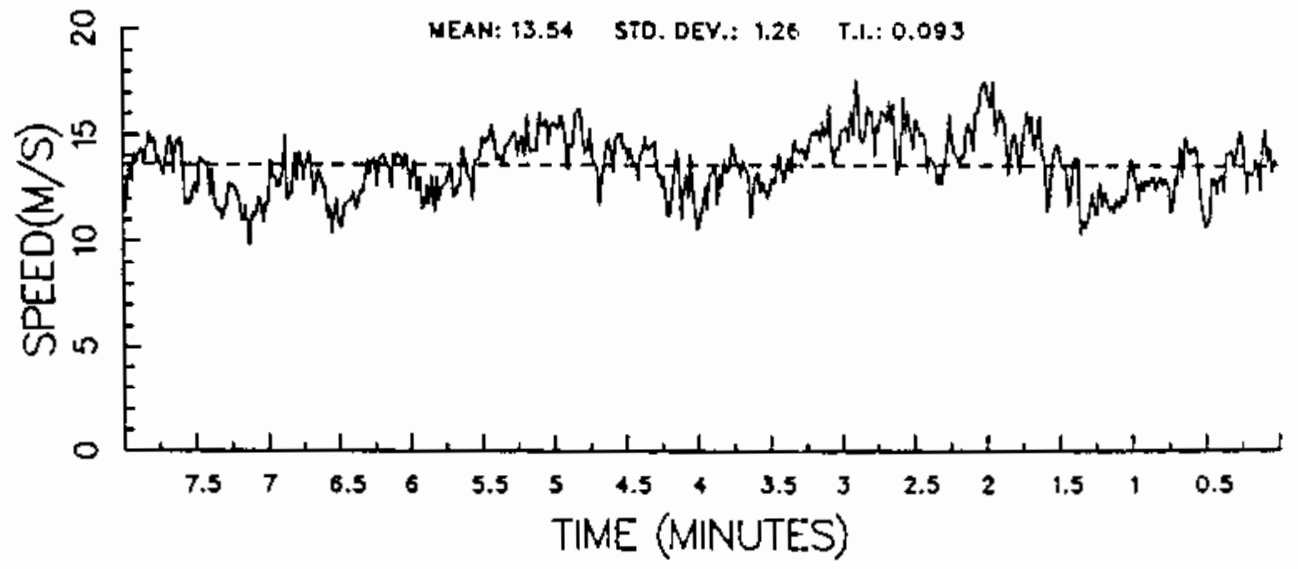

FIGURE 3.6. Comparison of the 1-s Time Series of Wind Speeds at Towers 7 and 8 for an 8-min Period, Showing the Affect of Trees on the Wind Gust Structure. The mean wind speed, standard deviation of the wind speeds, and turbulence intensity are also listed for each tower. 
of the wake characteristics (except the analysis of the vertical profile of the wake at the PNL tower) was based on measurements at $32 \mathrm{~m}$; turbine hub height was $61 \mathrm{~m}$ and the bottom of the rotor disk was $15 \mathrm{~m}$.

In order to estimate the wind directions when a tower is downwind of a turbine, information on the direction alignment between the tower and the turbine is needed. Table 3.1 lists, for each of the nine towers and turbines 2 and 3 , the direction from the tower to the turbine and the distance between the tower and the turbine. Table 3.1 indicates that there are a total of 11 turbine/tower wake scenarios within the range of wind directions $\left(230^{\circ}\right.$ to $320^{\circ}$ ) used in the analysis.

The directions and distances between the towers and the turbines were computed from the coordinate locations given in Appendix $C$. These coordinates were determined using an aerial photograph, showing the relative locations of the nine towers and three turbines, and a detailed topographic and surveyor's map.

\subsubsection{Velocity Deficits}

Using Table 3.1 and Figure 3.1, one can compare the actual direction from the tower to the turbine against the wind direction at which the maximum velocity deficit from the turbine wake occurs. The maximum velocity deficit occurs at the wind direction where the wind speed ratio reaches its minimum value. At most of the towers, the turbine wakes are easily depicted in Figure 3.1, because the wind speed ratio in the turbine wake decreases markedly in comparison to the ambient ratio. The wind direction of maximum velocity deficit is usually within about 2 to $5^{\circ}$ of the actual direction from the tower to the turbine. As discussed later in Sections 3.2.5 and 3.2.6, these differences are probably caused by wind direction errors and not curvature of the wake trajectory.

Average maximum velocity deficits were estimated for the ten turbine/tower wake scenarios where more than $50 \%$ of the entire wake was visible in Figure 3.1 and a minimum speed ratio was evident. These deficits are listed in Table 3.2. (The turbine $3 /$ tower 5 wake scenario was excluded because the minimum speed ratio was not clearly evident.) Maximum velocity deficits ranged from about $34 \%$ at $1.9 \mathrm{D}$ to about $7 \%$ at $10.0 \mathrm{D}$. The maximum velocity deficits are plotted, as a function of distance, in Figure 3.7 and a regression line has been fit 
TABLE 3.1. Directions and Distances Between the Towers and Turbines. The direction is from the tower to the wind turbine, expressed in degrees from true north. Distances are expressed in both meters and rotor diameters. One rotor diameter is $91.4 \mathrm{~m}(300 \mathrm{ft})$.

\begin{tabular}{|c|c|c|c|c|}
\hline Tower & Turbine & $\begin{array}{r}\text { Direction }\left({ }^{\circ}\right) \\
\text { (Tower to Turbine) } \\
\end{array}$ & $\begin{array}{l}\text { Distance } \\
\text { (m) }\end{array}$ & $\begin{array}{l}\text { Distance } \\
\text { (D) }\end{array}$ \\
\hline 1 & 2 & 41 & 541 & 7.0 \\
\hline 1 & 3 & 52 & 187 & 2.0 \\
\hline 2 & 2 & 122 & 103 & 1.1 \\
\hline 2 & 3 & 203 & 463 & 5.1 \\
\hline 3 & 2 & 350 & 327 & 3.6 \\
\hline 3 & 3 & $262^{(a)}$ & 329 & 3.6 \\
\hline 4 & 2 & $312^{(a)}$ & 202 & 2.2 \\
\hline 4 & 3 & $241^{(a)}$ & 483 & 5.3 \\
\hline 5 & 2 & $273^{(a)}$ & 177 & 1.9 \\
\hline 5 & 3 & $231^{(a)}$ & 575 & 6.3 \\
\hline 6 & 2 & $272^{(a)}$ & 478 & 5.2 \\
\hline 6 & 3 & $245^{(a)}$ & 830 & 9.1 \\
\hline 7 & 2 & $259^{(a)}$ & 523 & 5.7 \\
\hline 7 & 3 & $239^{(a)}$ & 914 & 10.0 \\
\hline 8 & 2 & $296^{(a)}$ & 543 & 5.9 \\
\hline 8 & 3 & $260^{(a)}$ & 772 & 8.4 \\
\hline 9 & 2 & 41 & 303 & 3.3 \\
\hline 9 & 3 & 207 & 159 & 1.7 \\
\hline
\end{tabular}

(a) Directions within the $230^{\circ}$ to $320^{\circ}$ range used in the analysis. 
TABLE 3.2. Wake Statistics for the Ten Turbine/Tower Wake Scenarios

\begin{tabular}{|c|c|c|c|c|c|}
\hline $\begin{array}{l}\text { Wake Scenario } \\
\text { Turbine/Tower } \\
\end{array}$ & $\begin{array}{c}\text { Distance } \\
\text { (D) } \\
\end{array}$ & $\begin{array}{l}\text { Maximum } \\
\text { Velocity } \\
\text { Deficit } \\
(\%) \\
\end{array}$ & $\begin{array}{c}\text { Maximum } \\
\text { Turbulence } \\
\text { Intensity } \\
\text { Ratio } \\
\end{array}$ & $\begin{array}{l}\text { Full } \\
\text { Wake } \\
\text { Width } \\
\text { (D) } \\
\end{array}$ & $\begin{array}{l}\text { Wake } \\
\text { Core } \\
\text { Width } \\
\text { (D) } \\
\end{array}$ \\
\hline $\mathrm{T} 2 / 5$ & 1.9 & 34 & 1.7 & 1.6 & 0.9 \\
\hline $\mathrm{T} 2 / 4$ & 2.2 & 32 & 1.9 & 1.6 & 0.8 \\
\hline $\mathrm{T} 3 / 3$ & 3.6 & 28 & 1.8 & 1.9 & 1.0 \\
\hline$T 2 / 6$ & 5.2 & 24 & 1.4 & 2.4 & 1.1 \\
\hline $\mathrm{T} 3 / 4$ & 5.3 & 17 & 1.5 & 2.0 & 1.2 \\
\hline $\mathrm{T} 2 / 7$ & 5.7 & 20 & 1.3 & 2.4 & 1.2 \\
\hline $\mathrm{T} 2 / 8$ & 5.9 & 22 & 1.4 & 2.0 & 1.2 \\
\hline $13 / 8$ & 8.4 & 13 & 1.3 & 2.7 & 1.5 \\
\hline $\mathrm{T} 3 / 6$ & 9.1 & 9 & 1.3 & 2.7 & 1.7 \\
\hline $13 / 7$ & 10.0 & 7 & 1.2 & 2.6 & 1.7 \\
\hline
\end{tabular}

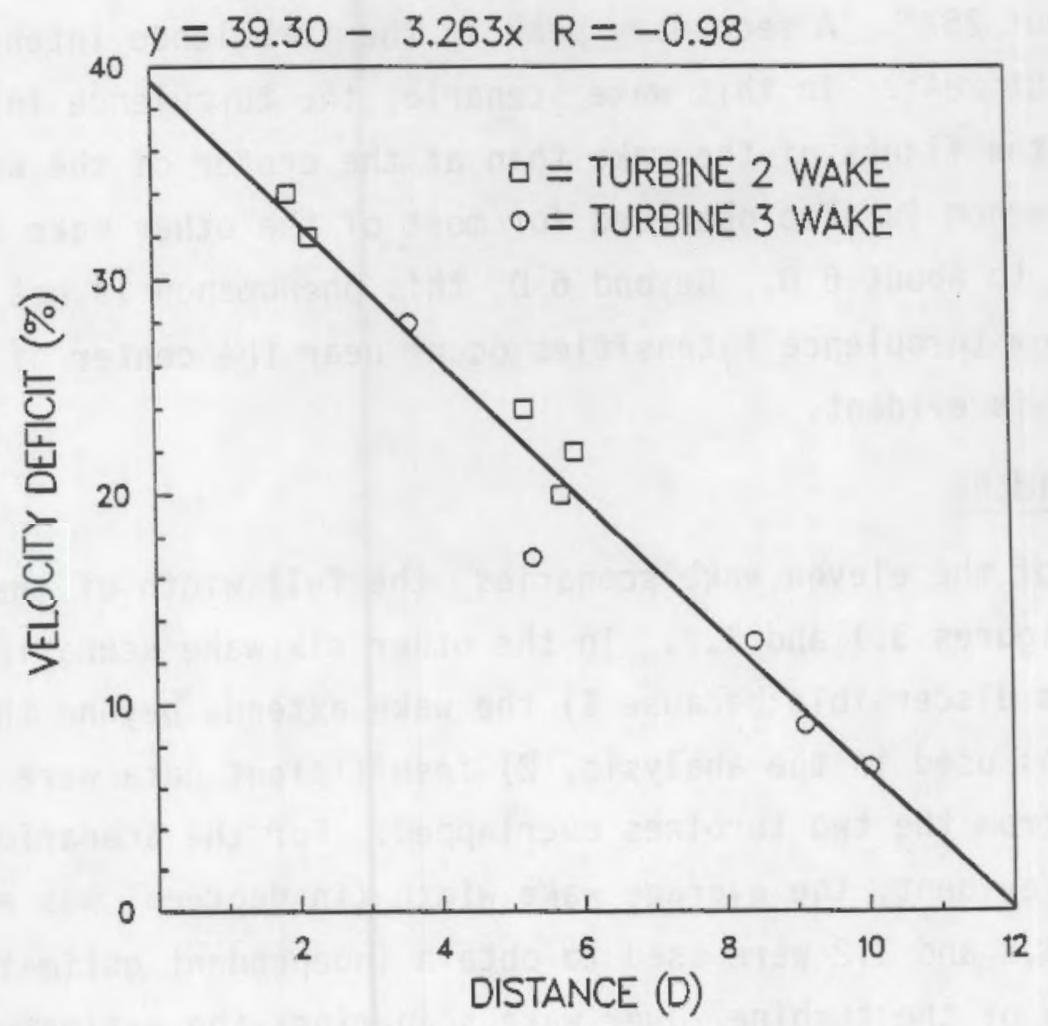

FIGURE 3.7. Average Maximum Velocity Deficits in the Turbine Wakes Plotted Versus Downwind Distance 
to the data points based on a least squares fit. The regression equation for this line and correlation coefficient are also included in Figure 3.7. The correlation coefficient $(-0.98)$ is quite good. The regression line indicates that the maximum velocity deficit would decrease to $0 \%$ (i.e., the wake would disappear) at about $12 \mathrm{D}$.

\subsubsection{Wake Turbulence Intensities}

Figure 3.2 shows that the turbulence intensities in the turbine wake are substantially higher than the ambient turbulence intensities for the same wind directions. Average maximum turbulence intensities in the turbine wake are about 1.7 to 1.9 times greater than ambient turbulence intensities at distances of 2 to $4 \mathrm{D}$ and about 1.2 to 1.5 times greater at distances of 5 to $10 \mathrm{D}$ (see Table 3.2). Comparing the directions of minimum speed ratio in Figure 3.1 versus the directions of maximum turbulence intensity ratio in Figure 3.2, one observes that a significant difference exists in some of the wake scenarios. For example, at tower 5 for the $1.9 \mathrm{D}$ wake, the minimum speed ratio occurs at about $270^{\circ}$, whereas the maximum turbulence intensity ratio occurs at about $257^{\circ}$. A secondary peak in the turbulence intensity ratio occurs at about $284^{\circ}$. In this wake scenario, the turbulence intensities are higher along the flanks of the wake than at the center of the wake. Evidence of this phenomenon is also observed for most of the other wake scenarios for distances out to about $6 \mathrm{D}$. Beyond $6 \mathrm{D}$, this phenomenon is not discernible, because maximum turbulence intensities occur near the center of the wake and only one peak is evident.

\subsubsection{Wake Widths}

In five of the eleven wake scenarios, the full width of the wake is discernible in Figures 3.1 and 3.2. In the other six wake scenarios, only part of the wake is discernible because 1) the wake extends beyond the range of wind directions used in the analysis, 2) insufficient data were available, or 3) the wakes from the two turbines overlapped. For the scenarios where the full wake was evident, the average wake width (in degrees) was estimated. Both Figures 3.1 and 3.2 were used to obtain independent estimates of the wake width for each of the turbine/tower wake scenarios; the estimates agreed reasonably well and were typically within a few degrees. The figures were then re-examined to determine the causes of any differences and to make final 
estimates of the wind direction angles. In three of the scenarios, the wake width was more discernible in the turbulence intensity ratios than in the speed ratios, so the estimates based on the turbulence ratios were used in these cases. In the wake scenarios where the full wake was not discernible, the half-width of the wake was estimated and then doubled. (This was based on the assumption that the wake was symmetrical about the direction where the maximum velocity deficit occurs, which generally appears to be the case.)

After the full wake widths were determined for each of the turbine/tower wake scenarios, the wake width in degrees was converted to a wake width expressed in rotor diameters using the following equation:

$$
W D=2 D \tan \left(\theta_{W} / 2\right)
$$

where $W D$ is the wake width in rotor diameters, $D$ is the distance between the tower and the turbine in rotor diameters, and $\theta_{W}$ is the wake width in degrees. The width of the wake core was also calculated, where the wake core was defined as that part of the wake in which the velocity deficit is at least $50 \%$ of the maximum velocity deficit.

The widths of the full wake and the wake core are listed in Table 3.2 and plotted in Figure 3.8, along with the regression lines (which are based on least squares fits). Full wake widths ranged from $1.6 \mathrm{D}$ at a distance of $2 \mathrm{D}$ to about 2.6 to $2.7 \mathrm{D}$ at distances of 8 to $10 \mathrm{D}$. The wake core widths ranged from about $0.8 \mathrm{D}$ at a distance of $2 \mathrm{D}$ to $1.7 \mathrm{D}$ at distances of 9 to $10 \mathrm{D}$. The correlation coefficient is better for the wake core regression line $(0.98)$ than that for the full wake.

\subsubsection{Consequences for Turbine Spacing}

Using these results on the observed velocity deficits and wake width, we can consider possible consequences for a wind farm of several rows of wind turbines. These consequences assume that the winds are generally unidirectional and that the wind speeds and turbulence intensities are comparable to those observed at Goodnoe Hills during this data collection period. Moreover, these consequences are based on velocity deficits and wake widths at $32 \mathrm{~m}$, not at the hub height of $61 \mathrm{~m}$. Slightly greater velocity deficits and wake widths may exist at hub-height level, as discussed in Section 3.2.7. 


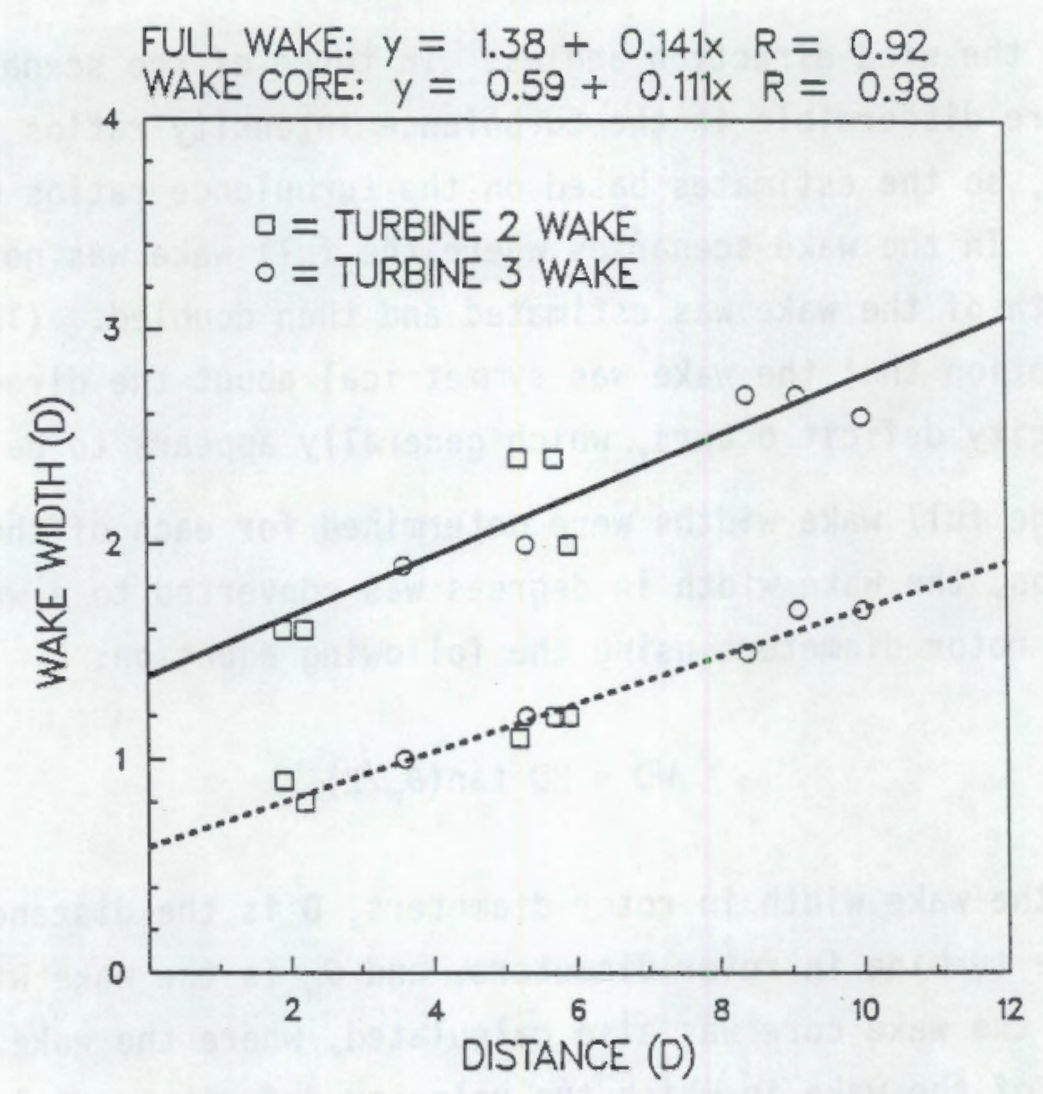

FIGURE 3.8. Average Wake Widths of the Full Wake (Solid Line) and Wake Core (Dashed Line) Plotted Versus Downwind Distance

If a turbine spacing of $10 \mathrm{D}$ (row separation) by $2 \mathrm{D}$ (lateral turbine separation) were used, which is typical of many of the existing wind farms in California, the turbine wakes at $10 \mathrm{D}$ would overlap each other by about 0.7 D. If the spacing were $10 \mathrm{D}$ by $3 \mathrm{D}$, no overlap would occur because the average wake width at $10 \mathrm{D}$ is about $2.7 \mathrm{D}$. The implication is that for a wind farm with a 10-D row separation, array losses would be greater for a 2-D spacing than a 3-D spacing as a result of the incremental effects caused by overlapping wakes. Decreasing the lateral spacing to $1.5 \mathrm{D}$ would result in substantially greater wake losses than occur for 2-D spacing, because the wake cores would be overlapping. If row separations were increased to $12 \mathrm{D}$ or greater, closer lateral spacings such as $2 \mathrm{D}$ would perhaps be suitable, because the individual turbine wake deficits are estimated to be near zero at these distances. 


\subsubsection{Wake Trajectory}

The wake trajectory as a function of downwind distance can be examined by comparing the wind direction of the maximum velocity deficit in Figure 3.1 to the actual direction between the tower and the turbine in Table 3.1. Some of the previous wake studies for the Goodnoe Hills site, such as those by Buck and Renne (1985) and Elliott, Buck, and Barnard (1988), indicated a significant curvature in the wake trajectory; differences as large as $14^{\circ}$ were observed between the wind direction of maximum velocity deficit and the actual direction between the tower and the turbine. However, it was not possible in these previous studies to determine if the wake trajectory was actually curving or if the wind directions were in error, because the wake was only observed at one downwind tower (the PNL tower). Using the nine-tower data set, we can more accurately examine the wake trajectory and at same time determine how accurate the wind directions are. This is possible because some of the towers are in almost perfect alignment between the turbine and another tower, which permits an examination of the curvature of the wake trajectory. For example, towers 5 and 6 are along nearly the same direction alignment to turbine 2 $\left(272^{\circ}-273^{\circ}\right)$, towers 3 and 8 are nearly along the same alignment to turbine 3 $\left(260^{\circ}-262^{\circ}\right)$, and towers 4 and 7 are nearly along the same alignment to turbine $3\left(239^{\circ}-241^{\circ}\right)$. We will examine each one of these three wake scenarios separately to observe the wake trajectory.

Towers 5 and 6 are $1.9 \mathrm{D}$ and $5.2 \mathrm{D}$, respectively, downwind of turbine 2, and the actual direction alignments to turbine 2 are within $1^{\circ}\left(272^{\circ}\right.$ versus $273^{\circ}$ ). In Figure 3.1 , note that the directions of maximum velocity deficits in the turbine 2 wake at towers 5 and 6 are also within about $1^{\circ}\left(270^{\circ}\right.$ versus $271^{\circ}$ ). Thus, the wake trajectory between towers 5 and 6 is approximately a straight line, on the average.

Towers 3 and 8 are $3.6 \mathrm{D}$ and $8.4 \mathrm{D}$, respectively, downwind of turbine 3 , and the actual direction alignments to turbine 3 are within $2^{\circ}\left(262^{\circ}\right.$ versus $260^{\circ}$ ). In Figure 3.1 , note that the directions of maximum velocity deficits in the turbine 3 wake at towers 3 and 8 are also within about $2^{\circ}\left(256^{\circ}\right.$ versus $254^{\circ}$ ). Thus, the wake trajectory between towers 3 and 8 is approximately a straight line, on the average. 
Towers 4 and 7 are 5.3 D and 10.0 D, respectively, downwind of turbine 3, and the actual direction alignments to turbine 3 are within $2^{\circ}\left(241^{\circ}\right.$ versus $\left.239^{\circ}\right)$. In Figure 3.1 , note that the directions of maximum velocity deficits in the turbine 3 wake at towers 4 and 7 appear to be within about $2^{\circ}$. Thus, the wake trajectory between towers 4 and 7 is approximately a straight line, on the average.

In all three of the above wake scenarios, the wake trajectory traveled in approximately a straight line, and there was no evidence of any significant wake curvature. An additional implication is that the wind direction variability over the site is, on the average, quite small and probably almost negligible.

One further analysis was performed to check for any evidence of wake curvature. For all ten tower-to-turbine wake scenarios, the difference between the actual direction from the tower to the turbine and the wind direction of the maximum velocity deficit was plotted as a function of downwind distance as shown in Figure 3.9. If wake curvature existed, the regression line would have a distinctive slope, i.e., the direction difference would increase or decrease versus distance. Rather, the direction difference is essentially constant, which further confirms that the wake trajectory, on the average, has no significant curvature.

\subsubsection{Wind Direction Alignment Errors and Wake Curvature Implications}

Figure 3.9 can also be used to estimate the accuracy of the wind direction measured at the reference anemometer. The actual direction determined by the tower/turbine direction is about $3^{\circ}$ greater than the measured wind direction at the maximum velocity deficit, on the average, which indicates that the wind direction at the reference anemometer is probably about $3^{\circ}$ off. However, a difference of $3^{\circ}$ is really quite small and within the range that can be expected for the alignment of a wind direction sensor. One could go back to Table 2.4 and determine the wind direction aligninent errors for all the anemometers and then correct all the anemometers to their true wind direction. The largest wind direction alignment errors were at the BPA 59-m and PNL $38-m$ anemometers (see Table 2.4). If the BPA 59-m anemometer (uncorrected) were used as the upwind reference anemometer (as was the case in the previous wake 


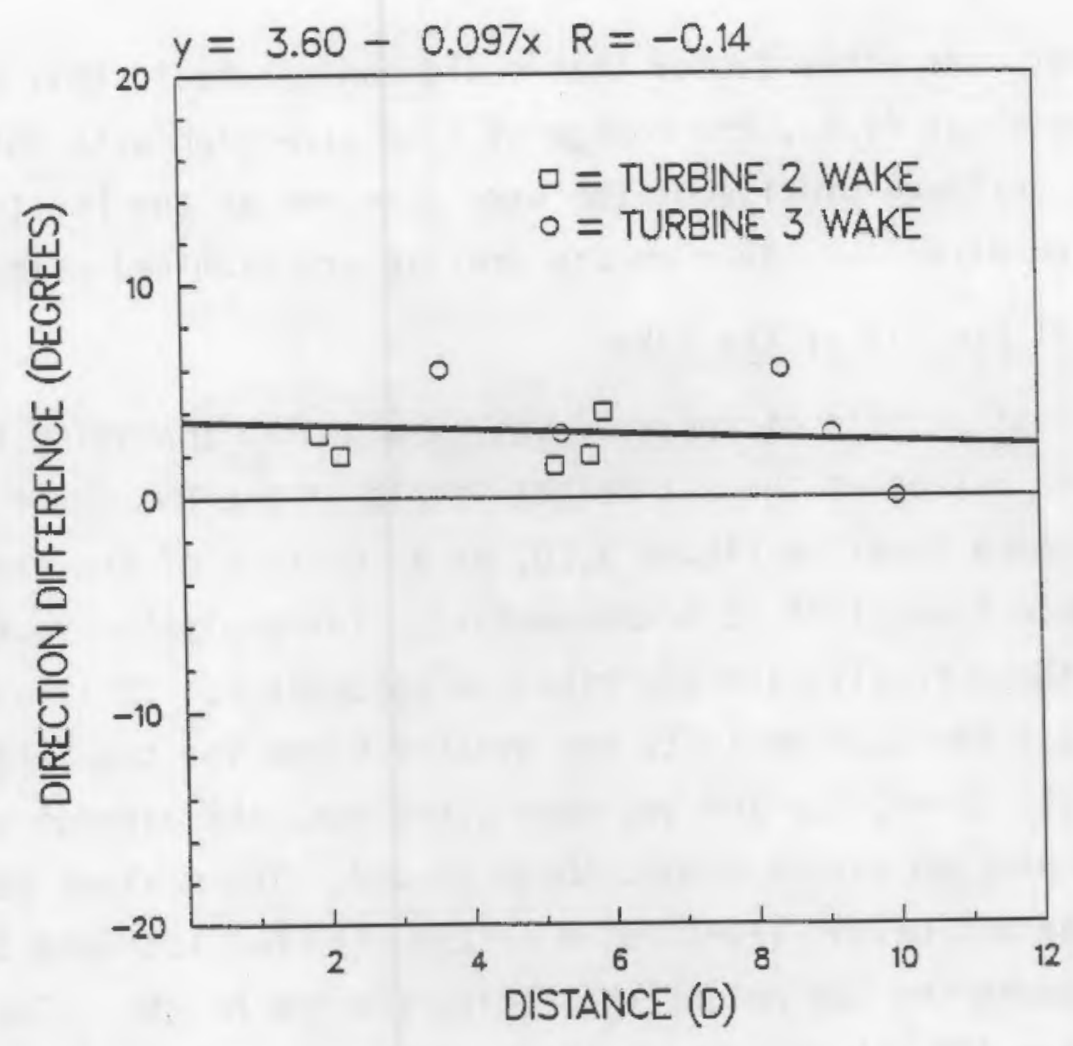

FIGURE 3.9. Difference Between the Actual Direction From the Tower to the Turbine and the Wind Direction of the Maximum Velocity Deficit, Plotted Versus Downwind Distance. This difference is the actual direction minus the wind direction.

report by Elliott et a1. (1988)), the wind direction of the maximum velocity deficit would increase by about $14^{\circ}$, which is the average difference between the BPA 59-m and BPA 32-m wind directions. This could give the false impression that the wake trajectory is curving significantly, especially if only one downwind tower were used to observe the wake, because the observed direction of the maximum velocity deficit would be around $14^{\circ}$ off the actual direction between the tower and the turbine. Indeed, in the previous wake study where the BPA 59-m anemometer was used as the reference anemometer, the $14^{\circ}$ error in the wind direction was misinterpreted to be wake curvature. In that study, the maximum velocity deficit for the turbine 2/PNL wake scenario occurred at a BPA 59-m wind direction of $306^{\circ}$; in this study, the maximum velocity deficit for the same wake scenario occurred at a BPA 32-m wind direction of $292^{\circ}$. Note that the difference is $14^{\circ}$. Aside from the wind direction 
alignment error, one other factor that could contribute to this difference is wind direction shear (i.e., the change of wind direction with height above ground). The vertical profile of the wake observed at the PNL tower and the effects of wind direction shear on the profile are examined next.

\subsubsection{Vertical Profile of the Wake}

The vertical profile of the wake was examined by analyzing the ambient and wake wind speed ratios at the six height levels of the PNL tower. These ratios are shown for each level in Figure 3.10, as a function of the wind direction at the reference tower (BPA 32-m anemometer). The analysis procedures used in producing these results are described in Appendix D. It is evident from Figure 3.10 that the wake deficits are greater below the hub height than above it. Figure 3.11 shows, for the two wake scenarios, the average maximum velocity deficits plotted versus height above ground. The maximum velocity deficits are at the hub-height level (61 m or $200 \mathrm{ft}$ ), but the wake diminishes more rapidly above the hub height than below the hub height. The velocity deficits at $15 \mathrm{~m}(50 \mathrm{ft})$ are substantially greater than those at $107 \mathrm{~m}$ $(350 \mathrm{ft})$. This situation is not surprising, because the ground restricts the vertical wake growth thereby 'concentrating' the momentum deficit in a region above the ground but below hub height.

\subsubsection{Wind Direction Shear}

The wind direction of the maximum velocity deficit is also plotted in Figure 3.11 for each of the six height levels of the PNL tower. The reference upwind anemometer, the BPA 32-m anemometer, was used for wind direction because of the wind direction alignment errors previously discussed. The wind direction of the maximum velocity deficit is quite constant with height and shows only a few degrees variation, which appears almost insignificant. This constancy indicates that the wake trajectory is not significantly different at any height, which implies that the wind direction shear (i.e., the change of wind direction with height above ground) is typically only a few degrees and has relatively little effect on the wake trajectory. Actually, if the "corrected" (true) wind directions are calculated and compared for each of the six anemometers on the PNL tower, one can observe that the mean wind directions are within a few degrees of each other, which confirms that the average wind direction shear is relatively small. 


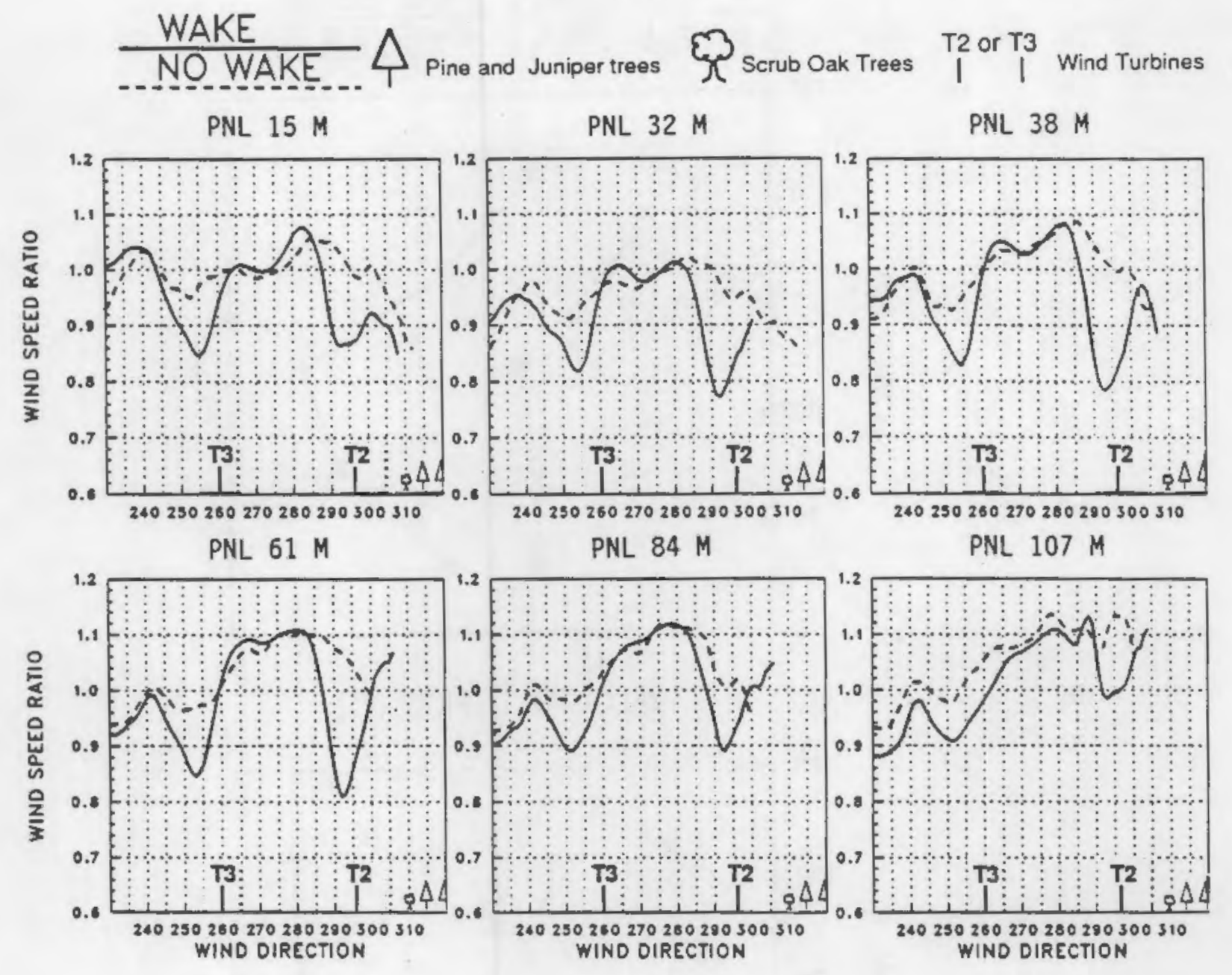

FIGURE 3.10. Wind Speed Ratios for Each of the Six Height Levels of the PNL Tower Plotted Versus Wind Direction. The curves stop short of $320^{\circ}$ because of a lack of data at the higher wind directions. Directions of major groves of trees less than $500 \mathrm{~m}$ away and directions of wind turbines are indicated. 


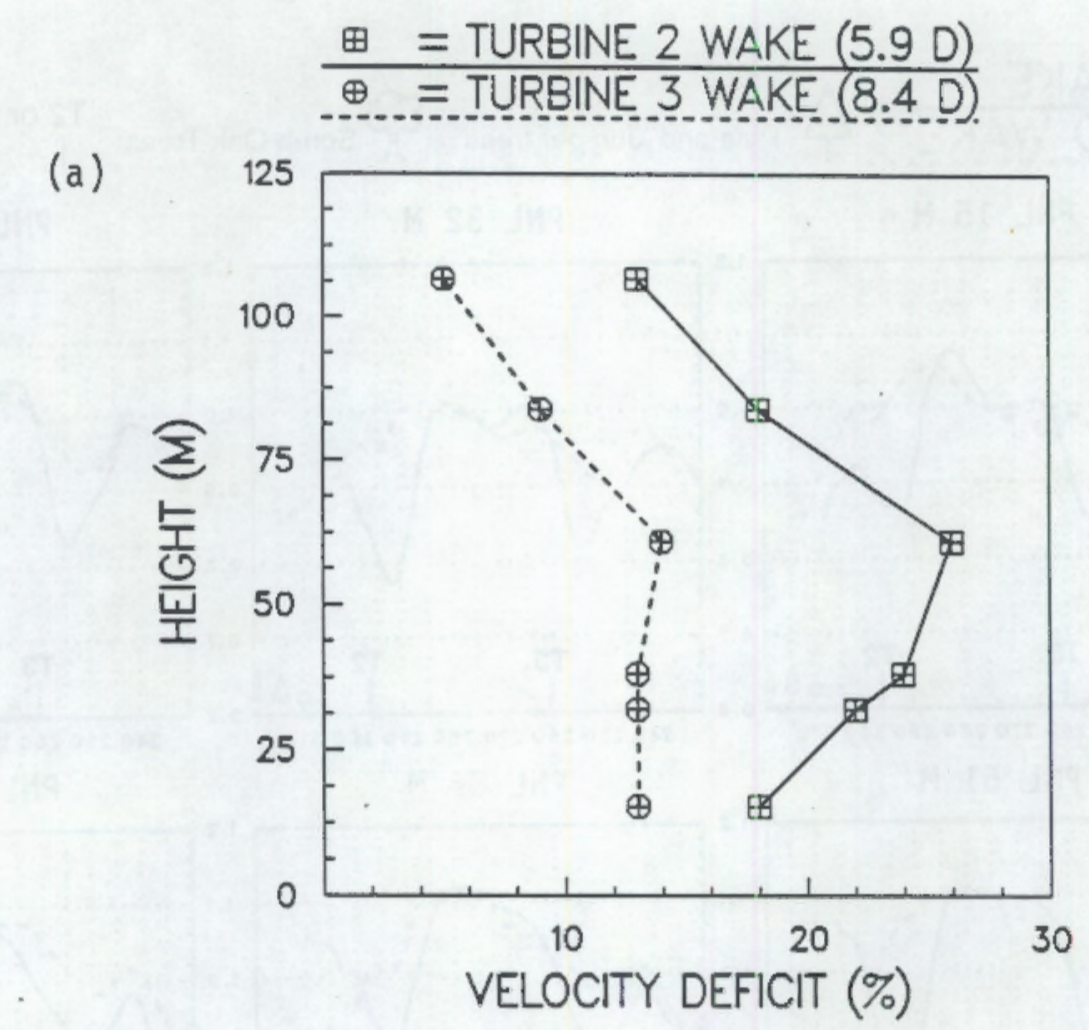

(b)

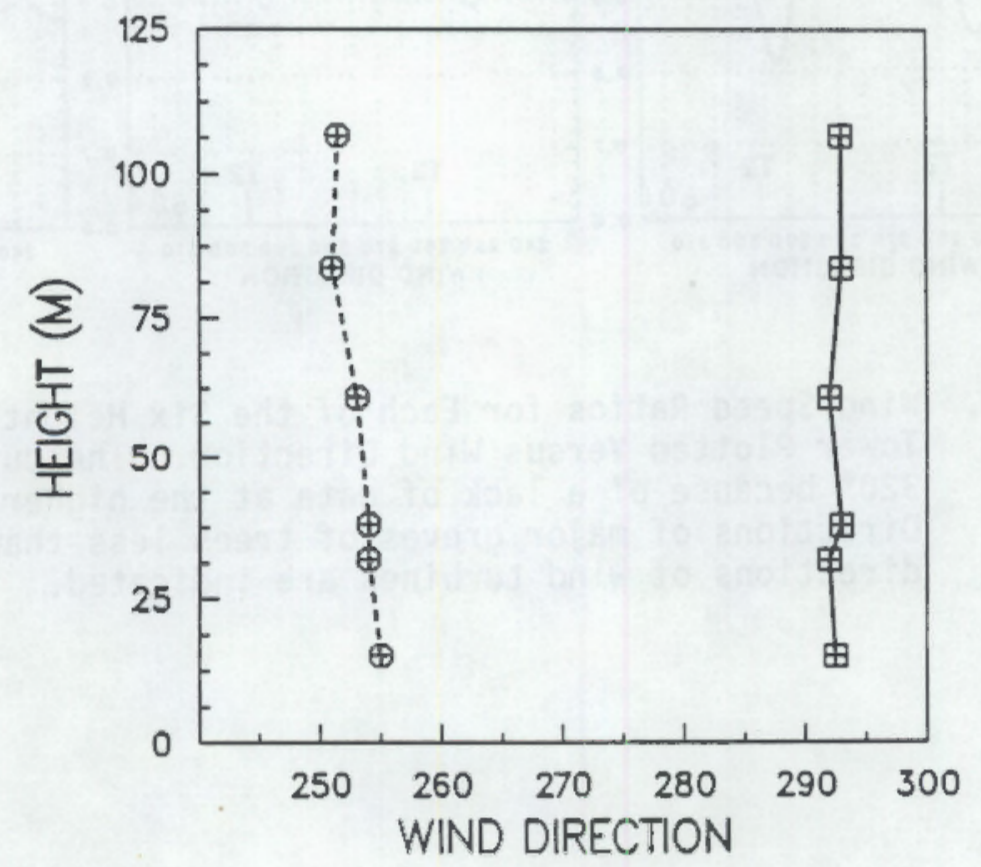

FIGURE 3.11. Average Maximum Velocity Deficits (a) and Wind Direction of the Maximum Velocity Deficits (b) at the PNL Tower Plotted Versus Height Above Ground 


\subsubsection{Velocity Deficits Stratified by Ambient Wind Speed and Turbulence Intensity}

Another analysis was to examine the velocity deficits as a function of the ambient wind speed and the ambient turbulence intensity. The relationship between wind speed and the MOD-2 rotor thrust coefficient is described in Appendix E. Generally, thrust coefficients are highest at low wind speed and decrease with increasing wind speed. Rotor thrust coefficients are about 0.8 at wind speeds of $6 \mathrm{~m} / \mathrm{s}$ and decrease to around 0.2 at wind speeds of $18 \mathrm{~m} / \mathrm{s}$ (see Figure E.1).

Four wake scenarios were selected for this analysis; these are listed in Table 3.3. Many of the other wake scenarios were determined to have insufficient data available for this type of analysis, because the data sets had to be divided into several smaller subsets for comparison of the ambient and wake wind speed ratios. The wake scenarios of turbine 2/tower 5 (1.9 D) and turbine $2 /$ tower $6(5.2 \mathrm{D})$ were selected, since these wakes were centered near $270^{\circ}$, the most frequent wind direction, and considerably more data were available for these two wake scenarios than for any of the other wake scenarios. The wake scenario of turbine $3 /$ tower $8(8.4 \mathrm{D})$ was selected in order to extend the analysis of the wake features out to $8.4 \mathrm{D}$. (Insufficient data were avaiTable for the 9.1 $\mathrm{D}$ and $10.0 \mathrm{D}$ wake scenarios, as they were at directions near $240^{\circ}$ where the amount of data is too limited for further stratifications.) The wake scenario of turbine $2 /$ tower $8(5.9 \mathrm{D})$ was also examined to provide another data point.

Table 3.3 lists the average maximum velocity deficits in each wake scenario for three different categories of wind speed and turbulence intensity. These categories were determined by examining the observed (wake data set) frequency distributions of wind speed and turbulence intensity at the BPA 59-m anemometer (see Appendix A) and dividing the distributions roughly into thirds. The 59-m level of the BPA tower was used, rather than the 32-m level, to stratify the wind speed and turbulence intensity because the wind flow characteristics at the 32-m level are significantly influenced by the upwind fetch of the trees as previously shown. The influence of the trees on the 59-m level was determined be considerably reduced, because this level is mostly above the tree-induced turbulent layer and its wind flow characteristics are 
TABLE 3.3. Average Maximum Velocity Deficits (\%) at $32 \mathrm{~m}$ Stratified by Ambient Wind Speed and Turbulence Intensity at $59 \mathrm{~m}$

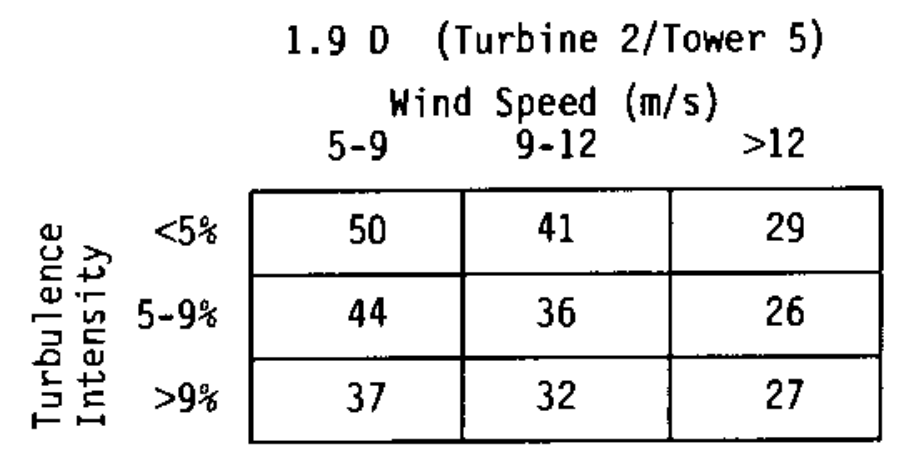

\begin{tabular}{|c|c|c|c|}
\hline \multirow{4}{*}{ 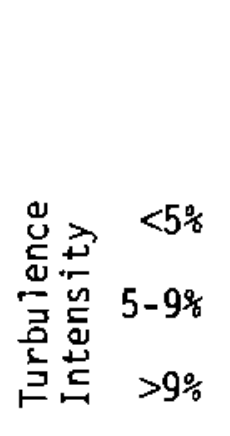 } & \multicolumn{3}{|c|}{$\begin{array}{c}5.20 \text { (Turbine } 2 / \text { Tower } 6) \\
\text { Wind Speed }(\mathrm{m} / \mathrm{s})\end{array}$} \\
\hline & 31 & 31 & 20 \\
\hline & 26 & 24 & 17 \\
\hline & 20 & 19 & 17 \\
\hline
\end{tabular}

$\underset{\omega}{\omega}$

5.90 (Turbine 2/Tower 8 )

\begin{tabular}{|c|c|c|c|c|}
\hline \multirow{4}{*}{ 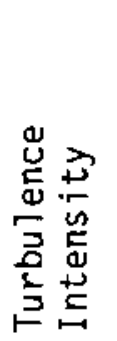 } & \multirow[b]{2}{*}{$<5 \%$} & \multicolumn{3}{|c|}{ 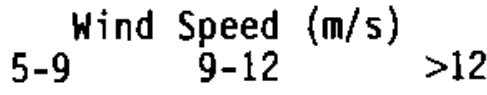 } \\
\hline & & 28 & 27 & 20 \\
\hline & $5-9 \%$ & 24 & 20 & 16 \\
\hline & $>9^{\circ}$ & 17 & 18 & 16 \\
\hline
\end{tabular}

8.4 D (Turbine 3/Tower 8) Wind Speed $(\mathrm{m} / \mathrm{s})$

\begin{tabular}{|c|c|c|c|}
\hline & \multicolumn{3}{|c|}{ Wind Speed $(\mathrm{m} / \mathrm{s})$} \\
\hline & $5-9$ & $9-12$ & $>12$ \\
\hline \multirow{3}{*}{ 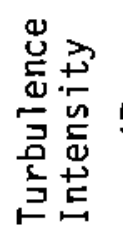 } & 16 & 18 & 13 \\
\hline & 16 & 12 & 11 \\
\hline & 13 & 10 & 10 \\
\hline
\end{tabular}


only slightly affected by the trees. For the purpose of this stratification, any slight influences that may be caused by the trees are probably negligible.

It is evident from Table 3.3 that velocity deficits at $32 \mathrm{~m}$ are for the most part highest at low turbulence intensities and low wind speeds (high thrust coefficients), and lowest at high turbulence intensities and high wind speeds (low thrust coefficients). The margin of error of these deficits is estimated to be only about $1 \%$ at $1.9 \mathrm{D}$ and $5.2 \mathrm{D}$, because a considerable amount of data was available for these wake scenarios. The amount of data available for the 5.9 D and 8.4 D wake scenarios was more limited, and the margin of error is estimated to be about $3 \%$. It is worthwhile to note that slightly higher deficits may occur at the hub-height level $(61 \mathrm{~m})$ than at $32 \mathrm{~m}$, as indicated by the analysis of the vertical profile of the wake for $5.9 \mathrm{D}$ and 8.4 $D$ in Section 3.2.7.

Under worst wake conditions (i.e., those that result in the greatest deficits), which occur when there are low turbulence intensities (0-5\%) and low $(5-9 \mathrm{~m} / \mathrm{s})$ or moderate $(9-12 \mathrm{~m} / \mathrm{s})$ wind speeds, average maximum velocity deficits at $32 \mathrm{~m}$ range from $50 \%$ at $1.9 \mathrm{D}$, to $31 \%$ at $5.2 \mathrm{D}$, and $18 \%$ at $8.4 \mathrm{D}$. Except at $1.9 \mathrm{D}$, deficits for moderate wind speeds are comparable to those at low wind speeds when turbulence intensities are low. This is not expected, because the deficits should decrease as wind speed increases since the rotor thrust coefficient for the MOD-2 is greatest at low wind speeds and decreases with increasing wind speed (see Appendix E). However, a considerable decrease in deficits does occur, as expected, in going from moderate to high wind speeds in the low turbulence intensity category.

Under best conditions (i.e., those that result in the smallest deficits), which usually occur when high turbulence intensities $(>9 \%)$ and high wind speeds $(>12 \mathrm{~m} / \mathrm{s}$ ) exist, average maximum velocity deficits at $32 \mathrm{~m}$ range from $27 \%$ at $1.9 \mathrm{D}$, to $17 \%$ at $5.2 \mathrm{D}$, and $10 \%$ at $8.4 \mathrm{D}$. It will be emphasized that, except for a very small fraction of the data $(\langle 1 \%)$, high turbulence intensities were between $9 \%$ and $20 \%$, with a mean of $13.3 \%$, whereas high wind speeds were between $12 \mathrm{~m} / \mathrm{s}$ and $18 \mathrm{~m} / \mathrm{s}$, with a mean of $13.7 \mathrm{~m} / \mathrm{s}$. If sufficient data were available to stratify the wake deficits for even higher turbulence intensities and higher wind speeds, it is expected that these deficits would be lower yet than those calculated here. 
The effect of wind speed on the wake deficit is substantially greater at low turbulence intensities than at high turbulence intensities. For example, at $5.2 \mathrm{D}$, in going from low wind speed to high wind speed, the deficits decrease from $31 \%$ to $20 \%$ for low turbulence and from $20 \%$ to $17 \%$ for high turbulence. Except at $1.9 \mathrm{D}$, at high turbulence intensities, it is apparent from Table 3.3 that wind speed has only a small influence on the deficits, because deficits at high wind speeds are only slightly less than those at low wind speeds.

The effect of turbulence intensity on the wake deficit is substantially greater at low wind speeds than at high wind speeds. For example, at $5.2 \mathrm{D}$, in going from low turbulence to high turbulence, the deficits decrease from $31 \%$ to $20 \%$ for low wind speeds and from $20 \%$ to $17 \%$ for high wind speeds. At high wind speeds, it is apparent from Table 3.3 that turbulence intensity has only a small influence on the deficits, because deficits at high turbulence intensities are only slightly less than those at low turbulence intensities.

A somewhat surprising feature at $1.9 \mathrm{D}$ is the strong effect of turbulence intensity on the deficits at low and moderate wind speeds. However, it will be emphasized that the 32-m level (at which the wake deficits were calculated) is $17 \mathrm{~m}$ from the bottom of the rotor disk and $29 \mathrm{~m}$ below the hub height, or about two-thirds of the distance from the hub to the bottom of the disk. At $1.9 \mathrm{D}$, the average maximum velocity deficits (at the $32-\mathrm{m}$ level) for low wind speeds range from $50 \%$ when low turbulence intensities exist to $37 \%$ when high turbulence intensities exist; thus, the effect of ambient turbulence on wake dissipation in the outer third of the rotor disk is quite substantial. Unfortunately, it is not possible to evaluate if the ambient turbulence has a substantial effect on hub-height deficits at $1.9 \mathrm{D}$.

At 8.4 D, which is close to the row separation distance of some existing wind farms, the average maximum velocity deficits at $32 \mathrm{~m}$ ranged from a high of 18\% for low turbulence intensities and moderate wind speeds to low of $10 \%$ for high turbulence intensities and moderate to high wind speeds. As shown in Figure 3.11, the deficits at $32 \mathrm{~m}$ at $8.4 \mathrm{D}$ are only about $1 \%$ less than those at hub height. As explained in Section 3.2.7, the ground restricts the vertical growth of the wake, thereby 'concentrating' the momentum deficit in a region above the ground but below the hub height. For this reason, we 
anticipate that the deficits shown in Table 3.3 for the $32-m$ level at $8.4 \mathrm{D}$ are fairly comparable to those at hub height; however, the effects of ambient wind speed and turbulence intensity on the vertical profile of the deficits are not known. 



\subsection{CONCLUSIONS AND RECOMMENDATIONS}

\subsection{CONCLUSIONS FROM OBSERVATION AND ANALYSIS OF DATA}

The free-flow variability across the Goodnoe Hills site was examined by comparing the wind speeds and turbulence intensities at each of nine towers to those at a commion reference tower. The mean wind speeds at $32 \mathrm{~m}$, averaged over all wind directions, were uniform across the site; wind speeds among the nine towers differed by less than 5\%. Mean turbulence intensities were also uniform, except at one tower that had about $20 \%$ higher average turbulence intensity than all the other towers. However, considerable variability was observed among the nine towers when the wind speed and turbulence intensity ratios were stratified by wind direction. Most of this variability was linked to changes in the surface roughness. At two towers, a $20 \%$ to $30 \%$ reduction in wind speed and a $100 \%$ to $150 \%$ increase in turbulence intensity were observed when these towers were downwind of an extensive grove of pine and juniper trees. At three other towers, up to $10 \%$ reduction in wind speed and $50 \%$ increase in turbulence intensity were observed when these towers were downwind of a grove of scrub oak trees. Terrain-induced effects on the free flow were evident at some of the towers, which caused variations of up to $10 \%$ in wind speed and $30 \%$ in turbulence intensity.

The 1-s time series of wind speeds at $32 \mathrm{~m}$ were examined to determine how changes in the surface roughness from grass to trees affected the wind characteristics over small time scales. A substantial increase in the magnitude of the wind gusts, as well as a considerable decrease in the mean wind speed, was observed when a tower was downwind of the pine and juniper trees rather than grass and sagebrush. Implications for a wind turbine at a height of about $30 \mathrm{~m}$ and located downwind of the trees are reduced power output, more variable power output, more start/stop cycles, and increased stress caused by the increased turbulence.

Wake characteristics of the flow examined when the wind turbines were operating included velocity deficit, wake turbulence, wake width, wake trajectory, vertical profile of the wake, and the classification of wake properties as a function of the ambient wind speed and turbulence intensity. The 
arrangement of the towers with respect to the turbines permitted observations of the wake characteristics at various distances ranging from 2 to $10 \mathrm{D}$. Most of the wake data were collected at a height of $32 \mathrm{~m}$; the MOD-2 hub height was $61 \mathrm{~m}$ and the bottom of the rotor disk was $15 \mathrm{~m}$ above ground.

Average maximum velocity deficits at $32 \mathrm{~m}$ ranged from $34 \%$ at 20 to $7 \%$ at $10 \mathrm{D}$. A regression line fit to velocity deficits indicated that the deficit would decrease to near $0 \%$ at $12 \mathrm{D}$. The relationship between velocity deficit and downwind distance was surprisingly linear. Maximum velocity deficits occurred at or near the center of the wake, in the near wake as well as the far wake.

Average maximum turbulence intensities at $32 \mathrm{~m}$ in the wake were 1.7 to 2.0 times greater than ambient values at distances of 2 to 40 and 1.2 to 1.5 times greater at distances of 5 to $10 \mathrm{D}$. However, maximum turbulence intensities occurred along the flanks of the wake, not the center of the wake, for distances out to $6 \mathrm{D}$.

Average wake widths at $32 \mathrm{~m}$ ranged from $1.6 \mathrm{D}$ at a distance of $2 \mathrm{D}$ to $2.8 \mathrm{D}$ at a distance of $10 \mathrm{D}$. Widths of the wake core ranged from $0.8 \mathrm{D}$ at 2 $\mathrm{D}$ to $1.7 \mathrm{D}$ at $10 \mathrm{D}$. Implications for turbine spacing are that, for a wind farm with a 10-0 row separation, array losses would be significantly greater for a 2-D turbine spacing than a 3-D spacing because of incremental effects caused by overlapping wakes. Decreasing the lateral spacing to $1.5 \mathrm{D}$ would result in substantially greater wake losses than for $2 \mathrm{D}$ because the wake cores would be overlapping.

Curvature of the wake trajectory was not evident. The absence of wake curvature implies that the wind direction variability across the site was, on the average, quite small and essentially negligible.

The vertical profile of the wake was examined at $5.9 \mathrm{D}$ and $8.4 \mathrm{D}$, based on an analysis of the velocity deficits at six levels on a tall tower encompassing the entire rotor height of the MOD-2 (15 $\mathrm{m}$ to $107 \mathrm{~m}$ ). The maximum velocity deficits were at the hub-height level $(61 \mathrm{~m})$, but the wake decayed much more rapidly above the hub height than below the hub height. At $8.4 \mathrm{D}$, the measured deficits at $15 \mathrm{~m}$ and $32 \mathrm{~m}$ were only slightly less than those at 
hub height, which indicates that in the far wake the ground effect diminishes wake decay.

Velocity deficits in the turbine wake were also examined as a function of the ambient wind speed and turbulence intensity at several downwind distances ranging from $1.9 \mathrm{D}$ to $8.4 \mathrm{D}$. Velocity deficits were highest at low wind speeds (high thrust coefficients) and low turbulence intensities and lowest at high wind speeds (low thrust coefficients) and high turbulence intensities. Turbulence effects on the velocity deficits were substantially greater at low wind speeds than at high wind speeds. The effects of wind speed on the deficits were substantially greater at low turbulence intensities than at high turbulence intensities.

\subsection{RECOMMENDATIONS FOR FUTURE WORK}

Considerable variability in the free-flow wind speeds and turbulence intensities was observed aming the nine towers when the data were stratified by wind direction. It would also be expected the power output and performance of the three wind turbines would show some variability, when stratified by wind direction. For example, turbine 1,1 like towers 6 and 7 , is downwind of the extensive grove of pine and juniper trees at certain wind directions. How does the change in surface roughness effect the power output and its variability at turbine 1? It was noted in a previous report (Elliott et al. 1988) that turbine 1 experienced more frequent shutdowns in high winds than did turbines 2 or 3 . Boeing (1985) reported that the pitch control algorithm installed in the Goodnoe Hills MOD-2 was not continually responsive under gusty wind conditions. Consequently, under these conditions the MOD-2s frequently shut down because the generator power exceeded the protective relay cut-off point.

Thus, the more frequent shutdowns at turbine 1 are apparently related to a greater frequency of gusty wind conditions than occurred at turbines 2 and 3. Turbine 1 was the downwind turbine and would be expected to experience somewhat more gusty wind conditions and greater power oscillations when it was in the wake of one of the two upwind turbines, as a result of increased turbulence associated with the turbine wakes. However, were some of the 
shutdowns at turbine 1 caused by the increased turbulence and gusty wind conditions when turbine 1 was downwind of the pine and juniper trees?

The power output and its variability at turbines 2 and 3 could also be correlated to changes in the surface roughness upwind of the turbines. Does the increased turbulence over the lower part of the rotor disk, and increased wind shear as well, affect the power output and performance at turbines 2 and 3 when they are downwind of the trees?

We recommend that analyses of the turbine power data be carried out to investigate these and similar questions.

One element not investigated in this report was the standard deviation of wind direction, or lateral turbulence intensity. We analyzed the longitudinal turbulence intensity, which is based on the standard deviation of wind speed. Longitudinal turbulence intensities were observed to increase by as much as $100 \%$ to $200 \%$ at towers 6 and 7 in the wake of the pine and juniper trees, and the magnitude of the wind gusts increased considerably. How would the trees affect the lateral turbulence intensity? What implications does this have on the magnitude of the wind direction fluctuations and how would this affect the turbine yaw angle and the turbine power output and performance? An examination of the lateral turbulence intensity in the wake of the trees and the turbine yaw error could provide some valuable insight into these questions. 


\subsection{REFERENCES}

Baker, R. W., and S. N. Walker. 1982. Wake Studies at the Goodnoe Hills MOD-2 Site. Report No. 82-11, Bonneville Power Administration, Portland, oregon.

Baker, R. W., and S. N. Walker. 1985. Wake Velocity Deficit Measurements at the Goodnoe Hills MOD-2 Site: A Summary of the 1982 and 1984 Findings. Report No. B4-15, Bonneville Power Administration, Portland, Oregon.

Boeing Aerospace Company. 1985. MDD-2 Wind Turbine Cluster Goodnoe Hills Operation, October 1982 - April 1985. DOÉ/NASA/0002-85/1, National Technical Information Service, Springfield, Virginia.

Buck, J. W., and D. S. Renne. 1985. Observations of Wake Characteristics at the Goodnoe Hills MOD-2 Array. PNL-5565, Pacific Northwest Laboratory، Richland, Washington.

Elliott, D. L., J. W. Buck, and J. C. Barnard. 1988. An Examination of Wake Effects and Power Production for a Group of Large Wind Turbines. PNL-6528, Pacific Northwest Laboratory, Richland, Washington.

Germain, A. C. 1984. Effects of Selected Atmospheric Variables on the Power Output of a DOE MOD-2 Wind Turbine. Master's Thesis, Oregon State University, Corvallis, Oregon.

Hadley, D. L., and D. S. Renne. 1983. "Wake Research in the Federal Wind Energy Program." In Proceedings of ASES '83 Annual Meeting and Wind Workshop VI, June 1983, American Solar Energy Socjety, Boulder, Colorado.

Lissaman, P. B. S., T. G. Zambrano, and G. W. Gyatt. 1983, Wake Structure Measurements at the MOD-2 Cluster Test Facility at Goodnoe Hills. PNL-4572, Pacific Northwest Laboratory, Richland, Washington.

Liu, H.-T., J. W. Waite, T. R. Hiester, P. H. Tacheron, and R. A. Srnsky. 1983. Flow Visualłzation Study of the MOD-2 Wind Turbine Wake. PNL-4535, Pacific Northwest Laboratory, Richland, Washington.

Miller, A. H., H. L. Wegley, and J. W. Buck. 1984. "Large HAWT Wake Measurement and Analysis." Presented at the DOE/NASA Wind Turbine Technology Workshop, May 8-10, 1984, Cleveland, Ohio.

Miller, G. E. 1985. Wake Interference Effects on M0D-2 Power Performance and Rotor Loads. Boeing Document D277-1034-1, Boeing Aircraft Corporation, Kent, Washington.

Sullivan, T. L. 1984. Effect of Vortex Generators on the Power Conversion Performance and Structural Dynamic Loads of the M0D-2 Wind Turbine. NASA TM-83680, NASA Lewis Research Center, Cleveland, Ohio. 
Walker, S. N., and R. E. Wilson. 1974. A FORTRAN Program for the Determination of Performance Loads, and Stabillity Derivates of Wind Turbines. NSF Grant No. GI 41840, Oregon State University, Corvallis, Oregon. 


\section{APPENDIX A}

PERCENT FREQUENCY DISTRIBUTIONS OF WIND DIRECTION, WIND SPEED, AND TURBULENCE INTENSITY 


\section{APPENDIX A}

PERCENT FREQUENCY DISTRIBUTIONS OF

WIND DIRECTION, WIND SPEED, AND TURBULENCE INTENSITY

This appendix presents the percent frequency distributions of wind direction, wind speed, and turbulence intensity for the 16 anemometers at the Goodnoe Hills site. The solid line on each plot shows the frequency for the wake data set, whereas the dashed line shows the frequency for the non-wake set. The number of 1-min records and the mean values are also included for the wake (W) and non-wake (NW) data sets. Turbulence intensity is defined as the standard deviation of the 1-s samples of the wind speed for a 1-min period divided by the mean wind speed for the same period. 

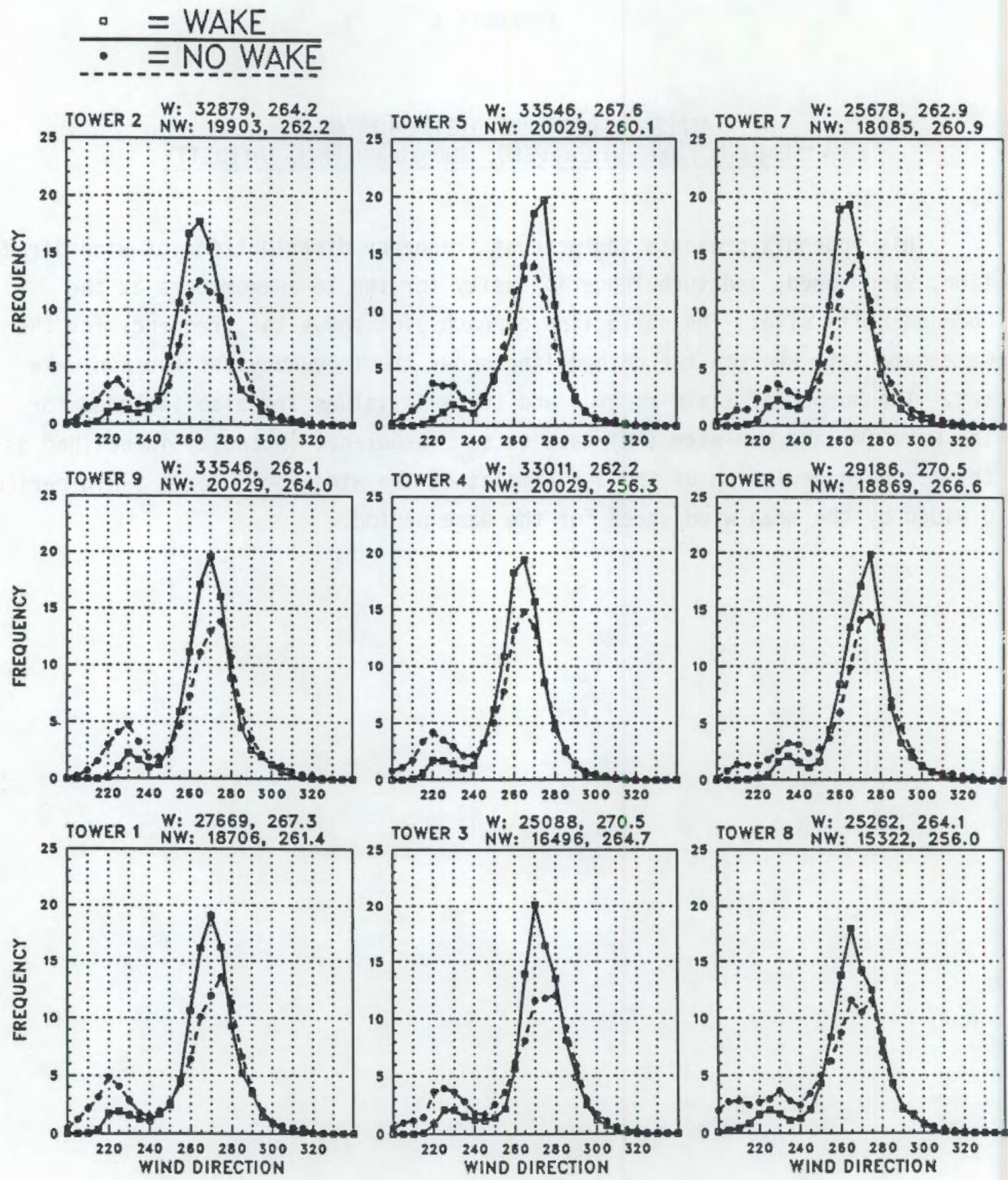

FIGURE A.1. Frequency Distributions of Wind Direction for the Nine 32-m (105-ft) Anemometers 

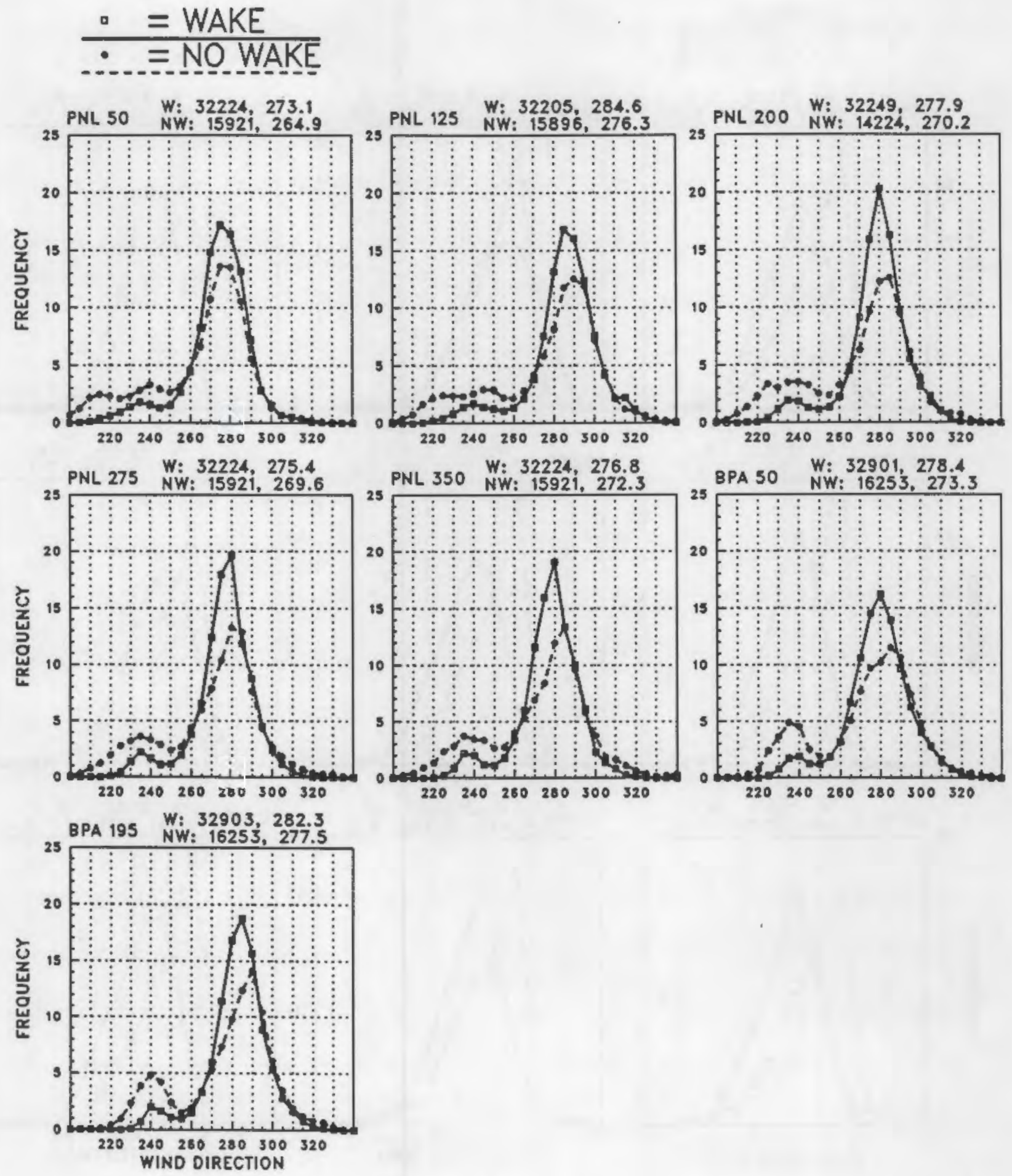

FIGURE A.2. Frequency Distributions of Wind Direction for Anemometers on the PNL Tower and the BPA Tower (Excluding the 32-m (105-ft) Anemometers that are shown in Figure A.1 as Towers 8 and 9 , Respectively) 


$$
\begin{aligned}
& =\text { WAKE } \\
& \therefore \quad=\text { NO WAKE }
\end{aligned}
$$
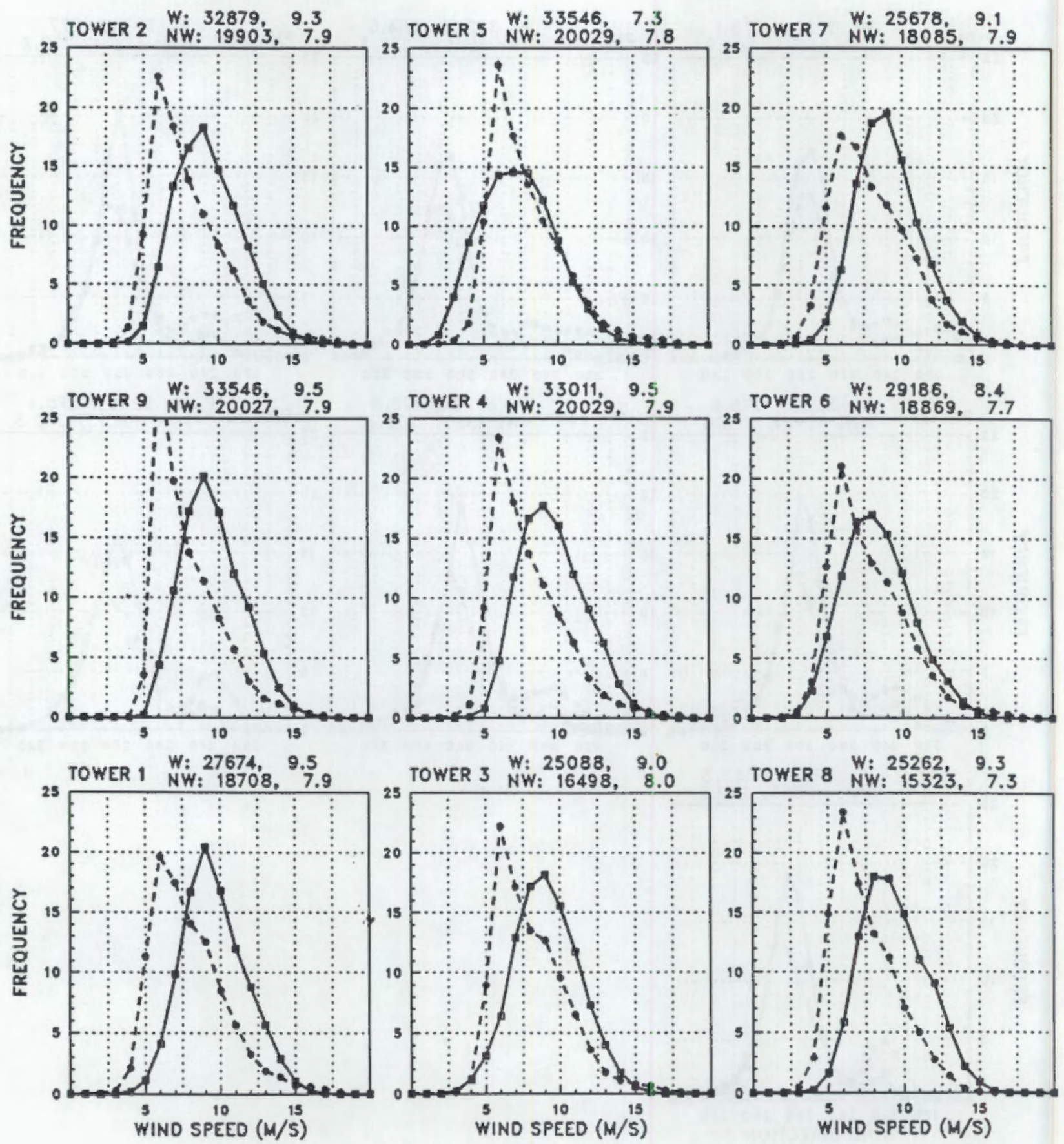

FIGURE A.3. Frequency Distributions of Wind Speed for the Nine $32-m(105-\mathrm{ft})$ Anemometers 


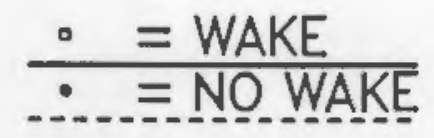
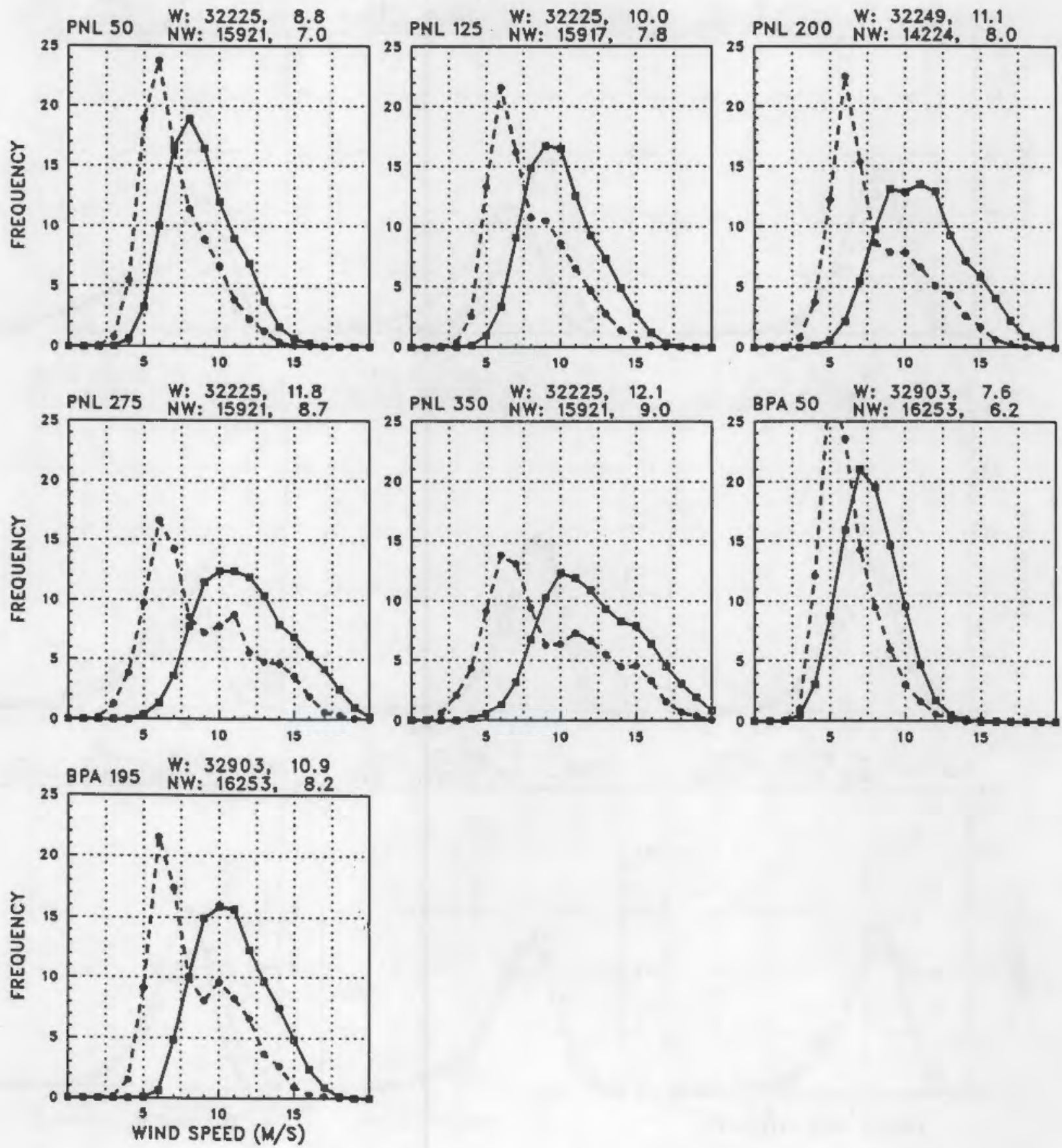

FIGURE A.4. Frequency Distributions of Wind Speed for Anemometers on the PNL Tower and the BPA Tower (Excluding the 32-m (105-ft) Anemometers that are shown in Figure A. 3 as Towers 8 and 9 , Respectively) 

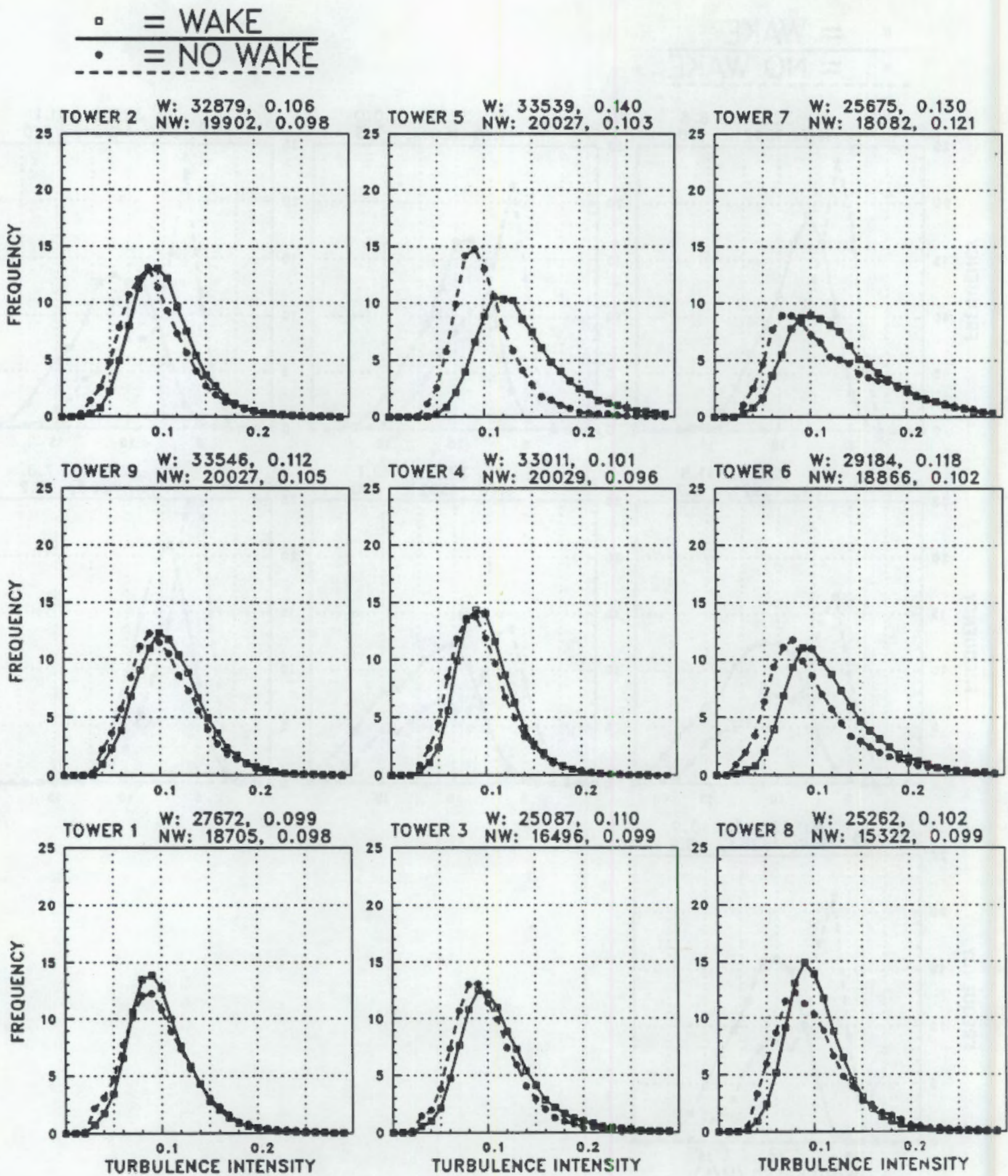

FIGURE A.5. Frequency Distributions of Turbulence Intensity for the Nine 32-m (105-ft) Anemometers 

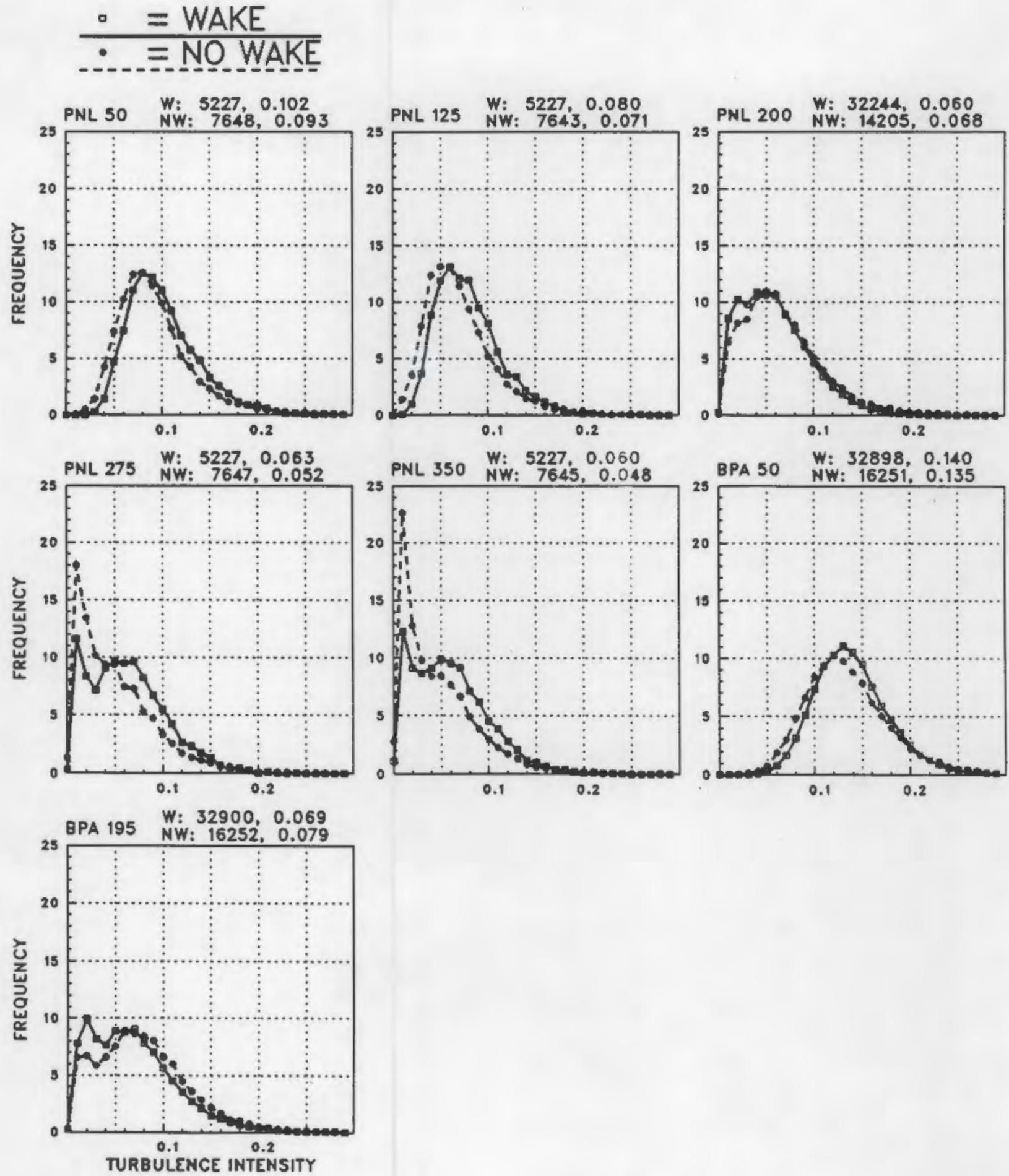

FIGURE A.6. Frequency Distributions of Turbulence Intensity for Anemometers on the PNL Tower and the BPA (Excluding the 32-m $(105-\mathrm{ft}$ ) Anemometers that are shown in Figure A. 5 as Towers 8 and 9, Respectively) 

APPENDIX B

DATA PROCESSING 
APPENDIX B

\section{DATA PROCESSING}

This appendix describes the methodology from which plots, such as those depicted in Figures 3.1 and 3.2, are derived. The non-wake and wake data sets that are described in Section 2.5 consist of 1-min averages of wind speeds, speed standard deviations, and wind directions. From these raw data, smoothed wind speed and turbulence intensity ratios are found as functions of the wind direction. This process is necessarily an averaging process, where for a given wind direction, a subset of the raw data is averaged to produce the smoothed ratio associated with this direction. The crux of the analysis is to determine an appropriate averaging procedure, which is described below. Although this averaging method has been derived in an admittedly heuristic manner, it appears to work well.

The first step of this analysis examines the correlation between the 1-min averages of the wind direction at the reference anemometer, the 32-m level on tower 9, and the corresponding averages of any other anemometer. For the sake of example, we take the "other anemometer" to be tower 5, and the correlation between the directions is shown in Figure B.1. In this figure, for each 1-min averaging period, the direction of tower 5 is plotted versus the tower 9 direction. For clarity's sake, only every 100 th point is plotted (out of a possible 20,027 and 34,026, for the non-wake and wake data sets, respectively). Physically, one would expect a high degree of linear correlation between the wind directions because the stations are quite close together (about $360 \mathrm{~m}$ apart), and indeed, this linearity is clearly apparent in Figure B.1.

Next, lines of regression are fit to the wind direction data. The standard linear regression model is not appropriate in this situation because it assumes that the independent variable, the tower 9 direction, is known without error, and that the departure from linearity occurs solely because of random fluctuations in the dependent variable, which in this example is the tower 5 direction. Obviously, random fluctuations occur in both variables, 


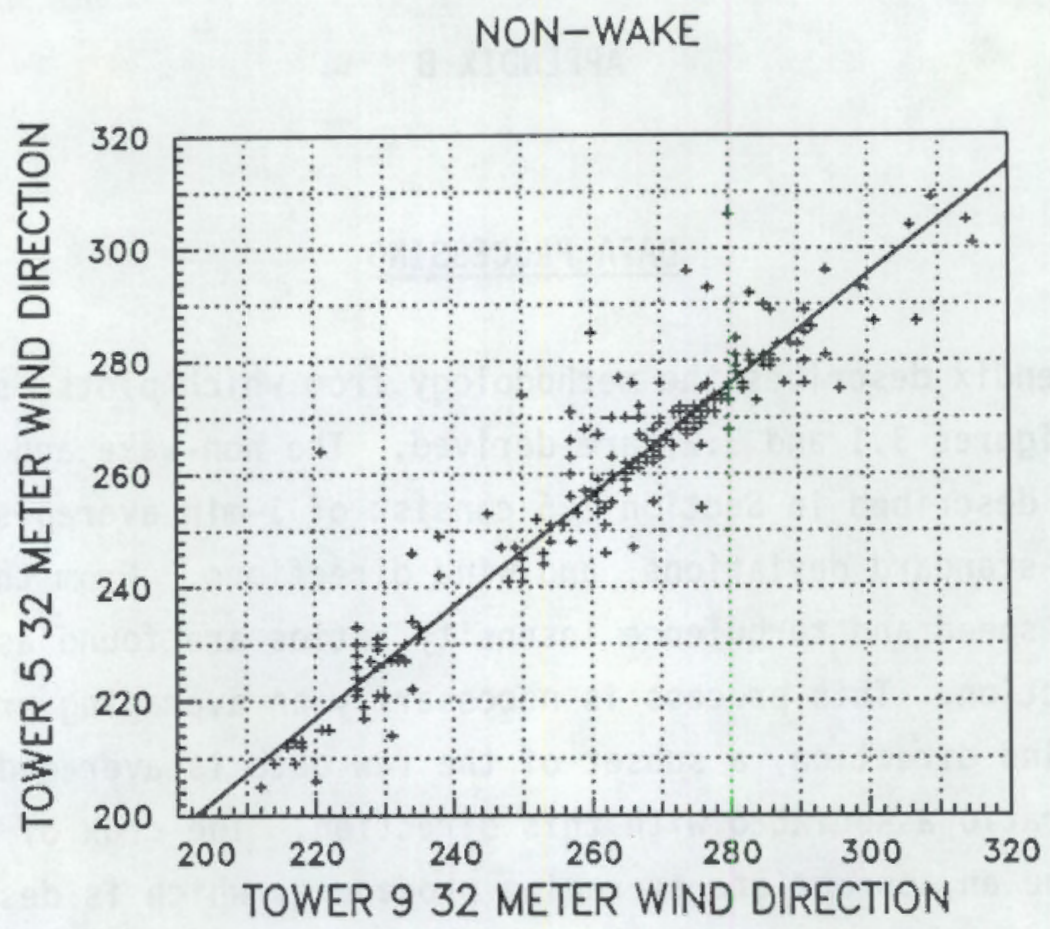

\section{WAKE}

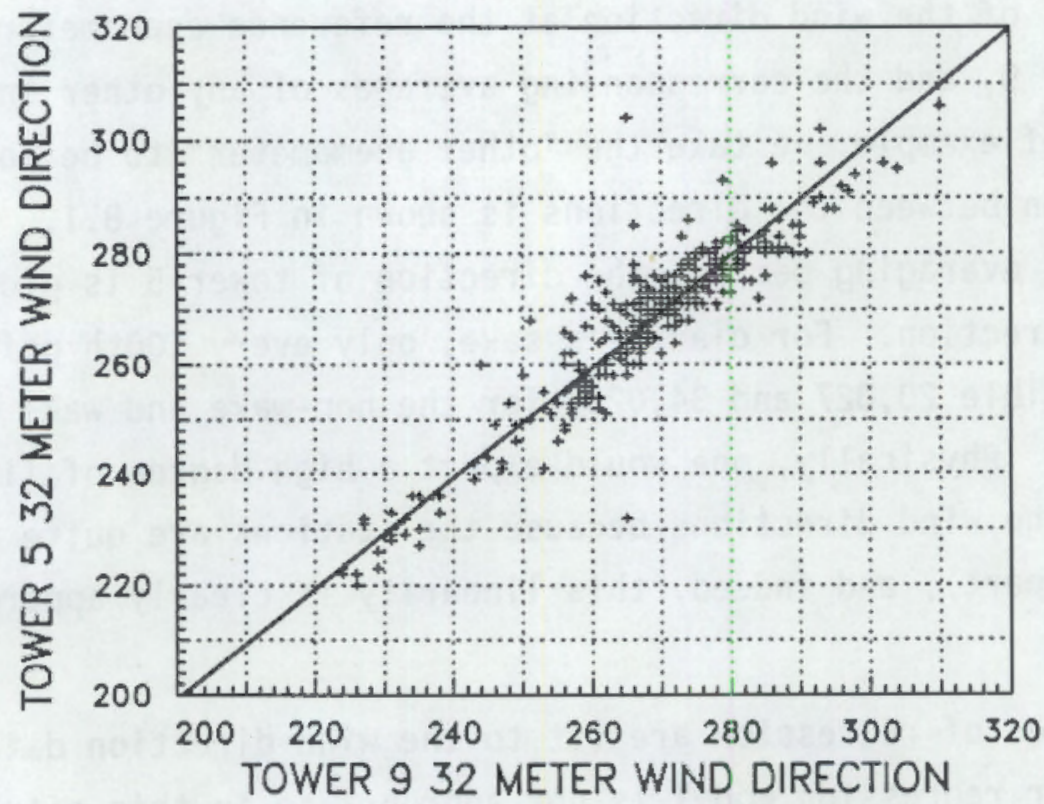

FIGURE B.1. Tower 5 Wind Direction Plotted Versus Tower 9 (32 m) Wind Direction for Both the Non-Wake and Wake Data Sets. The solid lines are lines of perpendicular regression fit to these data. 
and the regression model must consider this. One method of calculating a line of regression when both variables have a random component is the so-called "perpendicular regression," where the sum of the squares of the perpendicular distances from the points to the regression line is minimized. [Perpendicular regression is equivalent to "principal components regression" described by Draper and Smith (1981).] Using this technique, the regression line is the same regardless if tower 9 direction or tower 5 direction is used as the independent variable. Lines of perpendicular regression are shown in Figure B.1, and these are for the non-wake case, (tower 5 direction) $=0.978^{*}$ (tower 9 direction) +1.84 ; and for the wake case, (tower 5 direction) $=1.005^{\star}$ (tower 9 direction) - 1.79. (In this application, the distinction between the perpendicular and standard regression techniques is somewhat academic, as regression lines derived from both methods are nearly identical).

The regression lines provide a means for selecting data that can be averaged to provide smoothed wind speed ratios, turbulence intensity ratios, or other quantities of interest, as functions of the wind direction. Say that we wish to calculate the non-wake wind speed ratio (tower $5 /$ tower 9 ) at $1^{\circ}$ increments of the tower 9 direction. Given the tower 9 direction, we find the corresponding tower 5 direction using our non-wake regression relationship. These two directions form the center of a region from which data may be selected for averaging; this region is taken to be a circle. Intuitively, a circle seems appropriate since it does not preferentially weight either the tower 9 or tower 5 direction, and this is consistent with our assumption that random fluctuations occur in both these quantities. Each wind direction pair within the circle corresponds to a pair of tower 9 and tower 5 wind speeds observed during the same minute as the directions. Thus for each point in the circle, a wind speed ratio can be formed, and all these can be averaged to compute a smoothed non-wake ratio for the specified direction. The averaging that is performed is actually a weighted average that weighs data at the center of the circle more than at the edge. This is accomplished by a Gaussian weighing function $w(r)$ :

$$
w(r)=\frac{1}{\sqrt{2 \pi} \sigma} e^{-\frac{r^{2}}{2 \sigma^{2}}}
$$


where $r$ is the distance from the center of the circle to the point in question, and $\sigma$ is a measure of the width of the weighing function. The radius of the circle is chosen to be $3 \sigma$, at which distance the weighing function is virtually zero.

The averaging process is illustrated in Figure B.2. Here we have specified a tower 9 direction of $280^{\circ}$, and accordingly the origin of the circle is positioned at coordinates (tower $9=280^{\circ}$, tower $5=275.8^{\circ}$ ). The tower 5 direction is calculated through the non-wake regression line. Sigma is taken to be $1.69^{\circ}$, which results in a Gaussian function with a full-width at halfmaximum of $4^{\circ}$. This averaging procedure is performed at integer values of the tower 9 wind direction for both the wake and non-wake data to produce Figure 3.1. If in this procedure, turbulence intensity ratios are substituted for wind speed ratios, then Figure 3.2 results.

The character of the relationship between the smoothed wind speed ratios and the wind direction will depend upon the width, $\sigma$, of the weighing function. In fact, because the use of larger values of $\sigma$ results in averaging over more data, $\sigma$ acts as a smoothing parameter. The amount of smoothing must be chosen with care. Considerable smoothing removes noise and makes the shape of the ratio-versus-direction curve clear; however, this clarity comes at the expense of washing out the local extremes (i.e., peaks and valleys) of the curve. Because the maximum velocity deficit occurs at a valley in the ratio-versus-direction curve, the amount of smoothing will affect the magnitude of the maximum deficit as indicated on the ratio-versus-direction plots; the more the smoothing, the less the apparent magnitude. Thus it is desirable to minimize the amount of smoothing. In practice, the amount of smoothing was chosen by experimenting with different values of $\sigma$, and finally a value of $1.69^{\circ}$ was selected. With this value, the local maxima and minima of the curve are only slightly altered, while at the same time, an acceptable reduction in noise is obtained.

\section{REFERENCE}

Draper, N. R., and H. Smith. 1981. Applied Regression Analysis. John Wiley \& Sons, New York, New York. 


\section{NON-WAKE}

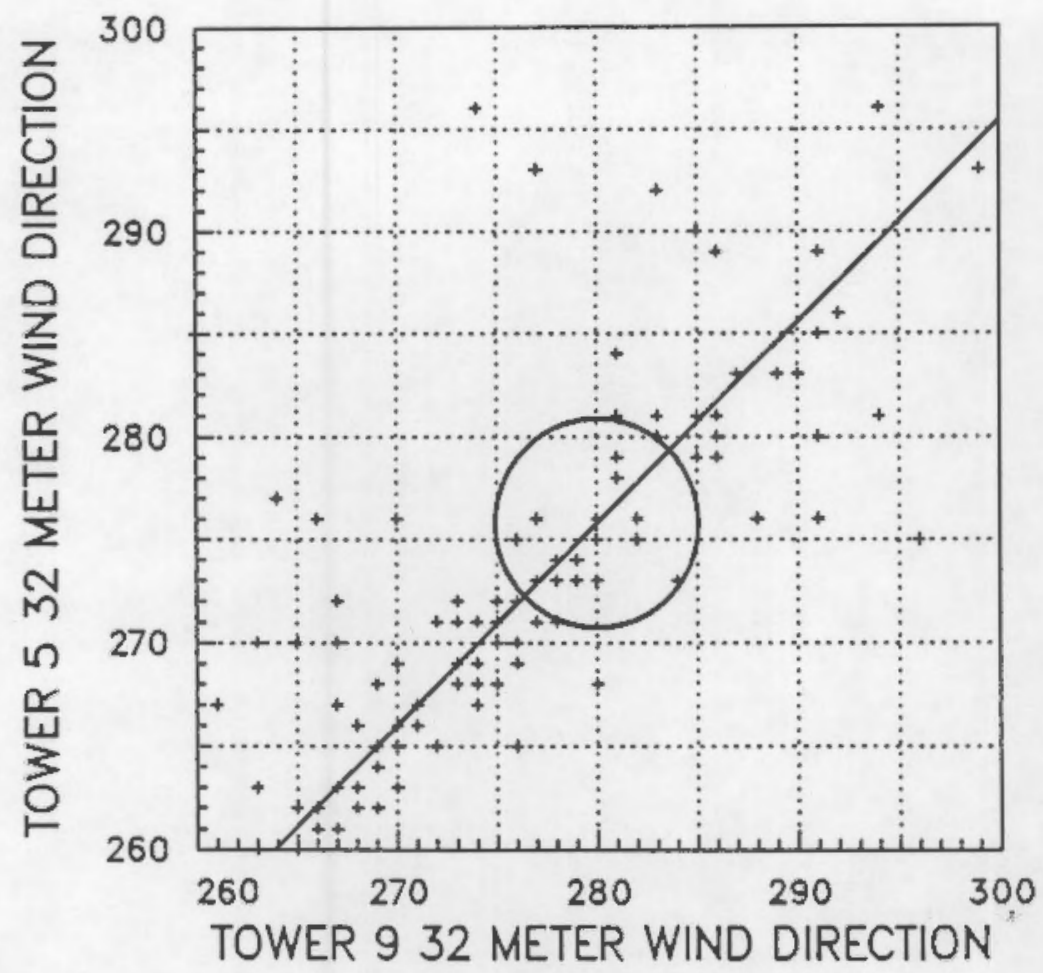

FIGURE B.2. Circle Over Which Data are Averaged. For a Tower $9(32 \mathrm{~m})$ direction of $280^{\circ}$, the data indicated by the crosses within the circle are averaged to compute non-wake wind speed ratios, or other quantities of interest. 



\section{APPENDIX C}

\section{COORDINATES AND ELEVATIONS OF}

TOWERS AND TURBINES 
Coordinates $^{(a)}$ and elevations of the nine towers at Goodnoe Hills:

\begin{tabular}{|c|c|c|c|}
\hline Tower & $x$ & $y$ & $\begin{array}{c}\text { Elevation } \\
\text { (ft) }\end{array}$ \\
\hline 1 & 1983,243 & 163,867 & 2543 \\
\hline 2 & 1984,330 & 165,639 & 2558 \\
\hline 3 & 1984,796 & 164,403 & 2610 \\
\hline 4 & 1985,110 & 165,016 & 2600 \\
\hline 5 & 1985,196 & 165,430 & 2587 \\
\hline 6 & 1986,185 & 165,416 & 2604 \\
\hline 7 & 1986,302 & 165,780 & 2588 \\
\hline 8 (PNL) & 1986,221 & 164,687 & 2623 \\
\hline 9 (BPA) & 1983,969 & 164,705 & 2577 \\
\hline
\end{tabular}

Coordinates $^{(a)}$ and elevations of the three turbines at Goodnoe Hills:

\begin{tabular}{|c|c|c|c|}
\hline Turbine & $x$ & $Y$ & $\begin{array}{c}\text { Elevation } \\
(\mathrm{ft})\end{array}$ \\
\hline 1 & 1986,616 & 165,212 & 2622 \\
\hline 2 & 1984,617 & 165,459 & 2573 \\
\hline 3 & 1983,729 & 164,243 & 2566 \\
\hline
\end{tabular}

(a) North American datum 10,000-ft grid based on Washington coordinate system, south zone (USGS). 



\section{APPENDIX D}

CALCULATION OF THE VERTICAL PROFILE OF THE WAKE 


\section{APPENDIX D}

\section{CALCULATION OF THE VERTICAL PROFILE OF THE WAKE}

As indicated in Table 2.1, the PNL tower (tower 8) was instrumented at 6 levels: $15,32,38,61,84$, and $107 \mathrm{~m}$. These multi-level wind measurements provide an opportunity to observe the vertical profile of the wake if measurements of the upwind wind speed - winds that are undisturbed by the wake - are also available at each of these levels. Wind observations that could serve as such upwind measurements were made at the BPA tower; here instrumentation was deployed at heights of 15,32 , and $59 \mathrm{~m}$. However, because the $15-\mathrm{m}$ anemometer is often influenced by upwind surface roughness (i.e., see Section 3.1.5), wind observations at this height are not a reliable indicator of the ambient flow. Although the 59-m BPA anemometer is vertically close enough to the 61-m PNL anemometer to provide upwind measurements for this level, there are still 4 PNL heights $(15,38,84$, and $107 \mathrm{~m})$ where reliable upwind measurements do not exist. Thus, it is necessary to develop a method of estimating winds at these heights.

One such method employs standard linear regression. In this case, we again take the tower 9 anemometer $(32 \mathrm{~m})$ as our reference anemometer. To estimate the ambient winds at other heights, a linear relationship is found between the wind speed at the reference anemometer and the wind speed at the 5 other elevations of the PNL tower. Because we are only interested in the wake-free speed at the height in question, the regression relationship must be developed using only speeds when wakes were not impinging on the PNL tower, that is, we use the non-wake data.

Development of the regression equations is of course quite easy. Using the non-wake data, tower 9 is taken as the independent variable, and one of the $5 \mathrm{PNL}$ levels is the dependent variable. For example, if the regression relationship between the tower 9 speed and the 107-m PNL speed is desired, then for each 1-min averaging period, PNL speed is plotted against tower 9 speed. Next, a line of regression is fit to these data using the standard 
least squares technique. The resulting equation is: [PNL speed $(107 \mathrm{~m})]=$ $1.57^{\star}$ (tower 9 speed) -2.86 , with a correlation coefficient $(r)$ of 0.83 . Given, the tower 9 speed, this equation then furnishes "proxy" upwind data for the 107-m PNL level. These proxy data are used in the data processing scheme described in Appendix $B$ to determine wake and non-wake speed ratios. These ratios are of the form: (measured PNL 107-m speed)/(proxy 107-m upwind speed), where the measured speed is either for non-wake or wake conditions.

But is the regression technique accurate? This can be checked for one PNL level, $61 \mathrm{~m}$, where the velocity deficits may be calculated using actual upwind data from the 59-m BPA anemometer, and the proxy upwind data derived from the regression method. Because this comparison revealed that the deficits using the real and proxy data were nearly identical, we may assume that the technique possesses reasonable accuracy. 


\section{APPENDIX E}

ESTIMATES OF MOD-2 ROTOR THRUST COEFFICIENTS 


\section{APPENDIX E}

\section{ESTIMATES OF MOD-2 ROTOR THRUST COEFFICIENTS}

Rotor thrust coefficients for the MOD-2, based on estimates from wind turbine performance PROP codes (Walker and Wilson 1974), have been published by Baker and Walker (1985) and are shown in Figure E.1. The $1982 C_{T}$ calculations for wind turbines 1 and 3 were obtained using the National Aeronautics and Space Administration's (NASA's) version of the wind turbine performance PROP code. In 1984, turbine 3 had vortex generators installed along its blades, and the thrust coefficients were determined from the PROP code using estimates of rotor drag with vortex generators (Miller 1984).

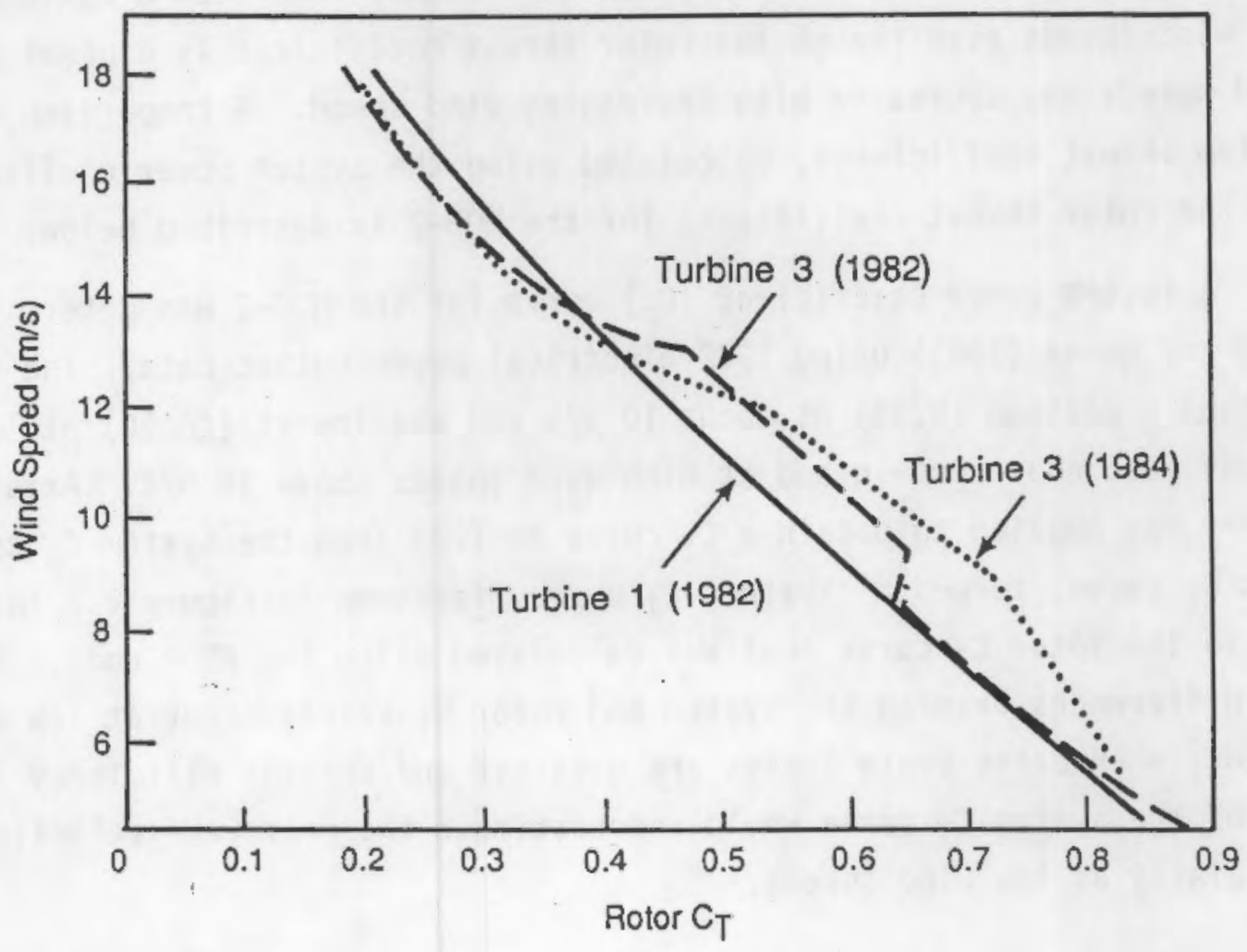

FIGURE E.1. MOD-2 Rotor Thrust Coefficient Versus Wind Speed 
Although minor differences exist in the estimated thrust coefficients for each of three cases shown in Figure E.1, the general trend is very similar for all cases with thrust coefficients around 0.8 at wind speeds of $6 \mathrm{~m} / \mathrm{s}$ and decreasing to around 0.2 at wind speeds of $18 \mathrm{~m} / \mathrm{s}$.

Other methods used to estimate rotor thrust coefficients, such as those based on electrical (system) power coefficients, are less reliable than the PROP code unless the rotor power coefficient can be estimated with sufficient accuracy, which requires data on the turbine efficiency as a function of power output. Data on electrical and mechanical losses are required to determine the turbine efficiency, but such data are often not available. Efficiencies and drive train losses for the MOD-2 as function of output power have been calculated by Wilson and Walker (1985). The efficiency was observed to decrease considerably at low loads, which is typical of most conmercial wind turbines. This observation explains why the electrical power coefficients are relatively low at low wind speeds (low loads) and reach a maximum at moderate wind speeds even though the rotor thrust coefficient is highest at low wind speeds and decreases with increasing wind speed. A comparison of the system thrust coefficients, calculated using the system power coefficients, and the rotor thrust coefficients for the MOD-2 is described below.

A system power coefficient $\left(C_{p}\right)$ curve for the MOD-2 was determined by Buck and Renne (1985) using 1982 electrical power output data. The $C_{p}$ value reached a maximum $(0.38)$ at about $10 \mathrm{~m} / \mathrm{s}$ and was lowest $(<0.10)$ at low wind speeds just above cut-in and at high wind speeds above $18 \mathrm{~m} / \mathrm{s}$. Axial momentum theory was applied to obtain a $C_{T}$ curve derived from the system $C_{p}$ curve. This $C_{T}$ curve, termed a 'system' $C_{T}$ curve, is shown in Figure $E .2$ in comparison to the rotor $C_{T}$ curve that was calculated using the PROP code. The greatest differences between the system and rotor $C_{T}$ values occur at low wind speeds, when drive train losses are greatest and turbine efficiency is lowest. Use of the system $C_{T}$ curve would underestimate the near wake velocity deficits, especially at low wind speeds. 


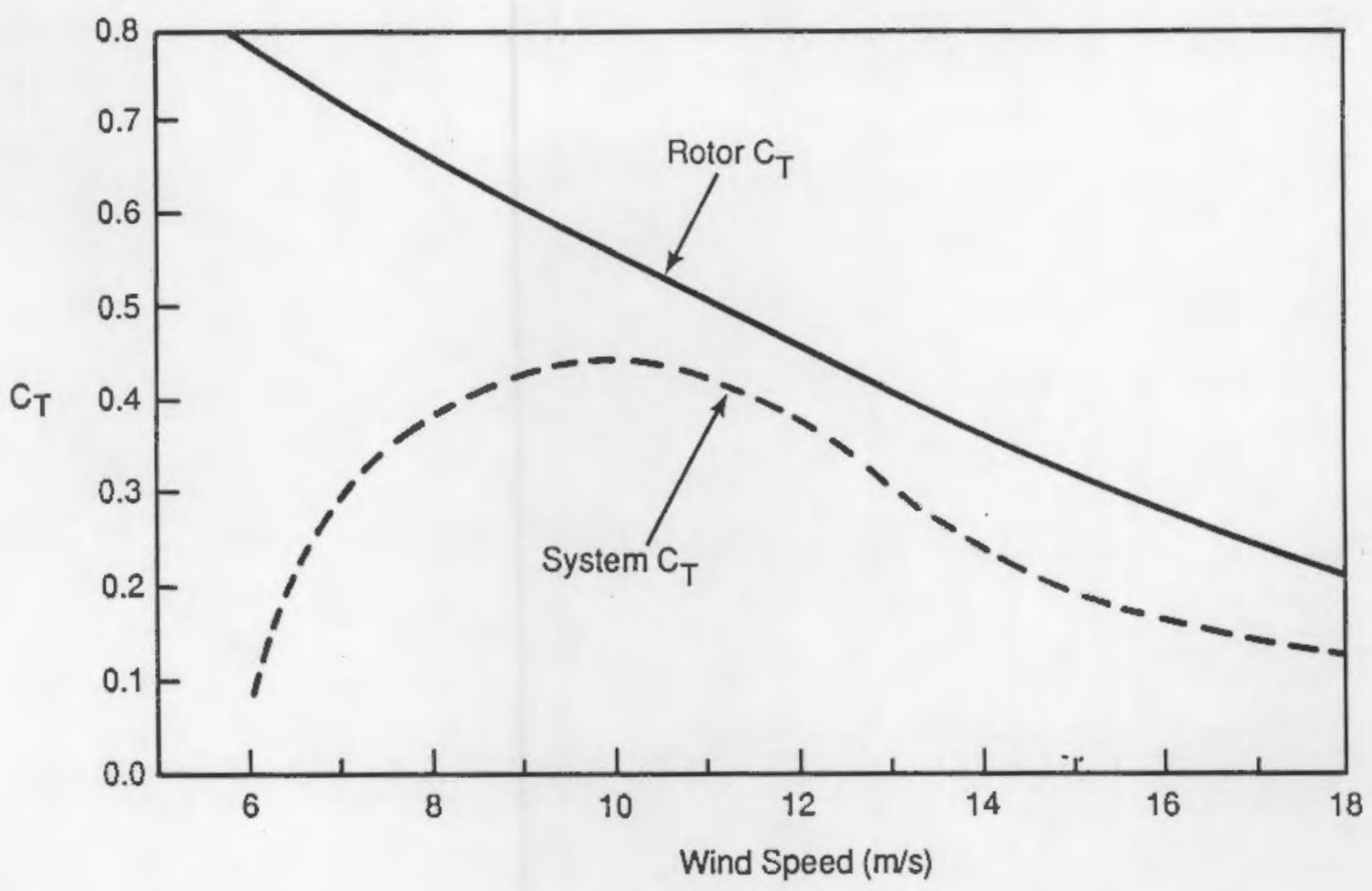

FIGURE E.2. Comparison of Rotor and System $C_{T}$ Curves for the MOD-2

\section{REFERENCES}

Baker, R. W., and S. N. Walker. 1985. Wake Velocity Deficit Measurements at the Goodnoe Hills MOD-2 Site: A Summary of the 1982 and 1984 Findings. Report No. 84-15, Bonneville Power Administration, Portland, Oregon.

Buck, J. W., and D. S. Renne. 1985. Observations of Wake Characteristics at the Goodnoe Hills MOD-2 Array. PNL-5565, Pacific Northwest Laboratory, Richland, Washington.

Miller, G. E. 1984. "Comparative Performance Tests on the MOD-2 Wind Turbine With and Without Vortex Generators." Presented at the DOE/NASA Workshop on Horizontal Axis Wind Turbine Technology, May 8-10, 1984, Cleveland, Ohio.

Wilson, R. E., and S. N. Walker. 1985. Performance Analysis of Horizontal Axis Wind Turbines. Oregon State University, Corvallis, Oregon. 



\section{DISTRIBUTION}

No. of

Copies

OFFSITE

10 DOE Office of Scientific and Technical Information

26 J. B. Cadogan

U.S. Department of Energy Wind/Ocean Technologies Division 1000 Independence Avenue, S.W. Forrestal Building, Room 5F064 Washington, DC 20585

B. Armstrong Seawest Industries 1455 Frazee Road, Suite 300 San Diego, CA 92108

C. I. Aspliden 1925 North Harvard Street Arlington, VA 22201

B. Bailey

Associated Weather Services 55 Colvin Avenue

Albany, NY 12206

R. Baker

3778 Wisteria Way Corvallis, OR 97330

S. Blake WINDUSTRIES, Inc. P. 0. Box 1006 Fairfield, IA 52556

J. R. Connell Colorado State University Engineering Research Center Foothills Campus

Fort Collins, CO 80523

K. Cousineau

Zond Systems Incorporated 13000 Jameson Road

Tehachapi, CA 93561
No. of

Copies

E. Davis

U.S. Windpower 6952 Preston Avenue Livermore, CA 94550

D. Foster AeroVironment, Inc. 825 Myrtle Avenue

Monrovia, CA 91016-3424

S. Hock

Solar Energy Research Institute 1617 Cole Boulevard Golden, CO 80401

R. H. Holeman Bonneville Power Administration P.0. Box 3621

Portland, OR 97208

S. Holets

Pacific Gas \& Electric Company

215 Market Street, Rm. 454

San Francisco, CA 94106

J. Kline

456 Larchwood Place

Oakley, CA 94561

P. B. S. Lissaman

Aerovironment, Inc. 825 Myrtle Avenue Monrovia, CA 91016-3424

R. Lynette

R. Lynette and Associates, Inc. 15032 N. E. 40th Street, Suite 206 Redmond, WA 98052

E. McCarthy U.S. Windpower 6952 Preston Avenue Livermore, CA 94550 
No. of

Copies

A. H. Miller 10013 Tepopa Drive Oakdale, CA 95361

R. Nierenberg

153 Sacramento Avenue

San Anselmo, CA 94960

M. Sacarny

Second Wind, Inc.

7 Davis Square

Somerville, MA 02144

L. Schienbein

Flowind Corporation

1183 Quarry Lane

Pleasanton, CA 94566

R. Simon

434 Oakdale Avenue

Corte Madera, CA 94925

D. Suehiro

HERS

P.0. BoX 730

Honolulu, HI 96808

R. Thresher

Solar Energy Research Institute 1617 Cole 8oulevard

Golden, CO 80401

W. A. Vachon

W. A. Vachon \& Associates, Inc.

P.0. Box 149

Manchester, MA 01944

S. Veenhuizen

United Industries Corp.

12835 Bel-Red Road

Bellevue, WA 98005
No. of

Copies

P. Veers

Sandia National Laboratories

Division 6225

Albuquerque, NM 87185

J. Wade

Pacific Wind Energy

P.0. Box 1671

Corvallis, OR 97339

S. N. Walker

Department of Mechanical

Engineering

Oregon State University

Corvallis, OR 97331

\section{ONSITE}

DOE Richland Operations office

D. R. Segna

30 Pacific Northwest Laboratory

J. C. Barnard

C. E. Elderkin

D. L. Elliott (10)

J. W. Falco

G. L. Gower

J. M. Hales

P. C. Hays

V. R. Morris

E. L. Owczarski

R. L. Skaggs

J. A. Stottlemyre

L. L. Wendell (3)

R. E. Wildung

Publishing Coordination

Technical Report Files (5) 